\title{
A Longitudinal Qualitative Study of the Journeys of Single Parents on Jobseeker's Allowance
}

Tina Haux, Debra Salmon, Lucy Taylor, Toity Deave, Sue Cohen, Laura Dewar, Tove Samzelius

with contributions from Charmaine Brown;

Miriela Dhillon; Fadumo Dualeh; Amina Jama; Jackie Jarrett; Lucille Smith; Ellie Stacey; Sarah Westlake; Anisa V.

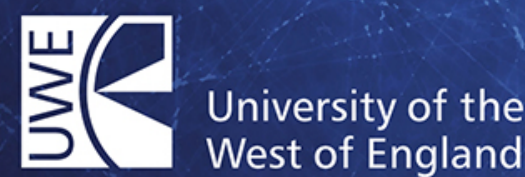

BRISTOL

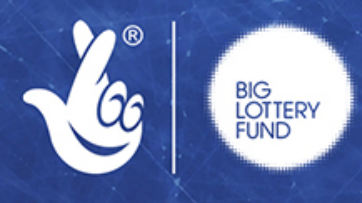

LOTTERY FUNDED

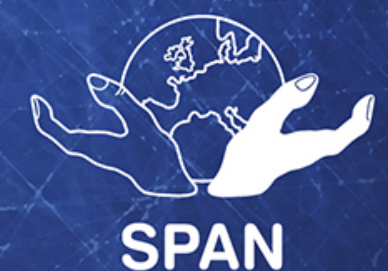

Single Parent Action Network 



\section{A Longitudinal Qualitative Study of the Journeys of Single Parents on Job Seekers Allowance}

May 2012

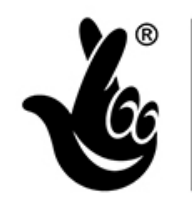

University of the West of England BRISTOL

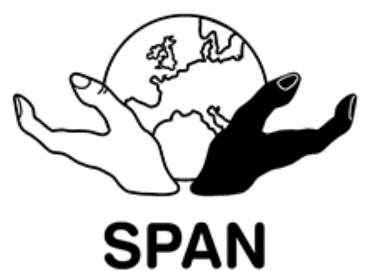

Single Parent Action Network 


\section{Acknowledgements}

We would like to thank all those single parents who gave up their time to be interviewed during this period of welfare change. The stories of single parents caring for their children and families, as they transferred to new benefit arrangements, looked for work, and undertook training were often expressed in terms of resilience and optimism which lie at the heart of this report. Special recognition must go to the nine single parent peer researchers Charmaine Brown; Miriela Dhillon; Fadumo Dualeh; Anisa V; Amina Jama, Jackie Jarratt; Lucille Smith; Ellie Stacey; Sarah Westlake. These peer researchers undertook the majority of the fieldwork, interviewing single parents in their own homes and at SPAN. The peer researchers brought enthusiasm, commitment and insight to the project, it was their insights and challenges, which shaped the development of the research and kept interviewees motivated to stay involved. Lucy Taylor and Helen Stone played an important role in supporting this participation and thanks goes to them. Toity Deave was pivotal to the training programmes, and supported both the participation and all aspects of research endeavour through the life of the project.

Thanks also goes to the three administrators who worked tirelessly to organise the fieldwork and overall administration of the project, Isobel Birden, Elly Sinclair and Sally Cosgrove. As well as Leigh Taylor, UWE Research administrator who led her team to support the ethics application processes and delivered the large number of transcriptions on time. Susy Guillari contributed to the overall methodological development of the research and the initial phase of data collection. Lyn James contributed and played an important role in the second phase of data collection. Thanks also goes to the BIG LOTTERY for their encouragement as commissioners of this research.

SPAN Staff and academics from UWE, Bristol wrote this final report and are listed on the front cover. Special thanks should go to Tina Haux for her patience and skill in drawing together all the contributions into the final report.

\section{Sue Cohen and Debra Salmon}

For enquiries contact:

\section{Sue Cohen}

Chief Executive

Single Parent Action Network.

Millpond, Baptist Street, Easton

Bristol, BS5 OYW

01179514231

email: sue@spanuk.org.uk

www.spanuk.org.uk

Debra Salmon

Faculty of Health \& Life Sciences

University of the West of England, Bristol

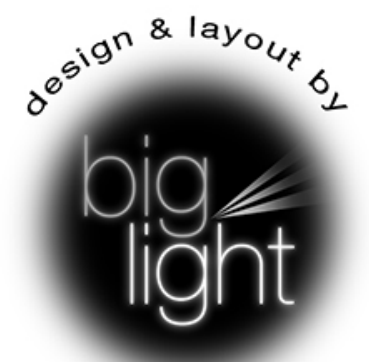

email: debra.salmon@uwe.ac.uk

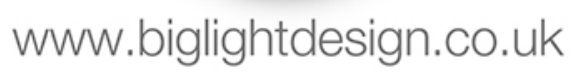

01173288468 


\section{Contents}

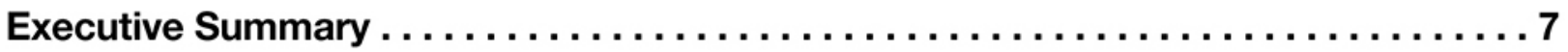

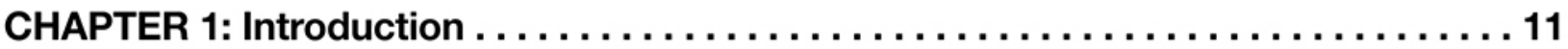

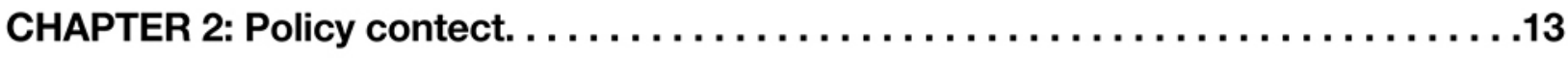

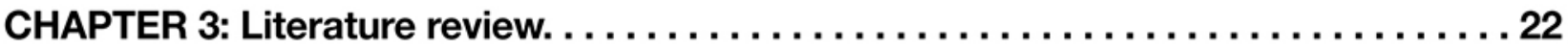

The problems with the adult worker model

Barriers to employment and employment sustainability

Lone Parent Obligations research

CHAPTER 4: Research Aims and Methodology

The aim of the research

Underpinning approach

Methods

Recruiting and training the peer researchers

Recruitment took place through a number of mechanisms

Following the journey of the Single Parent Peer Researchers

Recruiting and sampling single parents

Exclusion criteria and the challenges

Data collection with single parent participants

Data analysis

Ethical Considerations

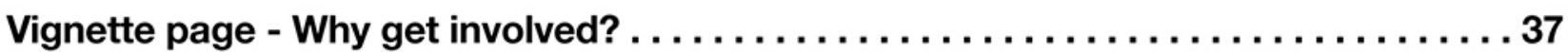

CHAPTER 5: Bristol $\ldots \ldots \ldots \ldots \ldots \ldots \ldots \ldots \ldots \ldots \ldots \ldots \ldots \ldots \ldots \ldots \ldots \ldots \ldots \ldots, 38$

The characteristics, labour markets and poverty levels in Bristol

Employment support and training in Bristol

Summary 
Finding out about the changes in policy

Initial reaction to the changes

Understanding of the regime:

New to single parents and advisors

Expectations

The first meeting

Downstairs and upstairs

'Overqualified and under-experienced'

Transitions either between benefits or

between benefits and employment

Who looks after the children?

Summary

Vignette Page - Factors Supporting Involvement

Vignette Page - Factors that made ongoing involvment more difficult

Chapter 7: Moving into Paid Employment

What are the characteristics of single parents?

What jobs have single parents moved into?

What are the links between the jobs and the qualifications \& work experience

of single parents in this study?

How did they get there?

How many hours were single parents working?

Are their jobs secure and sustainable?

How do they feel about where they are?

Positive experiences of being in work

Negative experiences of being in work

What made work work?

Has it affected the relationship with their children?

What is their outlook on the future?

Summary

CHAPTER 8: Moving into self-employment

Who are the single parents in this group

Determination

Seeking help

Managing self-employment

Additional financial support

Impact of being self-employed on the single parents and their children

Payment changes

Adaptable children

Outlook on the future

Summary 


\section{Arriving on ESA}

The experience of Employment Support Allowance

Managing illness and caring for children

Finance and the future

Summary

CHAPTER 10: Staying on JSA

Who are the single parents in this group

What are they doing now?

Working less than 16 hours per week

Doing voluntary work

Work search and ideal jobs

The Work programme

Impact of being on JSA on the single parents and their children

Outlook on the future

Why are they not in work?

Summary

Vignette Page - What did peer researchers get out of being involved?

CHAPTER 11: Caring for older children

Impact of childcare on work

Age of child when left on own

The ill child

Walking to school

Whose responsibility is childcare?

Summary

CHAPTER 12: Training opportunities

Expectations and motivations for training

Single parents views on the availability of training and support on JSA

Finding out about training

Experiences of training

Problems with attending training courses

Cost of training

Suitability of training

Training attended

Existing experiences and training

Summary 
JCP: Seeing a different advisor each time

What makes a 'good' or 'bad' advisor?

Knowing the right questions to ask - potentially move to Jobcentre section

Advice for searching for jobs

Taking the children to the Jobcentre

The use of sanctions

The feel of the new regime

Views of welfare reforms

Understanding the context of welfare reforms

JSA and Caring for Older Children

Summary

CHAPTER 14: Discussion

CHAPTER 15: Policy recommendations $\ldots \ldots \ldots \ldots \ldots \ldots \ldots \ldots \ldots \ldots \ldots \ldots \ldots \ldots$

References 


\section{Findings for change: Summary of}

\section{A Longitudinal Qualitative Study of the Journeys of Single Parents on Job Seeker's Allowance}

\section{Background}

There are currently 1.8 million single parents in the UK. Their relatively low employment rate and link to the risk of poverty means that single parents remain high on the political agenda. In 2008 when the Labour government introduced policy changes that required single parents with older children to look for work, single parents had to be parents of children at an increasingly younger age to qualify for Income Support. The age of the youngest child was initially set at 12 years but was gradually brought down to ten, then seven years. The current Coalition Government reduced this further to five years in May 2012. These changes, requiring single parents to move from IS to JSA and secure work of at least 16 hours, have been set in the context of a recession that has been forecast to have long-lasting consequences, particularly in terms of increasing intensification of labour market competition for jobs.

\section{What did we do?}

This research project aimed to explore the journeys of single parents on Jobseeker's Allowance (JSA), in particular how they experienced the support and training opportunities provided to facilitate their learning, possible advancement into sustainable employment and the implications for their well being subsequent to recent welfare reform. The research is based on longitudinal, qualitative research with fifty single parents, which took place between 2009 and 2012. The participatory nature of the research meant that single parent peer researchers undertook the fieldwork. Support and research training was provided throughout the study to underpin their personal development. Fifty single parents were recruited from a range of organisations to take part in the study. The age range of participants was from 25 to 60 years, from a diverse range of social and cultural backgrounds. The length of time participants had claimed Income Support ranged from six months to more than ten years. The research methods included semi-structured interviews on three separate occasions to follow participants over time and explored the longer-term outcomes for single parents. In total 135 interviews were completed. The research was funded by the Big Lottery Research

Programme, led by the Single Parent Action Network in collaboration with academics at the University of the West of England, Bristol.

\section{What did we find? Jobseeker's Allowance: transition \& advisors}

Overall, the experience of the new policy implementation was mixed. Single parents seemed to be well informed about the transition from Income Support (IS) to Jobseeker's Allowance (JSA) (see also Gloster et al., 2010; Casebourne et al., 2010) Single parents tended to be less well informed about how claiming JSA would differ in practice from claiming IS. No longer being able to speak to a lone parent advisor was commented on by single parents as a loss, as meeting a different advisor each visit could feel unsettling. Single parents felt that they had to repeat often personal experiences, and each advisor could initiate sanctions against them. 


\section{Wanting to work}

\section{There are a number of key themes coming out of this research.}

- Firstly, it is clear that there was a strong sense that single parents in this study wanted to work. The motivations for wanting to work ranged from wanting to be better off financially, being a role model for their children, gaining social contacts at work, building a career as well as coming off JSA.

- Linked to this is the second theme, namely, that suitable, part-time jobs were difficult to find as a result of the recent recession and Jobcentre Plus (JCP) was not perceived to be helpful when it came to finding jobs or liaising with potential employers. In this study, none of those interviewed who found work reported doing so through their Jobcentre contact, but through responding to vacancies, going approaching local businesses directly and existing networks such as friends and previous employers. JCP advisors focused on single parents going for any job rather than allowing them to restrict their job search to jobs for which they were qualified for whilst enabling them to fulfil their caring responsibilities.

- This is linked to the third major theme that came out strongly in the research, which was single parents' views on the caring needs of their (older) children. For example, being there when children set off to school and when they came home was seen as very important, particularly at this age; this was a particular concern for mothers of teenage boys. Again Jobcentre Plus was not seen to be helpful in this respect.

- A fourth strong theme in this study was single parents' expectations that they would be able to do training to move into jobs that they wanted to do and that had a career trajectory. This clashed with the requirements of JSA to be available for work immediately. Training opportunities were not necessarily discussed by JCP staff and the quality and usefulness of the courses single parents were able to access varied.

\section{Following single parents' journeys over time}

All single parents in the sample were in the target group of single parents to be transferred to JSA, i.e. all had children over seven. 18 months on, single parents in this study had gone on journeys with four destinations: employment, self-employment, on Employment Support Allowance or remaining on JSA. The key factors determining which direction the single parents took seemed to be:
- How close they were to the labour market - some who went into work were already in small part-time jobs;

- Whether they could access part-time work more generally;

- The level of access to social networks and extended family able to support them with their childcare;

- Travel times to work (most of those who found employment found it near to their home);

- Their health and the health/well-being of their children; 
- Finding flexible employers/sympathetic line managers;

-Whether they had a strong desire to come off JSA and take any job in the process, in which case their previous qualifications and skills were likely not to be utilised. Of those who found jobs and whatever their qualifications, all went into low paid work, mostly care work, childcare, supermarkets, and cleaning;

- In contrast, the main motivation of those moving into self-employment was to be able to do the kind of job they wanted and were able to do, as well as being able to combine it with looking after their children.

For those single parents who moved to ESA, their main issue was to manage their illness while looking after their children. Finally, the group of single parents who had not been able to find a job and were still receiving JSA at the end of the study seemed quite diverse in terms of their characteristics. They were not dissimilar to the group that found employment in that all were keen to work but they were also keen to combine that with looking after their children and to work part-time. Some had had experience of the pressure of shift work, for example and the ensuing impact on their families.
In terms of their outlook on the future, this depended to a large extent on where they were. On the whole, single parents in employment and self-employment felt more optimistic about the future than those on JSA and ESA. However, uncertainty about employment lasting, about the lack of jobs and impending changes to the tax and benefit system emerged as key worries. Health and well-being Those in work, including those who were self employed, often identified a sense of well-being and enjoyment connected to feeling part of the world of work, with improved self esteem and confidence. This was also associated with improvements in family life that additional income brought.

Feeling part of a team gave single parents a sense of connectedness, to colleagues and the organisations they were part of, which made them feel purposeful and optimistic about the future. Those single parents who had become self employed had sometimes seen this as a way of managing their long term conditions, having more control over the timing and the nature of the work taken on. However, this is not to suggest there were no negative impacts. For those who had taken up work perceived as menial, there was frustration and a sense of resignation, as the opportunities for training to improve their position were withdrawn. 
This was often in contrast to those in the 'not in work' groups, who were supported by ESA and JSA. Single parents who were supported by benefits suffered greater ill health than the general population. Similar to those in Peacey's (2009) study, those on JSA most often reported experiencing 'depression and stress' and for some this became severe enough to move onto ESA. For others, symptoms tended to be in a state flux, demanding intermittent visits to their general practitioner for treatment, or resignation that given their life circumstances 'it was to be expected'.
An additional aspect of health and wellbeing was associated with the significant number of parents who reported having children with longstanding health problems: respiratory illness, developmental and behavioural difficulties and mental illness. Similar to other work in the field, this study confirms that single parents with older children who are not themselves in work often had children with serious health difficulties (Peacey 2009) and had to deal with these challenges alone (Peacey, 2009; Ridge \& Miller, 2011).

\section{What do we recommend?}

- For the Work and Pensions Select

Committee to review the treatment of single parents in the benefit system with regard to advancing equality of opportunity in welfare to work policies and practices.

- For Jobcentre Plus, and contractors providing employment support to play a proactive role in both complying with the equality duty and in preventing the erosion of single parents' gender equality opportunities as both workers and parents.

- Reinstate the role of Lone Parent Advisors.

- Improve training structures for Jobcentre staff with regard to single parents advancement opportunities and their responsibilities as parents and as workers.

- Provide transparent information about training and childcare opportunities at all Jobcentres.
- Earlier and better signposting and support by Jobcentre Plus and training providers for single parents wanting to start their own business.

- Support for new training programmes that would further single parents' future advancement in the labour market.

- Jobcentre Plus and work training providers to develop initiatives that encourage employers to design quality jobs with parttime hours.

- The embedding of children's well-being into the ethos of Jobcentre Plus service delivery by government as this is already a legislative requirement in supporting parents into work.

- A government review of childcare for older children as a policy priority. 


\section{Introduction}

There are currently 1.8 million single parents in the United Kingdom. Single parents have been high on the political agenda for the last two decades, and have usually been seen as a challenging problem in political discourses. This has been either in terms of their numbers or their relatively low employment rate. Linked to this is their low income: over half of the children in single parent families are at risk of poverty.

The previous Labour governments (1997 2010) introduced a comprehensive programme of tax credits, childcare and the New Deal for Lone Parents, to enable more single parents to move into employment. Increasing the employment rate of single parents was a key part of the high profile target to abolish child poverty within 20 years. The employment rate of single parents did increase by around ten per cent during that time, however, this increase was seen as insufficient in the eyes of policy-makers.

Therefore, the Labour government introduced policy changes in 2008 , which required single parents with older children to look for work, i.e. to transfer to Jobseeker's Allowance if they were claiming Income Support. The age of the youngest child was initially set at 12 , but was gradually brought down to 10 and then seven years. The Coalition government (2010 - ) has since decided to bring it down further. From May 2012 onwards, single parents whose youngest child is five or over will have to be available for work. The introduction of these policy changes has been controversial for two reasons.

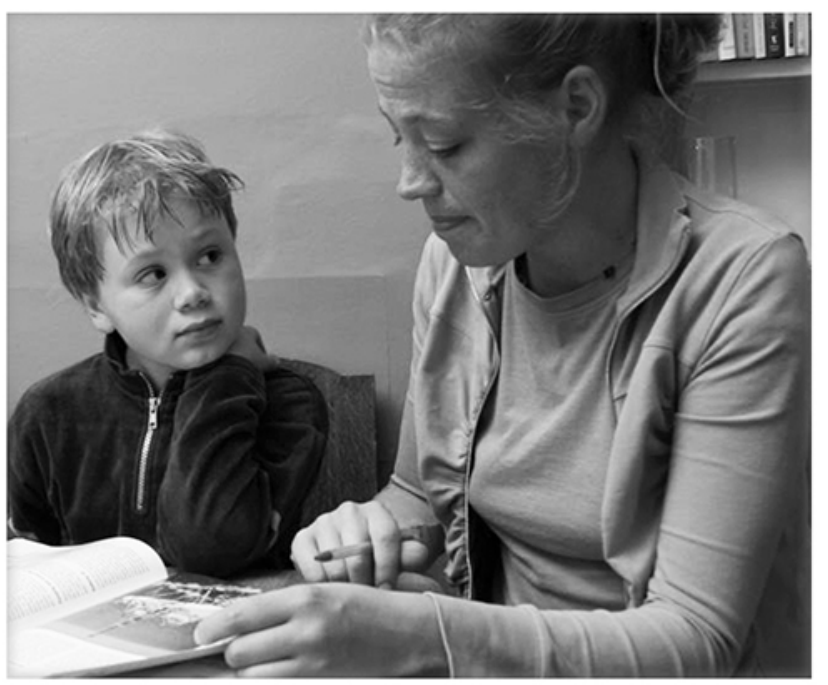

Firstly, doubts have been expressed about whether there will be sufficient and suitable childcare. Secondly, regarding the timing of such changes as Britain had just entered a recession that has been forecast to have longlasting consequences.

The aim of this study was to explore how single parents on Jobseeker's Allowance experienced the support and training opportunities in place to facilitate their learning, well-being and advancement into sustainable employment. The research was based on longitudinal, qualitative research with 50 single parents. These single parents were interviewed three times, over the course of the research. The interviews were carried out by peer researchers in the main, i.e. other single parents, who were provided with research training and support throughout the study. In addition, the peer researchers were interviewed about their experiences of conducting research.

The research was funded by the Big Lottery Fund's research programme and led by the Single Parent Action Network (SPAN), working collaboratively with the University of the West of England, Bristol. 
A number of other studies have been commissioned by the Department for Work and Pensions in conjunction with the policy changes (Casebourne et al., 2010; Gloster et al., 2010, Coleman and Lanceley; 2011 and Lane et al., 2011). In the report, we will be referring to this research as well as the other relevant studies on single parents (for example, Peacey, 2009 and Millar and Ridge 2008). This study adds to the existing body of previous research in a number of ways. Firstly, the longitudinal exploration of the experiences of single parents moving to Jobseeker's Allowance means that the stability of trajectories has been explored. Secondly, the research covers issues that have not featured prominently in other research, such as training, self-employment and caring for older children. Finally, the interviews were carried out by single parent peer researchers from within the communities of inner city Bristol and, therefore, could be deemed to have collected richer data than previous studies.

The outline of this report is as follows: chapter two sets out the broader policy context for this report, in addition to giving details of the rules of JSA. The relevant literature is discussed in chapter three. Particular attention will be paid to the studies commissioned by Department of Works and Pensions (DWP) on the policy changes as well as other longitudinal, qualitative studies about single parents. In chapter four, the methodological approach deployed in this study is outlined, for both the participatory element as well as the single parent sample. The location of the fieldwork, namely the city of Bristol, is introduced in chapter five with particular reference to labour market and child poverty data.
In chapter six, the first set of findings are presented, namely single parents' experiences of the transfer from being in receipt of Income Support to Jobseeker's Allowance. The next four chapters cover the journeys of single parents during the course of the research leading to four destinations, moving into paid employment (chapter seven), into self-employment (chapter eight), receiving Employment Support Allowance (chapter nine) or remaining on JSA (chapter 10). In chapter 11, one of the key issues that has emerged from the research will be discussed, namely caring for older children. chapter 12 deals with another of the key themes in the research, training opportunities. Finally, chapter 13 presents the views and experiences of single parents both of Jobcentre Plus and the policy changes more widely. Chapter 14 contains the summary and discussion and is followed by policy recommendations in chapter 15. 


\section{Policy Context}

In this chapter, the impact of the welfare changes, austerity measures and public sector cuts on single parents will be discussed. Future welfare changes including the Universal Credit and In-Work Conditionality are also considered. Finally, the impact of the rapid change of job-seeking requirements for single parents is explored, including the restrictions on training opportunities and the increased competition to secure flexible employment that fits in with caring for their children.

\section{The 2008 welfare reforms}

In 1997, $45 \%$ of single parents were in employment (ONS, 2009 in Coleman and Lanceley, 2011; p.10). The previous Labour Government (1997 to 2010) wanted to increase this employment rate. The Government set two interlinked targets: to halve child poverty by 2010 and for 70 per cent of single parents to be in employment, by 2010 (Thurley, 2003). The strategies began with voluntary programmes such as the New Deal for Lone Parents (NDLP), introduced in October 1998. These were aimed at helping single parents improve their work readiness and move into employment and a range of further policies were added, such as the new tax credits and the National Childcare Strategy. Significant progress was made towards both the reduction in child poverty and the employment target (Gregg et al 2006, and Brewer et al, 2010). For example, by 2006 the single parent employment rate had increased to 57\% (Gregg et al., 2006)
It has been estimated that around half of the improvement was due to the policies introduced, mainly the financial support through tax credits but also NDLP, and the other half to the generally favourable economic climate (Gregg et al., 2006). However, both targets were missed (HC452, 2010), despite substantial investment in benefit levels targeted at children (Brewer et al., 2010). Moving single parents into work was regarded as a key lever to meet the child poverty reduction target (Harker, 2006). Therefore, in 2008, the Labour government shifted the balance from encouraging single parents to move into, work towards requiring single parents with older children to be available for work.

Regulations introduced in November 2008 stated that single parents (who were fit to work), with children over a specified age, needed to take up job seeking requirements and were transferred onto Jobseeker's Allowance (JSA). The reform was introduced gradually. It began with parents whose youngest child was aged 12 or over. From October 2009, the age limit was lowered, the youngest child being aged 10 or over and then lowered again in October 2010, to 7 or over (Kennedy, 2010).

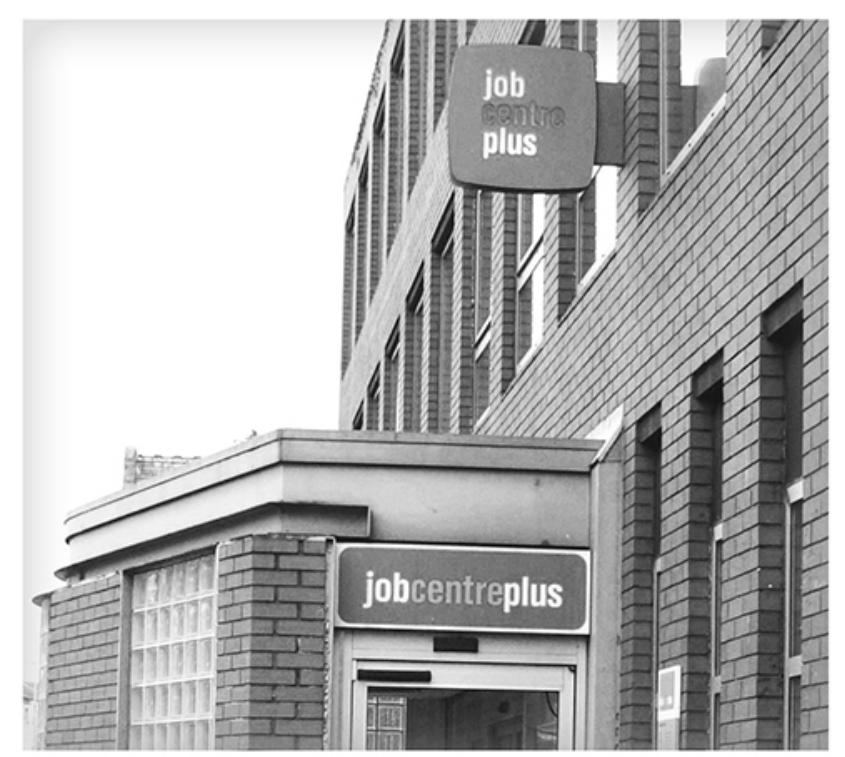


The Labour government justified the introduction of compulsion by arguing that (most) single parents with older children should work because:

-Working would have beneficial effects for single parents and their families,

- In terms of helping single parents into work, making work pay and the availability of suitable childcare (the infrastructure), was already in place or would be, in the course of 2010 ,

- Most other countries had greater conditionality in place for single parents,

- The employment rate of single mothers in other countries was much higher as was the employment rate of mothers in couples in Britain and

- Single parents with older children were 'able to work' as they were not required to look after their children full-time.

(White Paper (Cm7290 2007).

The introduction of a requirement to be available for work for (most) single parents with older children has had a mixed reception and a number of the previous Labour government's justifications such as the policy infrastructure have been challenged (among others, see HC42-1 (2008/09). The lack of affordable, high quality childcare generally and in the evenings and weekends and for disabled children in particular, has been highlighted as a key necessity for single parents to be able to move into employment.
Furthermore, the danger of single parents 'cycling in and out of work' and correspondingly, the importance of employee retention and the possibility of single parents not being lifted out of poverty by moving into work, have also been highlighted.

\section{What being transferred to JSA means for single parents}

Single parents transferred from Income Support (IS) to JSA have now to attend Jobcentre Plus more regularly than when they were on Income Support and have more contact with generalist advisors. Like all claimants on JSA, single parents must demonstrate that they are available for work and actively seeking employment. However, it is recognised in the legislation that account needs to be taken of the caring role that single parents have towards their children and their children's well-being. In terms of protecting children's well-being there is provision in the Legislation to take into account the impact of a working parent on the well-being of any affected child.

Flexibilities were introduced in the Jobseeker's Allowance regime, to meet the needs of single parents who were responsible for caring for a child or children. The most clear cut flexibility is the right for single parents who have a dependant child under 13 years of age to limit the hours they work to school hours. 
The other flexibilities require an element of negotiation of reasonableness with the Jobcentre Plus Advisor.

These include:

- Limiting the hours single parents are available to work (including those who have children up to the age of 16) to a minimum of 16 hours a week based on their caring responsibilities.

- The ability to refuse or leave a job because there is not appropriate childcare available.

- Temporary restrictions to job preparation and job seeking where a single parent has suffered a bereavement or other domestic emergency.

- Being treated as unavailable for work in the school holidays if the parent is unable to find appropriate childcare during this time.

- Restricting their availability for work such as when they are subject to a parenting order or have entered a parenting contract or when their child has been excluded from school and they cannot find appropriate childcare

- Permission for longer notice periods to attend interviews or take up job offers, if they are experiencing difficulty finding appropriate childcare.

To protect the well-being of children, Jobcentre Plus Advisors can also arrange for postal signings during school holidays (when there is not suitable childcare) and for work travel times to take account of the need to drop off and pick up children from school or childcare

\section{Welfare changes under the coalition government}

The Coalition Government which came to power in May 2010, set out their vision for welfare reform in the summer of 2010 (DWP, 2010). This consisted of introducing structural changes (such as the Universal Credit) with the aim of encouraging more people to take work (including jobs of a few hours a week) and punitive measures for those that did not take work, including a tougher sanctions regime. Their underlying aim was to stop what they considered welfare dependency. In addition, they considered the welfare system was not economically sustainable. In June 2010, the Coalition government cut $£ 11$ billion from the welfare budget and a further cut of $£ 7$ billion was set out in the Spending Review in October 2010. In the March 2012 Budget, George Osborne, the Chancellor, announced that the welfare budget faced a further $£ 10$ billion reduction by 2016 (Budget Statement 2012)). In terms of legislation, the key piece was the Welfare Reform Act (2012), which will be described in more detail in the next section.

\section{Structural changes to welfare provision}

The Coalition passed the Welfare Reform Act in 2012. This Act (which consists of a number of policy initiatives) combined a number of initiatives that impact on single parents.

One of the biggest changes was that from May 2012 onwards, single parents whose youngest child was five years old or older, had to be available for work. DWP (2012) estimates that an additional 124,000 single parents may have to look for work as a requirement of their entitlement to benefit. 
In addition, the Welfare Reform Act (2012) increased job seeker conditionality, with more pressure on people to seek work, with tighter sanctions on those who are not considered to be doing enough to find work (including potential withdrawal of benefits for up to three years). The Work Programme, introduced in June 2011, focuses on people who have been unemployed for long periods of time. Job seekers, including single parents, who have been on Jobseeker's Allowance (aged 18-24 years) for over 9 months and aged over 25 after 12 months will be transferred onto the Programme. More details on the Work Programme are provided in chapter 5 .

Other changes introduced by the Coalition Government have meant that the welfare system is less centralised, with more discretion for local decision makers (such as Jobcentre Plus Advisors and Managers). For single parents, there is less specialist support; they no longer have access to Lone Parent Advisors. The NDLP programme came to an end in March 2011. Since April 2011, single parents have had access to the Jobcentre Plus Offer that includes generalist advisor support and a menu of flexible support options. They may also have had access to Jobcentre Plus provision, including financial incentives and the range of services offered through 'Get Britain Working' measures. However, there is local autonomy in how services are provided within Jobcentre Plus, including financial support such as access to the flexible support fund. This can leave single parents not knowing what they can ask for and what services and support they can access. Recent DWP commissioned research concluded there is little awareness amongst single parents about the range of support that could be provided under the Jobcentre Plus Offer (Lane et al., 2011).

\section{The gendered impact of policy announcements}

In terms of welfare spending cuts, there are changes that will have a particular impact on single parents ( 9 out of 10 of whom are women) who are already more likely to live in poverty than coupled parents.

- The 2010 budget froze the rate of child benefit for a period of three years, eroding its value equivalent to $10 \%$ of its value (CPAG, 2012).

- Since April 2011 there has been 10\% cut in the Child care Element of the Working Tax Credit so parents can only claim up to $70 \%$ of their childcare costs $(64 \%$ of families receiving Childcare Tax Credit are single parents).

- In addition there have been cuts to the amount of Housing Benefit that a household can claim, including capping of the Local Housing Allowance, in relation to property size. $71 \%$ of all single parents who live in rented accommodation receive housing benefit, compared to $25 \%$ of couples (Gingerbread,2012).

Recent research has highlighted the disproportionate impact of the broader Coalition policy changes for women. There is concern about the cumulative impact of the policy changes, particularly the cuts to pubic services. Research for the TUC (Horton et al., 2010) showed the overall distributional impact of cuts to public services, by determining the 'cash value' of public services for different households. 
Single parents bear the brunt of cuts to public services, because they are more likely to rely on local services such as social care, libraries, education (further and higher) and early years care services. The research revealed that single parent households stood to lose the equivalent of around $18.5 \%$ of their net income, the equivalent of one month's income a year.

The Fawcett Society also provided evidence with the support of the Institute of Fiscal Studies highlighting that women, and single parents in particular, were bearing the brunt of the cuts to public spending (Sands, 2012). The Fawcett Society highlighted that women face a triple jeopardy as a result of the deficit-reduction measures and cuts to public sector jobs, wages and pensions. As state services are withdrawn, women are also left to fill in the gaps left by the cuts to these services.

\section{Single parents' experience of becoming jobseeker's}

The change towards job-seeking requirements for single parents has been rapid. Since 2009, 300,000 single parents have moved from receiving Income Support to having to meet job seeking requirements. The start of the recession in 2008 coincided with the introduction of the policy changes for single parents. This has meant that single parents were required to be available for work just as the labour market was about to contract.

\section{Training for single parent jobseeker's}

Single parents' opportunities to undertake training and improve their skills have been affected by their move onto JSA. In this section, we set out the Coalition's view of single parents and training. We also consider how women are fairing in the current job market and draw on current evidence about single parents' experience of the job market.

During the passage of the Welfare Reform Act 2012, the issue of training for single parents was discussed. Within these discussions, the Coalition Government reiterated the role of training for those on Jobseeker's Allowance.

"It provides for people who receive shortterm training support during their job search; it does not provide long-term ongoing support for an extended training course." Chris Grayling (House of Commons 2011)

DWP Minister Maria Miller, stated that there would be transitional protection for single parents of children aged 5-7 already on longer term courses, allowing them to remain on Income Support until they finished their course. However, after the transitional period,

"Lone Parents, whose youngest child is five and older who want to claim benefit after the transitional protection ends, will have to claim JSA if they are capable of work." (House of Commons 2011). Once on JSA, single parents are treated like other jobseeker's and can undertake only part-time training and education if they are actively seeking and available for work. They can also undertake up to two weeks full-time training in any twelve month period, with the agreement of their personal advisor. 
Parents can only access support for selfemployment training after six months rather than when they take up employment. These training restrictions limit opportunities for advancement, compared to the previous potential training opportunities open to single parents with children over 5 on income support. During the first twelve months on JSA, single parents can (like any other job -seeker) self-refer to training within the restrictions allowed for someone on job-seeking benefits.

Maria Miller stated that she hoped that single parents who were on Income Support and with a child aged under 5 who attended work-focused interviews would be encouraged by their personal advisor "to access work-related training to improve their job prospects, in readiness for them to move onto JSA." However, at present, it is not formalised at what stage they will be alerted to have sufficient time to undertake longer term training and study, before their child reaches five (House of Commons 2011).

\section{Rise in unemployment}

The unemployment rate stood at 8 per cent in January 2012 (ONS, 2012). The number of people who were unemployed and actively looking for a job increased from 1.61 million to 2.67 million over that period (Philpott, 2012). There are over one million women unemployed, up from 700,000 in September 2008. There are an increasing number of women on Jobseeker's Allowance, currently 531,700 (TUC, 2012).

\section{Competition for part-time roles}

For single parents with younger children who can restrict their hours to part-time hours, the employment picture for quality work is bleak. Single parents who are entering the job market have no right to request flexible working, such as restricting their hours, as this is only an option once someone has been in a job for at least six months. The Government's proposal to open up the right to request flexible working to all employees and not just to parents and carers does not include a day one right. The 26 week rule will still exist for everyone. Single parents have to contend with, and will continue to have to rely on the limited availability of advertised job vacancies.

Many women entering the job market and who want to work part-time have to downgrade the quality of work that they take. The Resolution Foundation (Resolution Foundation, 2012) study found that nearly half of all the women they surveyed had taken a lower skilled job, because they were working parttime. The Joseph Rowntree Foundation and Women Like Us (JRF, 2012) carried out a study of part-time job vacancies. They defined a quality part-time job as paying the equivalent of $£ 20,000$ per annum (pro rata). They found that intermediate and higher skilled candidates faced an acute shortage of quality part-time jobs, with one part-time vacancy paying this salary level for every 18 full-time vacancies at this level. They concluded that candidates with higher skills ended up taking a role below their skill level. Lower skilled candidates were then crowded out of the labour market, because of this competition with more highly qualified candidates. 
There is also increased competition for parttime jobs, because people who may want to work full-time are taking part-time roles. Only one in five of those taking new part-time jobs did not want to work full-time, while the remaining 4 out or 5 people in new part-time jobs were not able to get full-time work (TUC, 2012). This means more people who would previously have been able to get a full-time job will compete for part-time jobs. This negatively impacts on many single parents entering the job market and who want to work part-time.

\section{Single parents and self employment}

Self employment can be a route for single parents to use their skills and provide them with flexible work to fit around the responsibilities for their children.

The Government's introduced the New Enterprise Allowance (NEA) in August 2011. The scheme is managed by Jobcentre Plus to help people who have been claiming Jobseeker's Allowance (JSA) for at least six months who want to start their own business (by moving into self employment).

NEA is available to JSA claimants aged 18 and over who have been claiming for 26 weeks or more. In order to be accepted a job seeker needs to have a clear idea of what their business will involve and how it will be sustainable in the longer term. It is the decision of the advisers at JCP whether someone is accepted onto the scheme. Participants can gain access to a volunteer business mentor who will provide guidance and support as they develop their business plan and through the early months of training.
Once an applicant can demonstrate they have a viable business proposition with the potential for growth in the future, they will be able to access financial support. This consists of a weekly allowance and a facility to access a loan for start up costs.

\section{Job cuts in the public sector}

Over the next five years, there will be a major run down in public sector jobs, with at least 600,000 jobs expected to be lost by 2015-16 (The Work Foundation, 2011). This is in addition to further job losses expected in private firms supplying the public sector. The Office for Budget Responsibility (OBR, 2011) estimates that 710,000 jobs in the public sector will be lost by 2017. Cuts to public sector employment affects women more than men, as women are much more likely to be working in the public sector (TUC, 2012). The Trade Union Congress (TUC) has estimated that $40 \%$ of women currently in work are employed in public sector jobs, with women accounting for $64 \%$ of the public sector workforce overall.

Public sector employers have a public sector equality duty to promote equality of opportunity between men and women in their employ. This means that many public sector employers offer flexible employment as well as opportunities for training and progression to all their staff. Contraction of public sector employment may result in less flexible employment opportunities for women and further increase the number of women looking for work. This will add further competition for single parents entering the job market and less opportunity for them to find employment with family friendly policies. 


\section{Future changes to welfare provision with impact on single parents}

Starting in October 2013, the Welfare Reform Act 2012 introduced the 'Universal Credit' which will replace a range of existing meanstested benefits for people of working age. Claimants will be able to keep some of the money they earn as they enter work. As their earnings rise the Universal Credit will then be withdrawn at a constant rate (a taper level to take account of earnings). It is designed to simplify the benefit system by combining the means tested benefits into one 'out of work' benefit. The childcare element of the Working Tax Credit will be integrated into the Universal Credit, even where someone is working a few hours a week. Therefore, it may help single parents to move into the first stages of employment, for instance, enabling them to move into mini-jobs (of under 16 hours a week). The Government has calculated that this will support an additional 80,000 households, because of the removal of the need to work a minimum of 16 hours.

Although positive in financial terms for some single parents, who will work limited hours, there is concern about the negative impact on those who want to work over 16 hours or who are required to work longer hours as their children get older. Save the Children have modelled the impact of the changes under the Universal Credit and found that single parents working longer hours (16 or more) will be worse off (Save the Children, 2011). They give the example of a single parent with two children, working full-time on a wage of $£ 15,000$, with childcare costs of $£ 232$ per week, being nearly $£ 60$ worse off per week.
The Universal Credit will not financially encourage single parents to take on additional hours of work and may even penalise single parents, who may be required to work longer hours.

The Universal Credit will remove the separation between 'in work' and 'out of work' benefits and will include the introduction of in-work conditionality. This is designed to push claimants to work more hours and reduce their dependency on benefits. The Government intend to set the maximum threshold for a single claimant, at the level of earnings that would be accrued by working full-time at the National Minimum Wage. Certain groups, like single parents with younger children, will be expected to look for work that is compatible with school hours. However, in-work conditionality will mean that over time, they will need to increase their pay. This will have particular impact on the single parents who were pushed into low paid work with few prospects for advancement, when their children were younger. This policy also seems to be in contradiction to poor financial incentives in the Universal Credit for single parents to increase their hours above 16 hours.

Whilst smoothing some of the financial transition between benefits and work, the Universal Credit does not address some of the other core barriers faced by single parents entering work. These include the lack of availability of good quality, affordable childcare and the poor choice of flexible employment that is open to single parents. 


\section{Summary}

There has been a rapid change in welfare policy towards single parents. In the last two and a half years, the majority of single parents have moved over to job-seeking requirements and are experiencing the impact of the cuts to welfare spending and public services. Single parents have moved onto a job seeking service which has been largely designed for the single job-seeker, rather than a job-seeker with parenting responsibilities. There are in principle, flexibilities open to single parents who are jobseeker's, including the right to work during school hours when a child is under 13.
However, most of the flexibilities are around negotiated rights with a Jobcentre Plus Advisor. The lack of specialist advisors and an increase in local autonomy at Jobcentre Plus offices leaves many single parents unclear what services and options are open to them. The Universal Credit will help to smooth the financial transition of single parents into work but may in some cases penalise parents wanting to work over 16 hours a week. The Universal Credit does not address other barriers that single parents face in entering work, including the cost and availability of childcare and the poor choice of part-time job opportunities. 


\section{Literature review}

\section{The problems with the adult worker model}

When comparing the policy treatment of single parents across time and/or countries, a number of analytical concepts have been applied. The most prominent concept is that of the mother/ worker dichotomy of whether single parents are treated as mothers or workers in different countries, depending on the conditions for financial support and work conditionality. This concept of single parents being treated as mothers or workers has been derived from the male breadwinner model, an attempt to add a gender dimension to the welfare regime typology by Esping-Andersen (see original paper by Lewis and Ostner 1994 in Lewis 1997 and collections edited by Duncan and Edwards 1997 and Lewis 1997). Kilkey (2001) has taken this approach further by combining it with an analysis of financial outcomes suggesting that there are four groups: poor mothers, non-poor mothers, poor workers and non-poor workers.

Prior to 1997, the policy treatment of single parents in Britain has been categorised both as treating single mothers as mothers (Lewis, 1997) and as poor mothers (Kilkey, 2000). When New Labour came to power in 1997, the policy situation for single parents changed substantially (Millar and Rowlingson, 2001). They have increasingly been treated as parents of future citizens, rather than individuals with their own needs and aspirations (Lister, 2006). Lewis (2006) has suggested that in light of a general trend across many countries towards an adult worker model, i.e. where all adults are treated as workers,

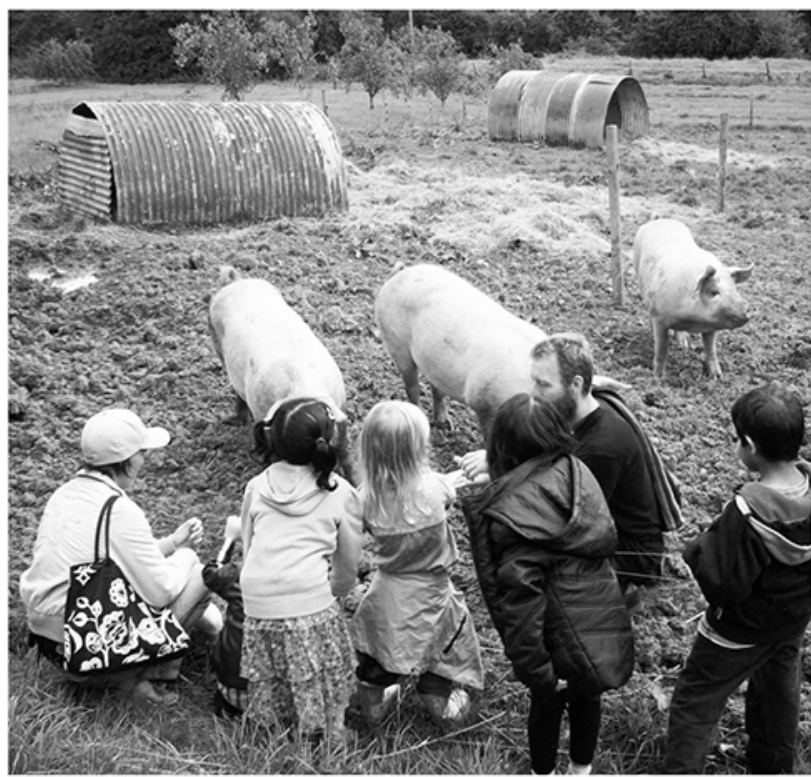

(in different countries) but when. In other words, while there is an international policy trend towards the activation of single parents (OECD, 2007, Carcillo and Grubb, 2006), it tends to be focused on particular groups of single parents rather than all single parents. In the UK, availability for work is determined by the age of the youngest child and since 2009 the age limited has been lowered successively from initially 12 to now seven and soon five years (see chapter 2 for more detail).

The full adult worker model is ostensibly built on gender equality by requiring all adults to move into paid employment with their care responsibilities effectively outsourced.

However, Lewis and Guillari suggest that:

'The problem is that care cannot be fully de-familialized or commodified, because it is passive as well as active, because it is emotional and relational, because the pressure for women to care is stronger than it is for men and is a part of gendered identity formation, and because the fragmentation that has resulted from welfare state restructuring has increased the need for family and informal care.' (2005; p. 95) 
Lewis and Guillari (2005) are also raising key issues for this research namely how the nature and importance of caring for older children has shifted for policy-makers, though not for single parents, which gives rise to a number of tensions regarding being able to find employment that fits with the care needs of older children.

As Millar and Ridge write:

'For mothers in employment, work and care are two sides of the same coin, which must be managed together. The familywork project is thus as much about sustaining care as it is about sustaining work.' (2008; p.109).

\section{Barriers to employment and employment sustainability}

It is worth mentioning that single parents generally and those not in employment in particular, have been the focus of a large number of studies over the past 20 years. Therefore, a large body of research exists on a number of topics of interest here, such as single parents' attitudes towards work and parenting, their success in finding work, the barriers to employment as well as their experience of the Jobcentre. The key studies are the survey of all single parents by Bradshaw and Millar (1991), the Programme of Research on Low Income Families (PRILIF- a longitudinal survey of single parents and couples on low income from 1991 to 2001), the Families and Children Study (FACS another longitudinal survey of families and children running from 1999 to 2008), the large evaluation programme of the New Deal for Lone Parents (NDLP), the qualitative research by Duncan and Edwards (1997) developing the concept of the gendered moral rationality and the longitudinal qualitative study of single parents who have recently moved into work (e.g. Millar and Ridge, 2009; Ridge and Millar, 2010). Three reviews of existing evidence have been carried out so far (Holtermann et al., 1999, Millar and Ridge, 2001 and Haux, 2009).

Previous research on single parents not in work has focused on three main areas with regards to single parents not in work: their characteristics, potential barriers to work and their work orientation (Haux, 2009). The research reviews suggest that on the whole, previous research has produced similar findings with regards to the characteristics of single parents not in work and their barriers to work. Single parents, not in work, are more likely to:

- Have a child under five,

- Have three or more children,

- Be single, rather than divorced or separated

- Have a health problem,

- Have no qualifications,

- Have no recent work experience and

- Have no plans to move into work in the near future.

(Haux, 2009; Millar and Ridge, 2001; Holtermann et al., 1999)

Further analysis of of the target group of the welfare reform, i.e. lone parents with older children, compared their characteristics with those of single parents with younger children. This analysis suggests that single parents with older children are not only more likely to have characteristics that place them at a disadvantage in the labour market but also that they are more likely to have a number 
of these characteristics, i,e. they are more likely to face multiple disadvantages with regards to moving into work (Haux, 2011).

The findings on barriers to work for single parents, also seem to be similar on various studies and the following list has been suggested by a number of studies:

- A preference to stay at home with the child(ren)

- Childcare issues (either that it is not available or affordable or that parents prefer to entrust it only to friends and relatives)

- Lack of confidence

- Personal health problems or child(ren's) health problems

- Financial issues (concerns about the financial disruption when going to work and not being better off),

- Employment conditions (the attitudes of employers and availability of flexible jobs) and

- Lack of skills and qualifications

(Haux, 2009; Millar and Ridge, 2001;

Holtermann et al., 1999)

Less agreement has emerged in the area of work orientation of single parents. The figure of nine out of ten parents wanting to work is perhaps the most quoted and has been consistent across many studies (see Holtermann et al. 1999; Millar and Ridge 2001 and Haux 2009). However, the existing research is less clear as to the factors influencing the decision to look for work. Duncan and Edwards (1997) argue that single parents are influenced by the behaviour and views of their friends and family. Analysis trying to identify the main factors influencing choices and constraints on work entry, retention and exit suggests that the main factors influencing single parents' decisions about employment are 'attitudes towards parenting as a job, perceptions of personal and family constraints and intentions to work'

(Tomaszewski et al., 2010; p. 29).

Previous research has also highlighted the issue of employment sustainability, particularly for single parents (Evans et al., 2004). This research suggested that single parents were twice as likely as individuals from the general working age population to leave employment, within twelve months of moving into the labour market (Evans et al., 2004). The characteristics of those single parents who left the labour market within a year of starting work were similar to those not in employment, i.e. they were more likely to be younger, to have fewer qualifications and less recent work experience (Evans et al., 2004). The qualitative, longitudinal on single parents who recently moved into work by Millar and Ridge (2008) suggested a number of reasons for why this might be the case, including changing nature of work patterns once in a job and number of hours worked which the single parent families were not always able or willing to accommodate.

\section{Health and well-being}

The impact of employment and income on mental health is well established (Gregg, Harkness \& Smith, 2009; Gardner \& Oswald, 2007; Winkleman \& Winkleman 1998). The reforms introduced in 1998 by Labour have improved not only levels of employment and the numbers of hours worked by single parents, but have also been protective of mental health. 
Exposure to different social and environmental influences contributes to the way that attitudes, values and behaviours are formed. These in turn affect their ability to make and take decisions.

The broad vision of health that encompasses not only physical health but also well-being, reflects the international acceptance of the interpretation of the term 'health' put forward by the World Health Organisation in 1947 as 'a state of complete physical, mental and social well-being and not merely the absence of disease or infirmity". There is clear evidence that young people who are born into poorer families are less likely to do well in life than their richer counterparts. Children's capacities to learn are shaped by their background and home circumstances as well as by their individual development. Thus children from poorer backgrounds are likely to grow up to have poorer employment prospects, higher rates of chronic illness or disability and unhealthy lifestyles (Field, 2010). Such children are at a decided and demonstrable disadvantage, compared to other children.

\section{Lone parent obligations research}

The change in policy to require single parents with older children to be available for work has been accompanied by a research programme including quantitative and qualitative studies (Coleman and Lanceley, 2011; Lane et al., 2011; Casebourne et al., 2010; Gloster et al., 2010). Together with a study of the early effects of this policy by Gingerbread (Peacey, 2009), they are forming the reference point for this study.
The research programme of the Single Parent Obligation, as the change in policy is called by the Department for Work and Pensions (DWP), is building on previous research, e.g. by using similar survey questions. So far, four studies have been published as part of the programme. The first two studies included a survey (Coleman and Lanceley, 2010) and a qualitative study (Gloster et al., 2010). The two studies focussed on single parents about to be transferred to JSA and therefore provide a good picture of single parents' characteristics, views on work and parenting and experience of the Jobcentre, prior to the policy change (Coleman and Lanceley 2011, Gloster et al 2010). The qualitative study also includes interviews with Job centre staff (Gloster et al., 2010). The two subsequent studies were both qualitative (Casebourne et al., 2010; and Lane et al., 2011). These studies explored the views, experiences and destinations of single parents once they were transferred to JSA (Jobseeker's Allowance), and one of them also included interviews with Jobcentre staff (Casebourne et al., 2010).

In addition to the government-commissioned studies, Gingerbread carried out qualitative research with single parents at the point of transition to JSA (Peacey, 2009). The findings of these studies will be discussed in more detail in the relevant chapters. The aim of the following sections is to give an overview of the key findings relevant to this study.

Peacey (2009) explored the reasons why single parents with older children on IS are not in work and found reasons such as the 
importance of being able to provide 'guidance and supervision' to older children, the cost of childcare, health problems, a lack of confidence, not having family around to support them, concerns about being better off in work and their employability.

After the introduction of the policy change, single parents who had been on Income Support (IS), moved into five directions: into employment, onto JSA, onto ESA (Employment Support Allowance), remained on IS or neither claimed benefits nor went into employment. The following section will discuss the findings for the three main groups, those moving onto JSA, ESA or into work, very briefly. Both the survey prior to the change in policy, as well as the qualitative studies afterwards suggest that single parents who moved into work tended to go into low paid, low skilled jobs

(Casebourne et al., 2010, Coleman and Lanceley, 2011; Lane et al., 2011). Whether single parents felt better off or not in work seemed to depend on whether they were working part-time, i.e. less than 30 hours, or full-time, i.e. more than 30 hours. Those who worked full-time were 'very mixed' about whether they were better off or not, while there was a clear sense of being better off among those working part-time (Casebourne et al., 2010). Additional benefits to working such as increased confidence, having made new friends and being a better role model were mentioned by single parents in all studies.
The longitudinal, qualitative study of single parents who had recently moved into work by Millar and Ridge (2008) suggested that moving into work was a 'family project' that was often supported by the children and had an effect on them. The authors also highlighted that it was not uncommon for single parents to have changed their work hours or even jobs over time (Ridge and Millar, 2010). In other words, employment arrangements tended to be less stable than they initially seemed. This links to work by Evans et al (2004) on retention, identifying single parents as being at a much higher risk of leaving work within the first year, than the working age population in general.

Where single parents had substantial health problems, they would usually be transferred to the Employment Support Allowance (Casebourne et al., 2010). For this group, the transition from IS was perhaps more difficult, with instances of paperwork getting lost and payments missed (Casebourne et al., 2010).

Single parents who moved to JSA from IS seemed to have a good understanding of the rules of JSA. Overall, the transition was reported to have gone smoothly by single parents and Jobcentre staff, though the change in payment frequency did lead to budgeting difficulties (Gloster et al., 2010). Peacey (2009), however, reported that single parents felt under considerable pressure to find work, when transferred to JSA. There were some problems in the transition, with advisors not being aware of all the single parent flexibilities. 
Yet, the overall mood of both staff and single parents is less negative at the "point of transition" captured in Gloster et al. (2010) than it is later on, as captured in Casebourne et a. (2010), even though the fieldwork took place within one year of each other. However, the comparison between the views of single parents of the Jobcentre on IS and JSA was striking. While on IS, single parents seemed overall to be quite positive about the Job centre: $83 \%$ said the advice they had received over the past twelve months had been useful and $69 \%$ were satisfied with the Jobcentre (Coleman and Lanceley, 2011; p. 6). However, once on JSA 'in general, (it was) felt that there was less support offered, fewer training opportunities, and a sense that they were offered a less personalised service' (Casebourne et al., 2010; p. 3).

A number of the studies also interviewed Job centre staff (Gloster et al., 2010; Casebourne et al., 2010) and thus shed light onto what has brought about the changed experience, in addition to the obvious change that single parents now had to be available for work. At the time of the policy change, Britain was going through a major recession and this added to the pressure of Jobcentres, as there were more claimants to deal with and fewer jobs to refer them to (Casebourne et al., 2010). In addition, not all generalist staff were sufficiently trained to deal with the new group of JSA claimants. This lack of training covered both the knowledge of the single parent flexibilities introduced into JSA as well as the experience of dealing with single parents, e.g. discussing working outside school hours and using formal childcare (Casebourne et al., 2011).

Childcare featured in all studies but different attitudes emerged, depending on the age of the youngest child. Single parents with older children (nine to twelve years) did not intend to use formal childcare for a number of reasons, such as the availability of suitable childcare for older children, as well as the potential cost (Casebourne et al., 2010). Single parents with younger children (aged seven to eight), however, seemed more positive about using formal childcare (Lane et al., 2011). Lane et al (2011) suggested that this could be due to having experienced free childcare for their children as part of the expansion of free nursery provision (Lane et al., 2011).

Training and the difference between single parents' expectations and the provision on JSA also featured in the different reports. For examples, single parents 'felt that training and education was no longer open to them, which meant they had less opportunity to progress and find a better paid or more satisfying job.' (Peacey, 2009; p. 53; see also Casebourne et al., 2010). There was also a sense of an information deficit, with regards to advisors not being aware of training opportunities and advisors telling single parents about those opportunities (Peacey, 2009), such as NDLP (Casebourne et al., 2010). 
The studies commissioned by DWP have covered many aspects of the policy change exploring the views of both single parents and JobCentre staff. In particular, the studies are very good on covering all the different elements and stages of the policy in detail. It is also very useful that the studies were carried out at different points in time of the policy implementation and therefore provide snapshots that can be compared. The study by Peacey (2009) added to this as it captured single parents' views and experiences when the reform was first introduced. However, none of the studies are longitudinal. The Lone Parent Obligations survey (Coleman and Lanceley, 2011) was designed to be longitudinal but subsequent waves have since been cancelled. Therefore, the studies do not capture the experience of single parents over time.

As the following chapter will outline in more detail, the study reported here has been undertaken with single parents over two years and can therefore add valuable insights on the journeys single parents have been on, since the policy changes have been introduced and how it has affected them and their families. 


\section{Research Aims \& Methodology}

This chapter outlines the methodological approach and methods employed throughout the study. It explores the contribution of participatory approaches to researching those who are often identified as 'hard to reach' and the impact of the involvement of a group of single parent peer researchers in the research process. The aim of the study is outlined, alongside the methods of recruitment in relation to both the peer researchers and the broader participation of the fifty participants. In addition, the chapter explores data collection, analysis and the ethical considerations that provided the framework for the fieldwork and analysis.

\section{The aim of the research}

The central question posed in the study was, "How do single parents on Jobseeker's Allowance experience the support and training opportunities in place to facilitate their learning, well-being and advancement into sustainable employment?" Within this, the research focused on two key areas. The first was to understand the views and experiences of single parents who were subject to recent welfare changes that removed them from Income Support (IS) and transferred them to Jobseeker's Allowance (JSA). The second was to involve single parents as peer researchers in the project and understand their personal journey through the research process, from the initial recruitment and training to the dissemination of the findings.

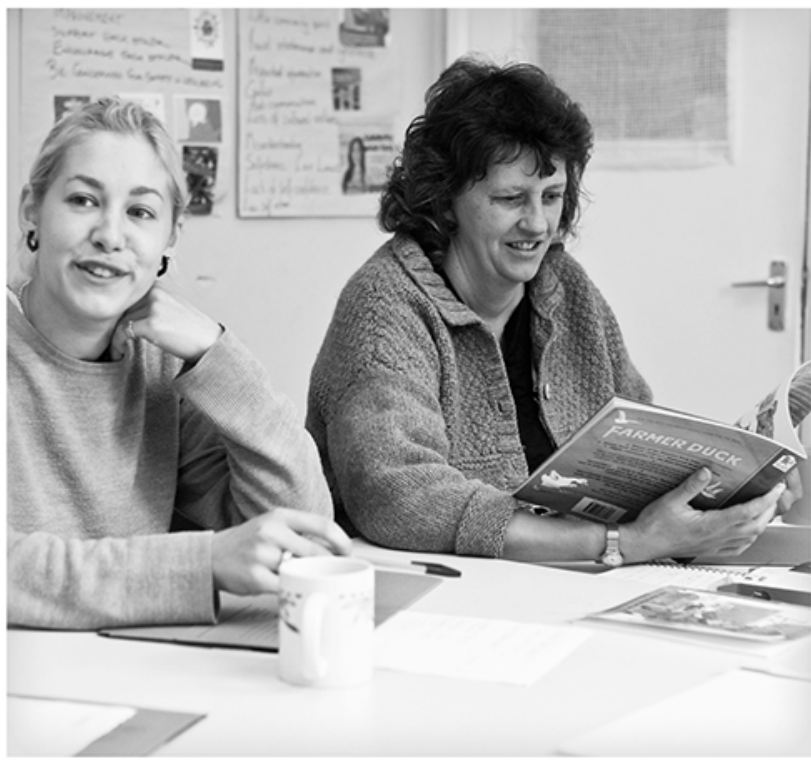

\section{Underpinning approach}

One of the key underlying principles of participatory action enquiry is that participants are co-researchers as well as co-subjects; participants are not researched on, in the traditional sense, but are researched with and by co-researchers (Bradbury and Reason 2006; Heron, 1996). This project was committed to equalising the often disempowering relationship between researcher and research participant (Bennett and Roberts, 2004). Co-researchers engaged in a process of reflective cycles and action (Bray et al, 2000; Heron, 1996). As new ideas were adopted, utilised and reflected upon, new knowledge was constructed and became part of an ongoing iterative learning process. In addition, using participatory methods made it possible to draw on direct experience that highlighted issues not easily accessible through other methodologies (Bennett and Roberts, 2004).

The significance of using peer researchers is that they can hold a privileged position for accessing groups, who can be difficult to reach through more traditional methods. This has the potential to improve the research. 
Supporters suggest it enriches understanding of the lived realities of those who are often marginalised and the findings can influence policies in ways that make sense to those affected (Elliot, 2002; Bennett and Roberts, 2004; Coppock, 2011). In particular, it gives people with experience of poverty more involvement and influence (Bennett and Roberts, 2004). Involving single parents in many of the aspects of the research process from research design, to data collection and analysis, allowed for the collection of richer and in-depth data. This led to a more grounded approach to the research which, it is anticipated, will inform policy in ways that more traditional research methodologies might have left participants in the research feeling voiceless. While the evidence for participation can be compelling, the practicalities of making it happen can be challenging and far from straightforward. There are a significant number of issues that need attention if the process is to be meaningful, which include: providing training and ongoing support for interviewers; consideration of childcare and remuneration; flexibility around roles and control; understanding the nature and boundaries of lay knowledge and a robust development and exit strategy for those who have taken part (Elliot, 2002).

Nevertheless, having the single parent peer researchers at the heart of the dissemination process, meant local and national decision makers would be part of a dialogue with single parents who both carried out the research, as well as experiencing the impact of the policy process.
Consistent with the philosophy of participatory approaches, it was also anticipated that as the single parent peer researchers became exposed to the ideas surrounding welfare reform and listened to the experiences of those they interviewed, their sense of ownership, influence and empowerment would also develop. Bennett and Roberts (2004) argue that this,
'brings gains for participants: increasing the confidence and 'voice' of people in poverty - but also acting as a learning process for those not in poverty who are involved, and often resulting in the creation of new networks........and by embodying the principle of the right of people in poverty to influence images of poverty and public debate; ........strengthening their claims to other rights and to full citizen- ship'

(Bennett with Moraene Roberts, 2004:2).

This sets the scene for the following sections which outline the methods employed to undertake the field work. 


\section{Methods}

\section{Recruiting and training}

\section{the peer researchers}

Recruitment took part in two phases, the initial phase in autumn 2009 and the second in spring 2010. For the first group of ten peer researchers, training consisted of sessions once a week over ten weeks, supported by the provision of crèche facilities. Staff at the University of the West of England, Bristol delivered these sessions, actively organised and supported by the Single Parent Action Network (SPAN) project worker. The sessions took place at the SPAN building or at local community centres; all the sessions had crèche facilities available on site. This process allowed peer researchers to develop a sense of group cohesion, identity and peer support. At the end of the programme, six of them had completed the training. The second group had sessions that were delivered over four longer sessions. Five peer researchers were recruited to this group but only three went on to fully complete the training.

The content of the training included introduction to research; development of interviewing skills; self awareness; ethics; safety and lone working; child protection; managing the research environment and relationships. A key aspect of the training was offering peer researchers the opportunity to accredit their learning through a university 'Evidencing Work Based Learning' module. Therefore, an additional focus of the training included preparation for the assessment process.
Students were assessed through a practice interview and portfolio of evidence of learning portfolio, based on a diary of reflections on learning and supporting activities. Students were able to study the module at their appropriate academic level, five completed at Level One and two at Masters Level.

\section{Following the journey of the Single Parent Peer Researchers}

The two academic researchers on the project were responsible for this aspect of the project. Peer researchers were interviewed three times over the life of the project. The first interview aimed to establish motivations and aspirations for becoming involved in the project. In addition there was an exploration of initial experiences of recruitment, involvement in the training delivered and the research process, engagement with the accreditation process and experiences associated with doing some preliminary pilot interviews with single parents within the community. Eight months later, the second interviews were conducted, focusing on peer researchers experiences of involvement in all aspects of the project. Questions were asked about their experiences of engagement, support, developing aspirations and advancement opportunities, their learning and the wider impact on the well-being of their families.

At the request of the first group of peer researchers, the first set of interviews was undertaken using a focus group. Otherwise, the interviews were one-to-one. Data analysis was undertaken using thematic analysis. The final aspect of analysis involved a validation workshop, where a group of peer researchers were asked to validate the dominant themes that emerged. 
Initial findings are reported as vignettes in this report, further discussion will be forthcoming.

\section{Recruiting and sampling single parents}

Single parents were recruited through a wide range of organisations and social networks. The table below (Table 1) summarises the numbers recruited through the different agencies.

\section{Table 1 Route of recruitment for participants}

\begin{tabular}{|l|l|c|}
\hline Organisation & Recruitment method & Number \\
\hline Single Parent Action Network & Face to Face & 10 \\
\hline Single Parent Action Network & Flyer & 3 \\
\hline Citizens Advice Bureau & Letter & 6 \\
\hline Jobcentre Plus & Letter and Flyer & 7 \\
\hline Peer Researchers & Face to Face & 5 \\
\hline Strengthening Families Strengthening & Face to Face & 2 \\
\hline Communities & & 8 \\
\hline Community Partners & Flyer & 3 \\
\hline Participants & Face to Face & 3 \\
\hline Don't know & Snowballed & 3 \\
\hline SPAN total & & 13 \\
\hline Other total & & 37 \\
\hline Total & & 50 \\
\hline
\end{tabular}

In collaboration the peer researchers, leaflets were designed and distributed through the organisations outlined. The leaflet explained the project and asked for volunteers. Prospective respondents were then able to contact the research office, where it was possible for them to elicit more information and ask any additional questions.

Involvement was voluntary.
Initially recruitment was slow. However, the Citizens Advice Bureau and Jobcentre Plus agreed to send an introductory letter and leaflet on behalf of the project to all single parents on their mailing list; this yielded an excellent response. Initially, the project aimed to recruit parents whose youngest child was aged 13. This reduced to nine years and finally seven years, thus reflecting the speed of policy change in this field. In total, fifty single parents were recruited to the project: two were male and forty-nine female. The tables below outline the biographical data and sample characteristics.

The age spread was between 25 and 60 with most participants being between $35-54$ years old with the ethnicity showing a predominance of 'White British' (67\%) (Table 3). Most parents had one or two children, but there were some with five or more (Table 4).

\section{Table 2 Age profile of} single parent interviewees in years $(n=50)$

\begin{tabular}{|c|c|c|c|c|c|c|}
\hline $\mathbf{2 5 - 2 9}$ & $\mathbf{3 0 - 3 4}$ & $\mathbf{3 5 - 4 0}$ & $\mathbf{4 1 - 4 4}$ & $\mathbf{4 5 - 4 9}$ & $\mathbf{5 0 - 5 4}$ & $\mathbf{5 5 - 6 0}$ \\
\hline 2 & 7 & 10 & 17 & 8 & $\mathbf{5}$ & 1 \\
\hline
\end{tabular}

Table 3 Ethnicity of single parent interviewees

\begin{tabular}{|c|c|}
\hline Ethnicity & Sample numbers \\
\hline White-British & 33 \\
\hline White - Other & 4 \\
\hline Black or Black British-African & 4 \\
\hline Mixed Parentage/Heritage & 6 \\
\hline Asian or Asian British-Pakistani & 2 \\
\hline Black African & 1 \\
\hline Totals & 50 \\
\hline
\end{tabular}


Table 4 Numbers of children in family

\begin{tabular}{|c|c|}
\hline Number of children & Number of families \\
\hline 1 & 19 \\
\hline 2 & 15 \\
\hline 3 & 6 \\
\hline $4+$ & 11 \\
\hline Totals & $\mathbf{5 0}$ \\
\hline
\end{tabular}

Forty seven of the participants were interviewed in English two in Somali and one in French. The number of months interviewees had been on Income Support ranged widely, from three weeks to 288 months (see Table 5 below).

Table 5 Time parents on Income Support $(n=50)$

\begin{tabular}{|l|c|}
\hline Amount of time on income support & $\begin{array}{c}\text { Numbers of } \\
\text { families }\end{array}$ \\
\hline Less than one year & 2 \\
\hline One year to two years & 7 \\
\hline Two years to four years & 8 \\
\hline Four years to 10 years & 17 \\
\hline Over 10 years & 10 \\
\hline Unsure & 1 \\
\hline
\end{tabular}

\section{Exclusion criteria and the challenges}

Although wherever possible, the researchers aimed to accept all volunteers into the study, there were a small number of occasions when this was not possible. When participants were suffering a severe and enduring mental health issue, or were unable to answer questions on their own behalf, consistent with the ethical approval process outlined below, they were not included in the study. An additional area, explored at the outset, was where peer researchers felt under threat or in danger; in reality, this did not occur.

It was possible to include single parents from a wide range of social, ethnic and cultural backgrounds, including those with English as an additional language. This was made possible by the ability of three of the peer researchers to speak fluent Urdu and/or Somali, and local translation services that were able to transcribe the interviews.

\section{Data collection with single parent participants}

The total number of interviews completed was 135 across the three phases. In wave one 50 were completed, wave two 45 and wave three 40. An initial interview was undertaken on recruitment to the project and this focused on setting the scene. A second interview, approximately five months later, explored ongoing advice, training and advancement and a final interview twelve months from the first, explored the outcomes for single parents. The content of the three interviews are described in the three boxes below. 


\section{Interview one: setting the scene}

Data collected included biographical data about themselves and their family, in particular the ages of their children and any specific health or social care needs. An understanding of the length of time they had been in receipt of Income Support and arrangements for their transfer to Jobseeker's Allowance (JSA). Researchers also explored their qualifications and experiences of work to date and aspirations for the future. This initial interview explored single parents' first experiences of Jobcentre Plus: about the change to JSA, including how single parents felt on receipt of their initial letter, the extent to which they understood what the changes meant and what was required of them. Participants were also asked to reflect on their first interview with Jobcentre Plus advisors, including the advice and support given in relation to future job and training opportunities.

\section{Interview two: ongoing advice, training and advancement}

This interview was undertaken five months after the initial interview. It focused on the medium term consequences of the move to JSA, particularly in terms of the consequences of looking for work. Participants were asked about the kinds of support they had received, and specifically to reflect on the role of lone parent advisors within the JCP. For those who had undertaken training, interviewers focused on the quality, flexibility and appropriateness of the provision. Interviewees shared their perceived benefits and limitations of being in receipt of JSA and any additional support arrangements connected to childcare or travel.
Specific attention was given to childcare needs and advice, including local provision. Participants were also asked to comment on the degree to which they had felt able to raise broader issues with their advisors throughout the interview. These included difficulties that prevented them taking up employment opportunities, such as ill health, housing problems or other caring responsibilities. Researchers attempted to explore the degree to which advisors had explained legitimate reasons for delay in transferring to JSA, such as domestic or personal crisis, bereavement of a family member or intimate partner violence. For those who spoke English as a second language, it was possible to explore any additional support JCP advisors offered. Where this had not been provided, participants were asked where they had turned to for help. The final aspect of this interview focused on the level and appropriateness of information received about training/learning provision.

Career guidance and possible links with colleges or universities were also explored. For those with English as an additional language, support mechanisms were discussed. The focus on training aimed to establish the impact on skills development, confidence and the degree to which the training had brought them closer to the sort of job they were hoping to get. For those who had not attended training, the focus was on the appropriateness of the opportunities they had been presented with. Other activities such as work trials, job or voluntary placements were also explored, using similar questions to those posed about training connected to the perceived benefits and limitations, and any additional support arrangements connected to childcare or travel. 
This interview was undertaken twelve months after the initial interview. For those who were working, it focused on the consequences of the move from JSA to work, particularly in terms of the type of work: whether it was appropriate for the participant's experience and skills, if they had received any training, whether they were better off and/or more financially stable and any impact on their own health and well-being. Participants were asked about the kinds of support they had received, specifically from the advisors in Jobcentre Plus, their experience of moving from JSA to work, whether

Interviews were undertaken face to-face, conducted in the main by the peer researchers, in participants' homes or in a confidential room within the SPAN Building. When it was not possible for peer researchers to complete the interviews due to sickness, family or work commitments, the interview was undertaken by one of two SPAN researchers. By completion of the project, peer researchers had undertaken approximately eighty per cent of all interviews. All the interviews were digitally recorded and transcribed verbatim. The findings from this part of the research project are interspersed as comments throughout the report.

\section{Data analysis}

Informed by grounded theory and using the method of constant comparative analysis, it was possible to move back and forth between conceptual speculation identified within the literature, data collection and analysis and personal reflection, using methods outlined by Strauss and Corbin (1990)
JSA had prepared them for work and any additional benefits that they might be receiving. There were also questions that related to childcare arrangements: ease of, and help with, finding care and satisfaction with the arrangements. Researchers also explored participants' aspirations for the future, general views of JSA and the government's lone parent policy. For those with English as an additional language, support mechanisms were discussed. Lastly, they were asked about their motivations for staying on the project and their experience of being interviewed.

The sample size enabled interview transcripts to be analysed using a traditional 'cut and paste' approach whereby the researcher reads and re-reads the transcripts drawing out themes and sub-themes (Gibbs, 2007). This data analysis was not a technique but part of what Crabtree and Miller (1992) describe as an iterative process of revisiting themes. This process illuminated a number of overarching themes: the transfer to JSA; single parent journeys; caring for children; training; experiences of Jobcentre Plus; views of welfare reform and the future. All of these themes are discussed in the findings section of this report.

Generally, the analysis is based on the whole sample, of 50 single parents. However, in the chapters where we describe the journeys of parents with the four destinations of employment, self-employment, on Employment Support Allowance (ESA) or remaining on Job Seekers' Allowance (JSA), 
we included those parents who had been interviewed at each interview wave, i.e. 40 single parents. This resulted in the following number of parents in each of these sub-samples:

- In employment: 14 parents

- In self-employment: 5 parents

- On ESA: 6 parents

- On JSA: 15 parents

\section{Ethical considerations}

On volunteering, research participants received a letter and detailed information sheet, outlining the aims and rationale of the research and contact details. Immediately prior to the first interview, participants were asked to read and sign a consent form that included agreement to have their interview digitally recorded and inclusion of their data in any subsequent publication.

The information sheet was discussed, with particular focus on the participant's right to withdraw at any stage of the research process. While the research did not involve methods or techniques that harm participants, researchers were fully briefed in the techniques of interviewing and in the conduct required of them as researchers. Where participants requested advice or emotional support, researchers were briefed to direct them to information leaflets that included local contacts for support services.
All researchers were made aware of the National Children's Bureau Statement of Values and Principles, Equal Opportunities Policy Statement, Child Protection in accordance with the British Sociological Association Statement of Ethical Practice (BSA, 2002; NCB, 2003).

In addition, researchers were made aware of the lone worker policy and the arrangements for keeping safe, particularly when doing interviews in the community. The guidance laid down in the British Educational Research Association, cited in the Revised Ethical Guidelines for Research (2004) was addressed throughout the research process. This included informed consent, voluntary participation, confidentiality and anonymity. Particular attention was given to training the peer researchers in issues of child protection and safeguarding. Interview practice allowed them to develop skills in raising the issue at the beginning of interviews and responding to positive disclosures, in line with Department of Health (2011). Ethical approval was obtained through the University of the West of England, Research Ethics Committee. 


$$
\begin{aligned}
& \text { "well this is quite different you know } \\
& \text { because this is a bit more of a higher level } \\
& \text { than l've done maybe recently } \\
& \text { and a bit more focussed and vocational even } \\
& \text { so yes I feel like I've got some skills } \\
& \text { and discovered some things I didn't know before } \\
& \text { you know about there's more to interviewing people } \\
& \text { than just asking them some questions." }
\end{aligned}
$$
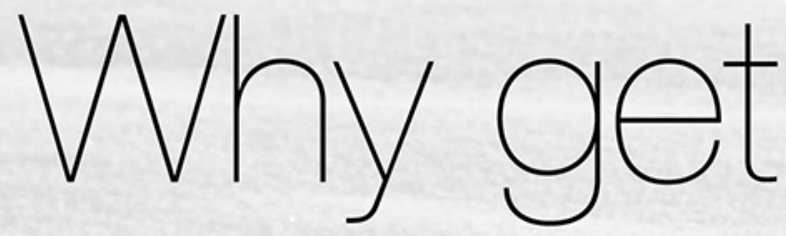

The single parents who volunteered to become peer researchers gave a number of reasons for what had motivated them in the first instance.

These included an opportunity to "get one's brain working", develop new skills, study and promote learning. For example, one peer researcher suggested that she wanted to challenge the norms and values of her culture that maintained that women do not work once they had children. This was important because she had enjoyed work and really missed the stimulation and social aspects of working in a large company. Involvement in the project was one strategy of returning to paid work in a

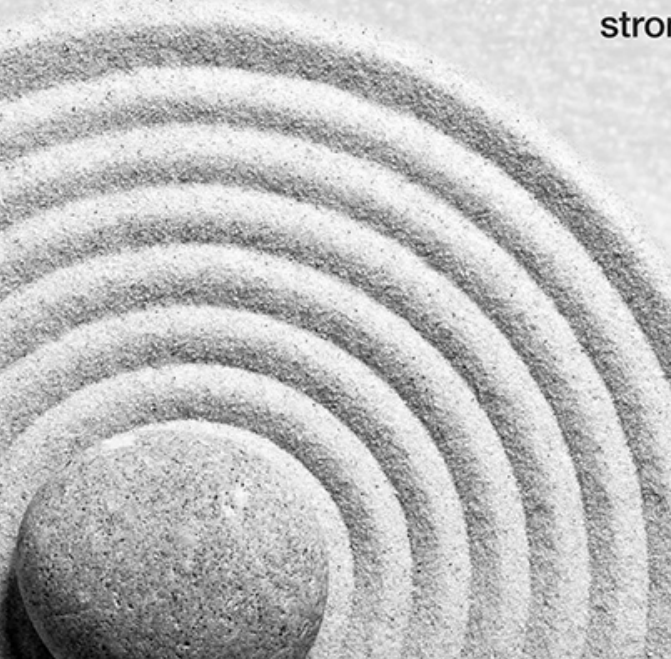

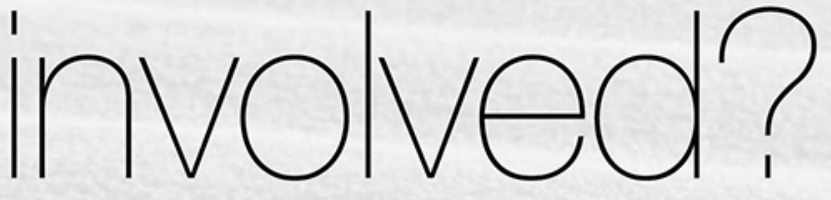

number of arenas including care work, education and health. Improving the chances of employability was a dominant feature of several of the interviews. One peer researcher had immigrated to the UK, learnt English but had given up work when her children were born. She hoped the project would give her an opportunity to meet other parents, stop the feelings of isolation and mitigate the stress of feeling trapped at home with her children.

The theme of meeting others as well as the chance to integrate and learn about the new and very different culture was particularly strong among those who immigrated to the UK. 


\section{Bristol}

This research project was carried out in Bristol. Therefore, the aim of this chapter is to provide an overview of the labour market and socio-demographic characteristics of Bristol, as well as the provision of training and employment support. The information provided in this chapter is mainly based on statistics released by Bristol City Council. However, the information contained in the second part of the chapter, focusing on training and employment support provision in Bristol, is based on informal interviews, analysis of information sent through the ways2work network and in-house knowledge.

Bristol is the largest city in the South West of England, with a population of 441,300 in 2010. In 2008, $37 \%$ of all families in Bristol were headed by a single parent. This was higher than the national average of $25 \%$. In the inner-city areas of the city numbers of single parent families were significantly higher with $67 \%$ of all families in Lawrence Hill, $56 \%$ in Ashley and 44\% in Easton. Social housing estates at the outskirts of the city, including Knowle West, Hartcliffe and Southmead are also areas with a high proportion of single parent families (Bristol City Council, 2011).

Bristol is a city that is generally considered prosperous, with overall high levels of economic activity, employment and workforce skills. However, despite its prosperity, there are also significant 'pockets' of persistent worklessness (Bristol City Council, 2011) and deprivation affecting specific communities.

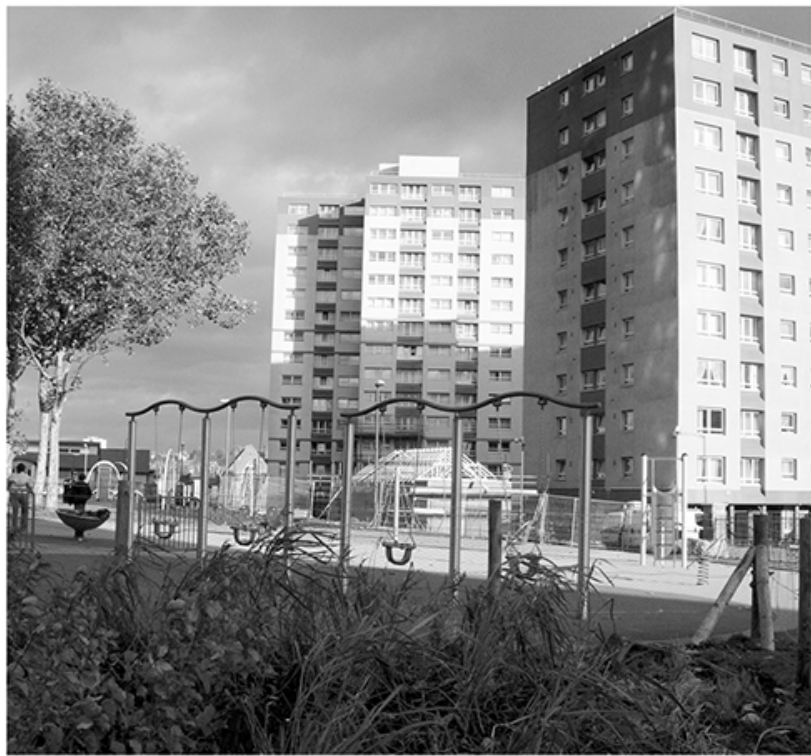

The concentrations of worklessness in particular neighbourhoods are largely matched by the spatial patterns of deprivation and disadvantage. The 2007 Indices of Deprivation (ID, 2007) highlight the fact that Bristol has some of the most and some of the least deprived areas in the country within the boundaries of its local authority. For example, more than half of the population living in the inner-city areas of St Paul's and the Easton Road are experiencing income deprivation (Noble et al., 2008)

Bristol has both a large number of highly qualified workers and significant numbers of residents without any qualifications. The high proportion of those with a qualification of first degree level or above is a key factor in driving the city's prosperity. The high proportions of those with lower level or no qualifications also goes some way to explaining the concentrations of persistent worklessness in several neighbourhoods across the city. The Education, Skills and Training Domain is also where Bristol experiences some of the highest levels of deprivation. 
This is particularly the case in the social housing areas of South Bristol, with five areas being among the 100 most deprived in the country. In areas such as Lawrence Hill, a combination of factors act as barriers to employment, including language barriers, low qualifications or overseas qualifications not recognized in the UK. There is a clear link between lack of qualifications and the likelihood of unemployment. Only $37 \%$ of Bristol residents with no qualifications are in employment, compared to $86 \%$ of residents with degrees (Bristol City Council, 2011b).

Around 40,000 working age people in Bristol are currently claiming out of work benefits (around $14 \%$ of our working age population, compared with $13 \%$ across Britain). In January 2012, there were 12,948 Bristol residents who claimed Job Seekers Allowance. This represents $4 \%$ of the working age population and is close to the national average. This is an increase of $2 \%$ since May 2008. There is no data of how many of the JSA claimants are single parents, nor do we know how many are on Employment Support Allowance or Incapacity Benefit. Single parents on Income Support are recorded as a separate category, in "out of work" benefits statistics and in May 2011, there was 5,430 single parents in Bristol who received this benefit.

Data on child poverty in Bristol also indicates that there are a significant proportion of single parents not in employment, or in low-paid jobs. In $2008,76 \%(21,835)$ of children in poverty in Bristol lived in single parent families, compared with $67 \%$ in core cities and $68 \%$ in England as a whole.
These figures are not evenly distributed across Bristol. Wards like Stoke Bishop and Henleaze have incidence of child poverty from 4\%, whereas Lawrence Hill has almost $60 \%$ of its children living in poverty, putting it in the bottom percentile of all wards nationally. Almost 2,300 children in Lawrence Hill live in poverty and out of those, 1750 live in a single parent family, i.e. $76 \%$. Bristol City Council expects that subsequent national data releases for 2009 and 2010 will show a marked increase in these levels. In the city's child poverty strategy, Bristol City Council has expressed a particular concern about the barriers faced by single parents in finding employment (all in Bristol City Council, 2011c).

According to Bristol City Council's latest Childcare Needs Assessment (2011), "Lone parents are twice as likely to need childcare but are amongst working families with the lowest earned incomes in Bristol". In 2008, $53 \%$ of all single parent families in Bristol were in employment, which was lower than the $57 \%$ national average. Again, patterns of the proportion of single parents in work were unevenly distributed across the city. In affluent areas such as Bishopston, Westbury-onTrym, Clifton and Redland, over 65\% of all single parents were working. In Lawrence Hill, only $27 \%$ of single parents were in work and deprived areas in South Bristol, including Filwood, Witchurch Park and Hartcliffe all have employment rates below 40\% (Bristol City Council, 2011a). 
From the childcare needs assessment for Bristol, we also know that childcare, particularly afterschool clubs and childcare for young babies, is more readily available in the affluent areas of the city where a higher proportion of single parents are in work. Most schools in disadvantaged areas do not have after school clubs (as a daily childcare option) and there are a limited number of childminders in those areas. Data on the uptake of the childcare element of working tax credits also shows that uptake among single parents in Bristol is generally low, with $31 \%$ in Henleaze being the highest and $8 \%$ in Clifton the lowest. In Lawrence Hill, the uptake was $22 \%$ and Hartcliffe $17 \%$. These figures might indicate that the majority of single parents work within school hours or rely on unofficial childcare arrangements with friends and family.

The 2018 parents surveyed through the childcare sufficiency assessment were also asked how they found out about their childcare. The most common source of information was family/ friends (41\%) and schools (28\%), while the least common source was Jobcentre Plus and the Library (0.40per cent). One of the recommendations in the report is to

"Increase partnership working between the Family Information Service and partners in Jobcentre Plus and Libraries".

\section{Employment support and training in Bristol}

Since this research project begun, there have been significant changes to the support on offer for single parents in the UK. This has also had an effect on the services available in Bristol. As described in detail in the policy chapter (chapter 2), one the biggest changes has been the abolishment of 'New Deal' schemes and specialist single parent advisors. The welfare reform and funding cuts to the public and voluntary sectors has also had a significant impact on the training and support services available to the unemployed in Bristol. Many providers are the same, but their contracts and funding streams have changed over the course of this research project, affecting the services they are able to offer. For example, some of the welfare-towork providers that were previously delivering the New Deal contracts and European Social Fund schemes, specifically targeting parents through voluntary schemes, are now subcontracted to deliver mandatory programmes such as the Work Programme and in some cases, other services like Next Steps .

When the initial mapping exercise of services in Bristol was carried out, none of the providers interviewed had any experience of working with single parents on mandatory programmes. By August 2011, as the work programme was taking off, some of these providers started to have a fairly large number of single parent clients.

During the first 12 months on JSA, a single parent can self-refer to a training and support provider, including the Work Programme providers, or one of Jobcentre Plus (JCP) 'Get Britain working' initiatives. 
In Bristol, as elsewhere in the country, what they access will largely depend on guidance from their JCP advisor, their own initiative / knowledge of local services and availability of services that meet their needs.

1 Job Clubs, Enterprise Clubs, New enterprise allowance, Work together, Work experience programme, Sector-based work academies, and, work choice (for disabled parents).

In Bristol, there are a number of different types of employment and training providers available to single parents, some of which they will be referred to by the JCP and others, that they can self-access. Some of these providers are linked through sub-contracting chains and/or joint partnerships.

There are a number of large national or multinational private businesses and charities that specialise in welfare to work provision. These draw down funding directly from the DWP or are part of the 'first tier' of the Work Programme, i.e. they are subcontracted by one of the 'primes'. Their services are target driven, as they are generally paid on result.

The Work Programme contracts for the South West of England, which includes Bristol, were awarded to JHP Training and Jobfit in the spring of 2011. Both have a chain of delivery partners who are described as 'end-to-end' providers and 'specialist providers'. 'End-toEnd' providers in Bristol include companies such as Seetec, Tomorrow's People, Pinnacle People, The Salvation Army Employment Plus, Prospect and City of Bristol College. 'End-to-end' providers take care of the JSA claimant, makes an initial assessment and should support the client through the job seeking process.
They have a small training and support budget, which they can use to buy services for their clients from specialist providers, or to pay for transport or childcare. They should also be able to advise clients where they can access further training and some of them provide in-house employability training.

In Bristol, JSA claimants are referred to either of the two primes and their delivery partners on a random basis. Who they actually end up seeing, will depend on which prime they have been allocated to and in which are of Bristol they live. As a result, not all single parents will receive the same service or support options. This will be determined by the organization they are referred to and what their supply chain looks like.

Through interviews with members of staff from some of the end-to-end providers, we know that they are not necessarily informed at referral, if a new client is a single parent or not. As showed in SPAN's recent report is the Work Programme Working for Single Parents? An Analysis of the Experience of Single Parents Moving onto the Work Programme, several single parents in Bristol have experienced difficulties when brining children with them to appointments or have been given appointments at times that coincide with school pick-up or leaving times. When asking about support to find childcare, they have been referred back to the Jobcentre (Dewar, 2011).

City of Bristol College (COBC) has been a major training provider in Bristol for many years and is now also sub-contracted to deliver the work programme. A new faculty called 'Work Skills' was established in 2011. 
City of Bristol College has campuses across

Bristol where they run 2-10 week courses in care and childcare, retail, business administration, security, hospitality, construction, IT and health and fitness. They offer courses in basic skills, including English, Maths and ESOL (English as a second or other language). City of Bristol College also run Employability courses and Work Clubs throughout the city. Job-seekers can use computers, search for jobs, get help with their $\mathrm{CV}$, job applications and interview preparation. Most of COBC courses are delivered between 9.15 am and $4 \mathrm{pm}$. They are able to fund childcare, but learners have to find the provision themselves.

Through their 'Faculty of Outward Collaboration', COBC also work in partnership with smaller community based organisations across the city, including SPAN Study Centre, the Beacon Centre, Hartcliffe and Withywood Ventures (HWV), the Park, Silai for Skills and CSV Avon training. SPAN Study Centre specialises in supporting single parents and all services are tailored (to their needs) around school times. SPAN has a crèche for children under five. HWV are also able to offer childcare, alongside some of their services.

Services on offer from all these organisations will depend on what funding they have at any given time and range from basic skills and employability to support around self-employment and personal development. COBC have also recently started to work in collaboration with the Volunteer Bureau, offering support through so-called 'Job Clubs' at the central library.
In summary, Bristol is a very diverse city with pockets of both high levels of prosperity and deprivation. The level of qualifications of the city's inhabitants is very diverse. There, is a clear link between having low level of qualifications and the risk of being unemployed. Child poverty levels, in particular, are high in Bristol. Poverty and deprivation also have a spatial dimension in terms of service provision in Bristol, with childcare provision more readily available in the more affluent areas. Finally, the training provision for single parents in Bristol has changed substantially during the fieldwork for this project. 


\section{Transfer to the Jobseeker's Allowance}

In this chapter, the experience of single parents in this study when they were first transferred from Income Support (IS) to Jobseeker's Allowance (JSA) will be discussed. Particular attention will be paid to information and understanding of the new policy and the experience of the new regime in terms of the advisors, job search requirements and the physical space.

\section{Finding out about the changes in policy}

Information about the change of policy came from a number of sources such as the lone parent advisor, a television campaign, other single parents and a letter from the Jobcentre. Discussions about the forthcoming changes in legislation and the impact of those for single parents, did form part of work-focused interviews on some occasions. Single parents also mentioned the television campaigns and talking to other single parents, as having alerted them to the change in legislation. The official letter arrived anytime between a two weeks and three months before single parents were switched over from IS to JSA. The source of information affected the timing of the information. Where the changeover had been discussed in work-focused interviews, single parents could be alerted as much as two years before the actual change. The letter seemed to be clear, if brief. However, it seems that the core message generally came across:

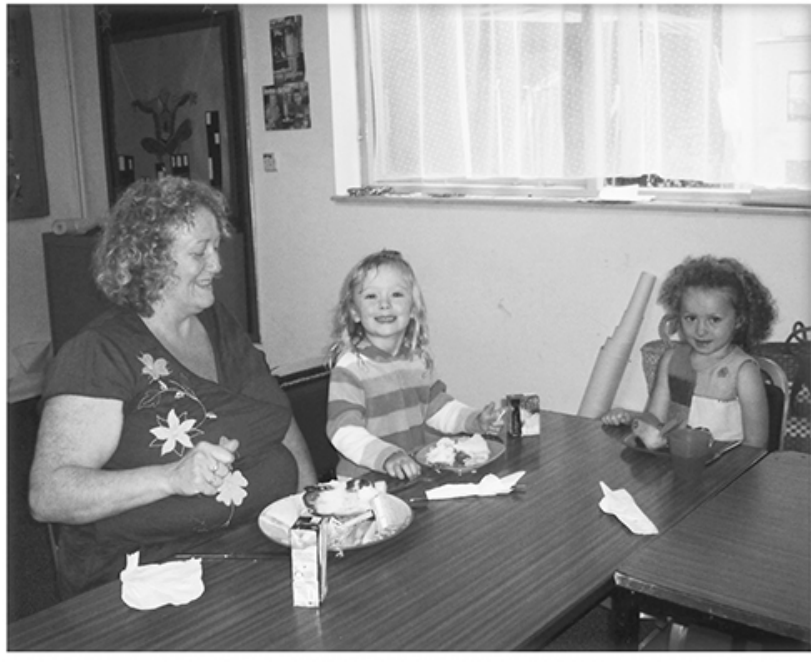

I: "What did you understand in the letter, when you went for the interview?"

R: "I just understood I have to go to work, I didn't get good explanation about help with my child and myself I was just told to go to work, they just told me if your child reaches 12 years you will have to go to work."

(Yasmin, W1).

\section{Initial reaction to the changes}

Single parents reacted to the letter informing them about the requirement to now sign on for JSA, in a number of ways. Being scared of money being taken away, was one of the key themes mentioned by single parents. Another major issue was worry about how the change would affect the overall finances of the family, e.g. whether the family would still receive housing benefit. Furthermore, there was concern over falling behind with bills, if a job did not work out. Other worries mentioned were additional caring responsibilities,concerns about not being able to meet the required job search activity and benefit being cut as a result. 
As one single parent put it:

"Um the letter itself was actually quite straightforward but I did feel worried and scared wondering how things were going to be affected other bills and benefit's and things would be affected. I do feel very pressurised because if I don't actually reach their targets for looking for work um which is very difficult to try and find the time sometimes to look for work then they say that they will actually cut my benefit and I mean that... I think they mean that as to stop the benefit not cut it or reduce it."

(Hannah, W1).

"We were sent a letter to attend a meeting and a presentation they gave us to explain what it is all about yeah its more theoretical, what I mean is its ok they gave us a warning kind of thing I knew what to expect."

(Hawa, W1)

Even where parents had been forewarned, the content of the letter was experienced as 'clear but it was also a shock' (Penny, W1). The most common phrase to describe the change was that the 'pressure was building' on single parents with older children. One reaction to the changes was to jump into work before being pushed, i.e. single parents moved into work, in anticipation of being transferred to JSA:

R: "so l've started the job that I'm in now, I started on the 1st November."

I- "Ok."

$R$ - "And yeah because of Lilly's age, I was on the cusp of going on to JSA."

I- "JSA."

$R$ - "but I escaped without having to do it."

(Katy, W1).

\section{Understanding of the new policy}

\section{by single parents and advisors}

In line with previous research, single parents in general, seemed have a good understanding of the detail of the policy changes, e.g. that they had to sign on regularly, that they were only required to work school hours and the amount of time they were allowed for travelling to work at different stages (Casebourne et al., 2010 and Gloster et al., 2010). However, it is worth noting that single parents' understanding of the new approach did get more confused once they escalated up the conditionality ladder (Casebourne et al., 2010). Research with Jobcentre advisors suggests that the levels of understanding of Jobcentre staff of the additional rules around this new customer group was mixed (Casebourne et al., 2010; Gloster et al., 2010). Lone Parent Advisors tended to be the most knowledgeable, while generalist advisors struggled, at times to be fully aware of the different rules, such as only having to work during school hours (ibid). This finding is supported by this piece of research where single parents report very different levels of knowledge between advisors, to the point that at times, the single parents knew more about their rights and responsibilities than the advisor.

\section{Expectations}

The focus of advisors whom single parents encountered, as part of the JSA policy was seen as different from before. It seemed that some single parents expected that the transfer to JSA was the beginning of a journey back to work. 
They assumed that they would be able to do some training, build up their own business and take part in Job trials. Instead, the focus of JobCentre advisors is to encourage single parents to move into work of 16 or more hours.

"But I had thought that I would be encouraged you know given the opportunity to kind of put myself back together as opposed to..." (Aisha, W1).

"I said I am looking to perhaps have some training back in admin to, how can I put it, broaden not my horizon but I like to know what I am doing before I go into a job, and she just flat out said you're too late to take any courses."

(Nikki, W1).

\section{The first meeting}

Previous research with advisors suggests that advisors were aware that a lot of ground needed to be covered in the first meeting. This led to concerns over how much would be taken in about important aspects such as the availability of in-work-benefits and the New Deal for Lone Parents (NDLP) (Gloster et al., 2010). From a single parent perspective, the first meeting seemed to be mainly about:

"what was going on really with the government and to sort of put you in the picture, this is what is going to happen..."

(Phoebe, W1).

Single parents are meant to have two meetings with Jobcentre staff, when they are first transferred from IS to JSA. The first meeting is to offer more detail about the policy changes and their new obligations.
The second meeting is then set up to be fully registered as a Jobseeker and to draw up a Job-seeker's agreement. In some cases, the first meeting seems to have been missed, due to staff shortages and this led to some confusion on behalf of the single parents, regarding the exact conditions of their JSA receipt in the interviews. Single parents tended to talk much more about the second meeting than the first. The main comment about the second meeting was that the advisor was pre-occupied with filling out what seemed to be very long forms.

A number of single parents commented on the amount of form filling involved and how it both structured and limited the conversation about potential jobs and job search options between them and the advisor:

"Well, she just gabbled through me... she was very busy scribbling away all the forms....because it was quite a lot of form filling ... if you are filling out forms you can't be talking at the same time you can't, it's very difficult to do..and it's all the forms, all the check boxes and stuff and all the stuff there to go through it basically was ... we didn't discuss any other ideas like let's say I couldn't come up with a third thing or something.... So and as I say it was so quick, she had to rush me through because she had another client due and she was taking on somebody else's workload as well."

(Sophie, W1).

The focus on filling forms left single parents feeling that they were not treated as individuals but needed to be fitted into existing structures and their answers into the available tick boxes. 
Furthermore, it was not always clear which part of the questions pertained to the Jobseeker's agreement, so some single parents only realised when they were asked to sign it, that they had in fact been answering questions regarding their job-seeking activities. It is fair to say that, on the whole, the second interview did not encourage helpful customer relationships.

\section{Downstairs and upstairs}

Perhaps the most striking difference for single parents arriving at the Jobcentre as a JSA claimant as opposed to an IS claimant, was the different approach taken by, often numerous, advisors they saw. A previous study suggested that single parents thought the new regime was less supportive, both on a professional and a personal level (Casebourne et al., 2010). The majority of single parents in the study had claimed Income Support prior to being moved onto JSA. This meant that they had gone to the Jobcentre for regular work-focused interviews with their lone parent advisor previously. As a result, they were used to the environment and being asked about their plans for moving into work. Yet, now that they had moved over to JSA, both the environment and the approach of the advisors were different:

"we usually kind of went upstairs where I would have my interviews and generally they were fairly okay once you sort of said yes I am going to see Paul or whatever yeah it was fine. I mean to be honest, I hated going down there um the whole atmosphere making you just feel like you were less a person, the security guards down there wandering around and pacing around and it's just demoralising basically, it's horrible I am no less a person than anyone else..."
"Before when they were helpful and trying to find you a college and different things and now they just completely ... I mean one of the questions she said to me was how was I going to find work and I just looked at her blank and I went I thought that was for you to tell me and she turned round and went no you have got to tell me and everything was just... from this friendly person to yes, no answers."

(Chloe, W1).

\section{'Overqualified and under-experienced'}

Given that the focus of Jobcentre staff now seems to be on moving single parents into work, the initial interviews were centered around finding work rather than building a career. The list of jobs suggested by Job Centre staff seems somewhat limited, essentially positions which required no or low qualifications and which were also poorly paid with low chances of progression. The main suggestions were care work, retail work, cleaning and childcare. Single parents were frequently encouraged to apply for jobs for which they had no previous experience. However, their lack of experience in particular jobs was seen as one of the key reasons as to why their subsequent applications were not successful. Some single parents questioned whether introducing this policy during a recession was sensible, as it made finding jobs even more difficult:

"they just send you to inappropriate employment really, but then again, what with the job market as it is, you can't expect to exactly get what you want."

(Emily, W1). 
However, the limitation in the list of jobs suggested by advisors had additional aspects. It seems that advisors, more often than not, interpreted 'work' as being in employment as soon as possible, i.e. jobs with vacancies that did not require any training or other lead-in time. This rather limited view resulted in issues regarding the match of previous experience and job suggestions by advisors. Some advisors were keen to make use of all previous experience, including caring for relatives for caring jobs, while other advisors did not seem to ask single parents about any previous work experience.

Furthermore, single parents who wanted to set up their own business tended to be met with little support and had to go to outside organisations for more information. As mentioned above, single parents' who planned to train for a particular profession tended to be met with little encouragement, even where single parents had researched the training thoroughly. Yet, the requirement to be available for work leaves little room for training commitments (Casebourne et al., 2010).

The level of information provided by advisors about how to go about jobsearching also differed. While some did a job search for the single parents during the interviews, others left this up to the single parents completely another indication of the different nature of the advisor-client relationship for those in receipt of IS. More on single parents' views and experience of training will be discussed in chapter 12 of this report.

\section{Transitions either between benefits or between benefits and employment}

Transitions between benefits and other financial support from government sources can both be stressful and go wrong. $A$ previous study has compared different transitions and identified the transition to the Employment Support Allowance as the one that has tended to be the most fraught with problems (Casebourne et al., 2010). This is confirmed by this study.

The four main issues with regards to transitions for single parents in this study were adjustment of budgeting routines, lack of information, uncertainty and disruption of finances. Starting with the adjustment of budgeting routines, this occurred most notably when single parents were transferred from IS to JSA and from JSA to employment of 16 hours or more per week. In both cases, the change in budgeting routines was necessary, due to the change in payment patterns and due to the new payments being made retrospectively. At the time of the research IS was paid weekly while JSA was paid fortnightly. In the transition from one benefit to the other, the payment for weekly IS would stop and a fortnight later the JSA payment would commence. In other words, single parents were required to budget ahead to cover the week of the transfer. At times this was not made clear or not understood in the communications between the Jobcentre and single parents about the changeover. However, even when single parents had been aware of the change, saving money in the previous weeks was difficult. Single parents could apply for a Lone Parent Transition Loan (LPTL) to cover this time period, 
However, as Casebourne et al (2010) point out, the value of the loan varied substantially between families and could be as low as £10 and therefore, was not perceived to be particularly useful. In addition, some single parents were reluctant to take out a loan. Therefore, the uptake of the LPTL was lower than anticipated by JCP (Casebourne et al., 2010).

While it may seem to be stating the obvious, it is worth emphasising that single parents on low income have very little room for flexibility with regards to their finances. None of the single parents in this study lived with extended family. While some had adult children living with them, these children were often studying or not in regular employment. This not only caused problems, of which more later, but also meant that the single parents in this study were solely responsible for paying all the bills, putting food on the table and finding money for clothing and other essential items. A previous study suggested that, one coping strategy on low income is to have set bill payment amounts and dates and for the latter to coincide with payment days of benefits and/or wages (Millar and Ridge, 2001). This strategy was also employed by some single parents in this study. Therefore, if the single parent had not anticipated the change in payment intervals, the bills planned for the transition week would still be due and the absence of expected income could cause real distress:

"I could not afford the necessities. I felt l'd let my boys down. I went two days without eating to make sure my boys had enough..."

(Melissa, W1).
The transition period of available benifts could result in single parents having to borrow money from family and friends or not paying the bills and accumulating arrears and fines:

"where it's changed as well to a two week instead of a week l've got in debt with bills, $T V$ licence and things like that they have sent the red letter, now we're going to refer it because you are two payments later which is only £10 something but it's still £10 something. I'm not keeping up with my agreement, so yet again, everything is getting messed around..."

(Ashley, W1).

The different payment routine could be problematic even after some time:

"Yes, I'm struggling, it's bad because you're paid every two weeks. By the end of the first week my money is practically gone. I don't get a lot anyway, I just find by the time you pay your bills and your shopping you've go nothing left..."

(Eleanor, W1).

The payment structure of IS has since been aligned to JSA and it is also paid fortnightly. Therefore, the potential for the problems at the first transition, i.e. from IS to JSA, has been removed.

However, disruption of payments could also take place when single parents started work. When benefits were stopped the day they moved into work, while the wages were paid in arrears either fortnightly or, often, monthly:

"I was quite worried because they said, well, you'll get your money for another two weeks and I said but that's five weeks before I get paid. Oh, well, your money will last, you'll have to make it last..."

(Olivia, W1). 
Given the state of the labour market during which the reform has been introduced, a number of single parents in the study had temporary jobs and moved back onto JSA and potentially into work again. Thus, they experienced a number of changes to payment frequencies, all of which have to be anticipated and accommodated.

Where benefits were not paid at all due to clerical errors, this could be very frustrating:

"It's so frustrating you know like they can't even pay you right, last week I had to go down to the Jobcentre at a ridiculous time, something like 10-o-clock in the morning. Well I had to get my daughter to school, I had to get a bus but because they didn't pay me how they should pay me i.e. by BACS into my bank account and the money was late as well which has affected my bills and everything this month and I had to make lots of calls. I had to go to this appointment but yet I had no money to get there and I was really stressing and I didn't feel very well anyway."

(Imogen, W1)

The third issue raised by transitions is that of uncertainty and its effect, that often accompanied these changes. Not being certain of how much monies they would receive as a result of transitions was a prominent theme in this study. This uncertainty stretched beyond the JSA payment and wages to housing and council tax benefit to school meals and prescriptions. Therefore, single parents were frequently unsure, not only whether they would be better off in work, but more fundamentally, whether they would be able to make ends meet. This caused considerable stress and anxiety among the single parents in this study.
Until now, the discussion in this chapter has focused on the challenge of transitions that took place as planned. The final issue that arose in the context of financial transitions was that of interruptions due to mistakes. In a number of instances, payments were delayed due to what seemed to be clerical errors or changes in status not being communicated to the appropriate sections within the Job centre. The lack of appropriate payments that the single parents were entitled to could last several weeks. As discussed above, this could result in single parents falling behind on a number of bills and even being threatened with eviction:

I: "but they have taken you off by mistake?"

R: "They have done, two times now."

I: "Which has affected your financial..."

R: "well, it does because it stops the housing benefit and everything and then my rent is not paid, then my landlord is shouting at me and it kind of spirals out of control..."

(Aisha, W1)

While the disputes of single parents in this study have all tended to be resolved and back payments being made, these back payments usually did not cover the fines and other costs incurred of not having been able to pay the bills in the first place, thus leaving single parents worse off than before. 


\section{Who looks after the children?}

\section{Childcare was one of the issues single} parents had to raise themselves, at times. This was presumably because single parents were only required to work school hours. There also seemed to be a clear expectation by advisors that any childcare needs would be covered by out-of-school clubs and informal sources of childcare such as family, friends and neighbours:

"Yeah, they said use holiday clubs or after school clubs, friends and neighbours, you got good friends and neigherbours, well, yeah, all right, if you are lucky enough to have good friends and neighbours, some don't even speak to their neighbours, do they?"

(Heidi, W1).

"No, what it comes down to was I was just told that I had to get my child into breakfast clubs, after school clubs, holiday clubs, after care whatever I could do to my child to make him not be at home when I'm at work, basically, that is what I had to do."

(Samuel, W1).

In general, single parents again felt that the onus to find childcare was placed on them rather than something the Jobcentre helped with. The amount of information given to single parents about how to find childcare differed substantially. Some single parents were given the number of the Family Information Service to find out about available childcare in their area; other advisors did not discuss childcare at all.
I: "Have the Job Centre said anything about finding suitable childcare if you needed to?"

R: "No." (Francesca, W1)

I: "What was said about finding suitable childcare?"

R: "Nothing, nothing at all...."

I: "Childcare, what did they say about childcare within school hours for like now the six week holidays?"

R: "Nothing at all, nothing, absolutely nothing, that didn't even come up." (Melissa, W1).

When single parents returned to the Job centre, having been told that there was no childcare in their area for their combination of children's ages, some were told to try harder or to look into getting a nanny. This seemed an unrealistic suggestion given the wage expectations of some of the single parents in question.

$R:$ "The other thing that happened is they told me, I had to research childcare in my area...."

I: "Yeah."

$R$ : "... and they told me to get in touch with Bristol Children and Young People's

Services..."

I: "Yeah..."

$R$ : "and I phoned them up, explained the ages of my children and I was under pressure to get a job, and what childcare was available. They sent me a letter back saying, there's no childcare in your area, have you considered a nanny? Which that was my reaction, I just laughed."

I: "Yeah, because obviously,..."

$R$ : "So I went back to the Jobcentre and said, there is not childcare and she said, well that's not good enough, you need to delve into this further, you need to find out why there is no childcare and what else you can do and she was saying things like, you need to have an $A$, $B, C$ and $D$ plan..."

(Jessica, W1). 
Another issue for single parents was having childcare cover in school holidays and in case of illness. The level of information given on this topic by Jobcentre staff varied considerably.

I: "Did they say anything when you said about school holidays?"

$R$ : "Well, what she said was I can remember her saying when she put it on the computer an hour away to get my job, she told me that and she put down 9:30 to 2:30 to be home in time fit the children and to be able to drop them to school, but it don't help with the holidays?"

I: "And the inset days."

R: "And the inset days."

(Phoebe, W1).

Information on other issues around childcare, such as cover in the case of sickness, tax credit support for childcare expenses, in the case of sickness, being allowed to help children settle into childcare the week before starting a job was varied. These topics seem to have been covered in some, but not all introductory sessions.

In addition, the cost of childcare was mentioned by single parents as something they worried about:

"No, that's what I am worried about you know how can you... what do you do because so many people that I know they are spending like... I mean my neighbour she pays out £120 a week and she is a hairdresser and it's like you know at the end of the day she said I haven't made that much money because I have got to put my daughter in child care and its oh god it seems to me the child care aspect of it is a minefield because I have never done it before I don't know much about it, I don't know how much money I can claim and you know I haven't got a clue about the financial side of it at all."
A number of reasons were given by the single parents in the study as to why childcare had not been covered either at all or in great detail during their initial interviews. One suggested reasons was the age of the child:

I: "Were discussions held about childcare needs?"

$R$ : "Well, none, because [child's name] is 14, so it didn't even come up." (Hailey, W1).

Another reason given was that some of the advisors were single parents themselves and therefore felt that the single parents new to JSA would manage to find childcare given that they themselves had managed:

"Well, the funny thing was like some of the people that's interviewing me they are single parent people themselves, so it's like, oh well, we've done it, so we were single parents as well so you can do it." (Heidi, W1).

(Rhiannon, W1) 


\section{Summary}

Overall, the experience of the new policy implementation was mixed. Single parents seemed to have a good understanding of the nature of the changes and, on the whole, had been informed ahead of time that they would be taking place. Yet, single parents tended to be less well informed about the change in the payment arrangement from weekly to fortnightly and as a result, a number of single parents experienced financial problems. In terms of the financial transition, the problems that occurred as a result of the payment rhythm and benefits being stopped by mistake altogether, tended to be the same regardless of the kind of transitions, e.g. from IS to JSA or JSA to ESA. This suggests that these problems will not disappear completely even though the payment rhythms of IS and JSA have since been aligned. While overall single parents were well informed about the transition to JSA, they were less well prepared for the different nature and administration of JSA.
Previously, single parents had been able to see a specialised lone parent advisor, usually the same advisor, and the discussions tended to focus on their plans for moving into work, which could include talking about training. After the transfer to JSA, the focus in meetings with advisors shifted towards finding a job as soon as possible, irrespective of the qualifications of the single parents or the state of the economy. As a result, some single parents felt pressured and demoralised. However, perhaps the most striking finding about the experience of single parents at this stage is the extent to which their expectation of the new regime differed from the reality. Single parents expected the new regime to be more supportive of longer term and less standardised job plans as well as supportive in terms of helping with finding childcare or getting in touch with potential employers to arrange work trials. Instead the onus seemed very much on the single parents' initiative and knowledge, something single parents did not necessarily feel was appropriate or helpful. 
"I think just generally it's just kind of made me feel like...

I'm overstating it slightly but a bit more like worthwhile

and like all my chances haven't passed me by

and that definitely translates down into just a

generally happier me which translates into

a generally happier life for me and my daughter (PR4)."

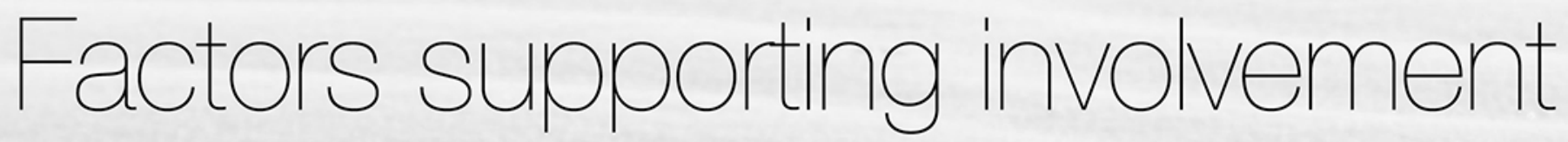

Involving peer researchers in a three-year project is ambitious. A number of factors enabled the peer researchers to continue throughout the life of the project and supported their ongoing involvement. First was the crèche facility at SPAN. This enabled single parents to attend training sessions, carry out interviews and attend debriefing sessions, whilst feeling confident that their child was well looked after. In addition, the crèche was flexible and could take children at short notice; this was a crucial factor as voluntary childcare arrangements at home could break down and this enabled peer researchers to meet their commitments to the project. This is rarely the case with other childcare provision. The presence of a community support worker from SPAN whose approach was described as helpful, caring and kind was essential to help build confidence and develop new skills in a $n$ unfamiliar setting.
Peer researchers particularly valued the community support worker's proactive approach as she anticipated their needs and stayed in touch on a regular basis. Communication was maintained through text messages and provided support when tasks such as having to complete homework and practising interviews created some anxiety among peer researchers. In addition, the opportunity to reflect on their journeys and what they had learned both on a one-to-one basis and as a group was valued by the peer researchers. A key factor facilitating the ongoing involvement was the training provided training from researchers at UWE. Peer researchers reported that they were improving existing skills and learning new skills as well as becoming more confident. The training element was also important in that it added to the sense of empowerment and supported the aspiration that involvement in the three-year project would lead to an opportunity to move into skilled employment. 
"Yes it's not that people you know have the best intentions,

everyone has committed to best intentions but you know ...

particularly you have a lot more challenges as a single parent

you know, it doesn't take much to throw you, if your child is sick,

you're sick, you know something happens you're chasing some money,

someone offers you a good paid work that you aren't going to come in

you know, someone says oh I'll give you a hundred quid if you come and help me strip my wallpaper, you're not going to say well I've made a commitment to SPAN to do ... you know to go for some training and particularly because

also ... because you know the ones turning up it's clear that there's the same few that are turning up (PRZ)."

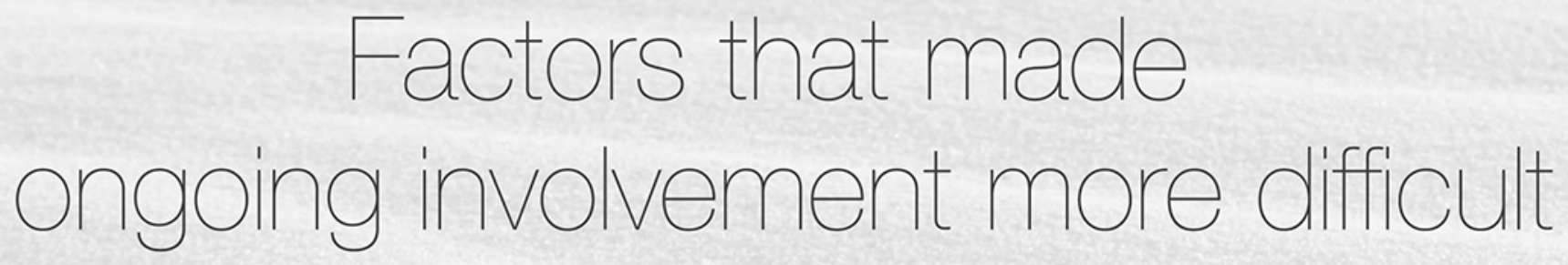

As is perhaps inevitable with projects that last over several years, there was some staff turnover and this caused some anxiety among the peer researchers. There was a sense that the changes could have been communicated better.

Equally important is the management of expectations both in terms of benefits for the peer researchers as well as the required commitment at different stages of the project. For example, the fluctuations in the fieldwork intensity came as a surprise to some of the peer researchers.

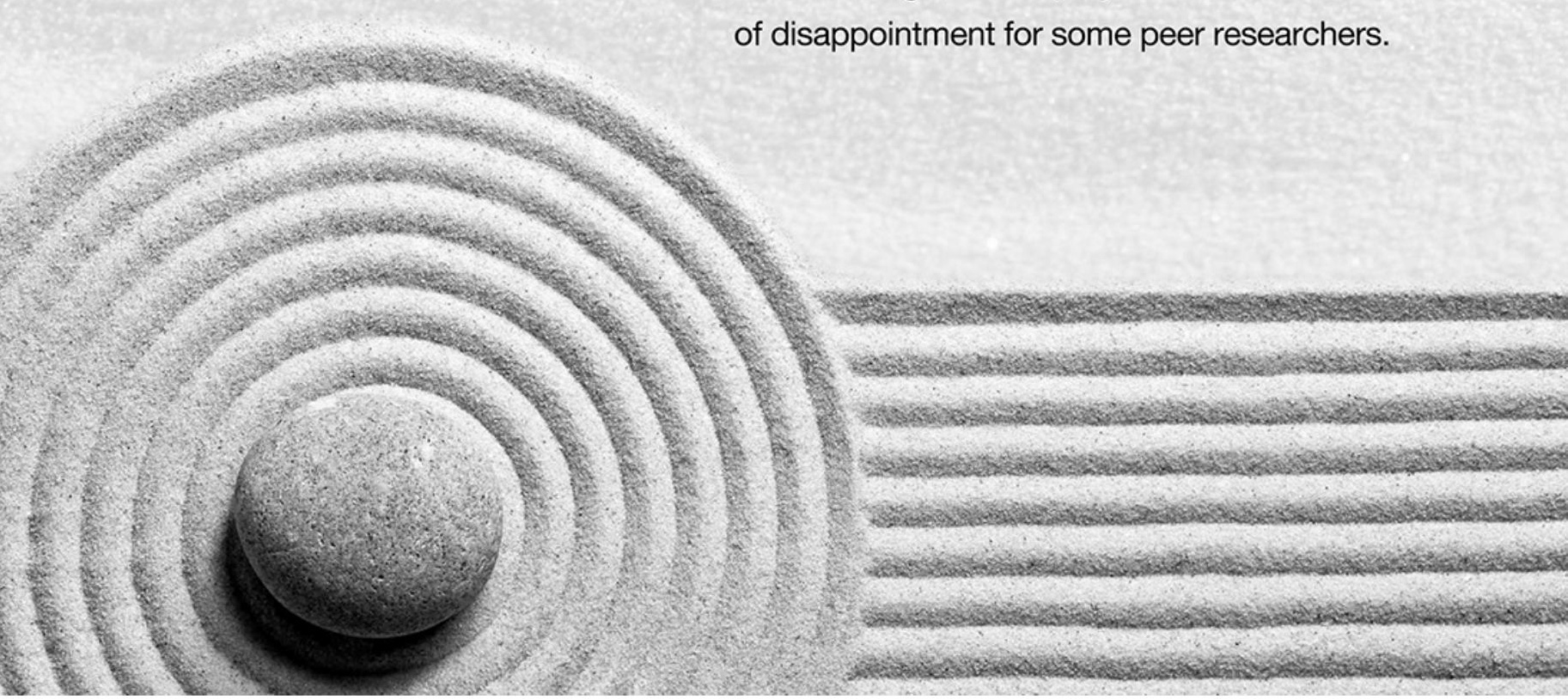

As the interviews of participants needed to be at least three months apart, there were peaks and troughs in the fieldwork schedule and these were not always communicated clearly to peer researchers.

Arranging interviews could take time as frequently, childcare and other commitments needed to be co-ordinated for both the peer researcher and the participant. Finally, the involvement of the peer researchers in the project focused strongly on the data collection and was less pronounced at the later stages of the project. This was a source of disappointment for some peer researchers. 


\section{Moving into Paid Employment}

This chapter explores the journeys of the single parents who had moved into paid work during the course of the study. Single parents'characteristics, their routes into employment, their experience of being in work, the impact of being in work on their financial situation and on the relationship with their children and the factors contributing to those single parents being able to work will be outlined below.

\section{What are the characteristics of the single parents in this group?}

The characteristics of the single parents in this group in terms of their age, number and age of children, educational qualifications and work and benefit history will be briefly outlined below. Starting with the age of single parents in this group, this was one aspect where the single parents were perhaps the most similar. Of the 14 women in this group, two were in their thirties, one in her fifties and the remaining 11 in their forties. Twelve of these women were white British, two of mixed heritage.

With regard to work experience and their benefit history, 11 single parents in this group had worked in the past, either prior to claiming IS or a few hours a week while being on IS. The length of time single parents in this group had claimed IS for differed. Eight single parents had claimed IS for five years or less, five for six to 11 years and one single parent for more than that.

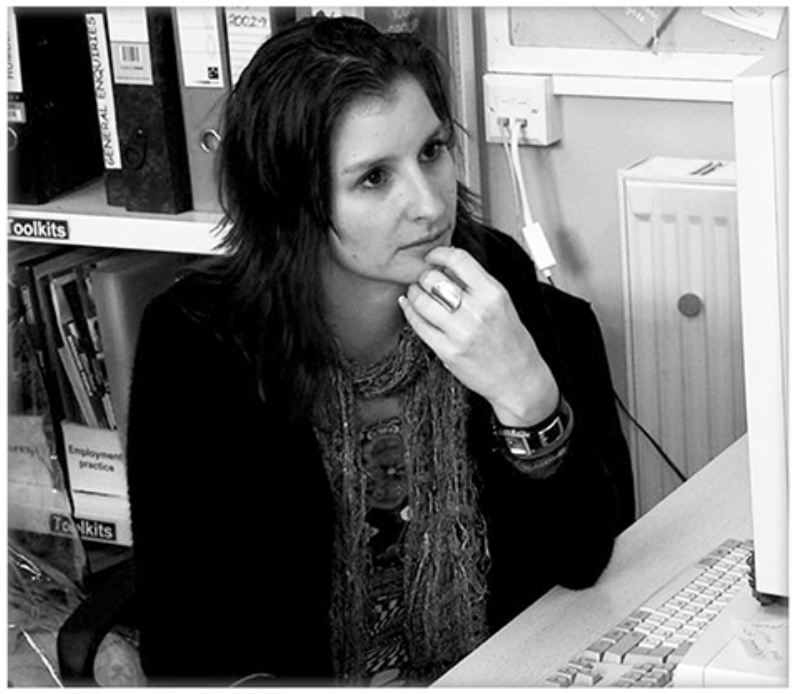

Moving on to qualifications, the single parents in this group had a range of qualifications. Some had no formal qualifications; others had school qualifications including GCSEs and A Levels, while others had further and higher education qualifications, including one single parent with a degree.

Finally, the number and ages of children of single parents varied considerably in this group. Their youngest children were between the ages of nine and 14, with the majority being around 12 years old. Eight of these women had an eldest child who was over the age of 16. Two had one child, 11 had either two or three children, and one had more than three children.

\section{What jobs have single parents moved into?}

All of the single parents in this group were in paid work. The majority were working in four distinct occupations: working with children; retail and service work; cleaning and administrative roles. A recent survey of single parents with younger children showed a similar spread of occupations; over three quarters of single parents who were working 
16 hours or more, were working in either personal services, sales or customer services or elementary occupations (Coleman and Lanceley, 2010). The jobs undertaken by the single parents within these four groups, are outlined in more detail below before a brief commentary on their earnings.

Starting with the group of single parents who were working with children:

Single parents were working in schools either directly with the children at lunch times or as catering assistants:

"I am a catering assistant in a school"

(Grace, W3).

"It's at a primary school where my daughter goes and it's at lunchtimes from 11.30 until 1.30 "

(Penny, W3)

"I clean up after the cook, help serve the dinners, um get all the plates ready it's just really working around the cook so that everything is up and ready before we got to serve and then we clear it all away after"

(Phoebe, W3).

\section{Another single parent was working with} children in a children's home as support worker:

"it's as a child residential support worker in a children's home so it's right in the field that I wanted"

(Laura, W2).

Moving on to the second group, single parents working in retail were often working in supermarkets and food related service:

"I am just a store assistant now.

I just work in a shop"

(Caroline, W2)
"I'm working for [supermarket] part time as a checkout operator"

(Megan, W3)

"Customer sales assistant at [supermarket]"

(Heidi, W3)

"I am at [take away] making sandwiches"

(Olivia, W3)

The third area of work that single parents moved into was cleaning:

"I'm still continuing with the job that I go as a cleaner"

(Habiba, W3)

"It's cleaning mostly but I also do shop floor work where I stack shelves and help customers and also till work as well so it's quite varied which is nice" (Joyce, W3)

Finally, some single parents also took administrative positions:

"I've just started at the reception at [business]" (Leah, W3)

In terms of earnings, single parents in paid employment, tended to be paid between the minimum wage and £10 per hour. Some single parents in this group had already seen their wages increase since starting work. However, in the main, they were relying on tax credits to top up their earnings to a level that would lift them out of poverty.

This section shows that single parents who had moved into paid employment during the course of the study had moved into a range of occupations, though most of them fell into four groups, as described above. 
The next section will explore to what extent the qualifications and work experience of single parents matched those jobs.

\section{What are the links between the jobs and the qualifications and work experience of single parents in this study?}

Although some single parents in this group had few qualifications and therefore would struggle to access employment other than low skilled work, others had a variety of further education qualifications such as NVQs in administration, accountancy and teaching. They also all had work experience, though not necessarily recent work experience. Of the fourteen single parents, just under half were working in low skilled jobs that required fewer qualifications and less experience than they had. For example, looking at the qualifications of single parents who were working in supermarkets, of the four single parents working in a supermarket, three were over-qualified for the position they had taken. One was a single parent who had spent 18 years working as a photographer. She was keen to restart her own photography business; another had worked as an English teacher in further education; the third had an NVQ in administration and had begun to set up her own childminding business, including gaining the relevant qualifications.

The situation was similar for those working as cleaners. One single parent working as a cleaner had an NVQ in administration and had undertaken a level two Access Course. She was also keen to continue her education and wanted to go to University. A second single parent working as a cleaner also had a further education administration qualification. It is clear that these single parents are undertaking work below that for which they are qualfied.
There was some recognition of single parents that their work experiences might have dated:

"you could say l'm over qualified because it's mostly cleaning but on the other hand it's so long since I worked, I'm not really qualified for anything so l'd say it's about right, really"

(Joyce, W3).

Overall, it is fair to say that a number of single parents in this group had moved into jobs for which they were over-qualified. It is beyond the remit of this study to ascertain to what extent being over-qualified for a job is a result of having been pushed into work as a result of the transfer to JSA, or to what extent it is a feature of the local labour market. Either way, as will be discussed below, some single parents were worried about getting stuck in these relatively low skilled and low paid occupations.

\section{How did they get there?}

The following section will explore the routes single parents in this group took to move into work. Their routes into work were not always direct ones. One route into work of 16 hours or more, was to increase the number of hours single parents worked in their jobs while on IS. These jobs were less than 16 hours and so entitled them to continue to claim the relevant benefit. These single parents were in time, able to increase their hours in these jobs to 16 in order to leave JSA:

"I originally started with him when I was on job-seeker's allowance um I was only doing 8 hours. I think for him at the time because there was nothing else available but when my hours came along, he put them my way"

(Lyndsey, W3) 
Another route into work, especially for those who were not already in work, when on JSA, was through friends:

"how did I find the job it was through a chap that I knew from somewhere that I worked"

(Lyndsey, W3)

and responding to adverts such as those in the local newspaper.

The Jobcentre however was not understood to have been helpful in finding work both in terms of job searching, contacting potential employers about work placements or opportunities of job share, where jobs were advertised as full-time.There was a confidence felt by those in the In Work Group that they would be able to find work; this is perhaps because of their previous work experience:

"I have got a lot of experience in other jobs so I think I just talked my way into it" (Grace, W3)

Single parents took a number of routes into work such as increasing the number of hours of existing jobs, hearing about jobs through friends, finding them in local newspapers as well as enquiring whether full-time jobs could be turned into two part-time jobs.

\section{How many hours were}

\section{single parents working?}

In order to come off JSA, single parents need to work, at least, 16 hours per week and generally, single parents were working around 16 hours a week (the minimum number of hours required both to move off of JSA and claim working tax credits).
This number of hours seemed to fit best with caring for children and other responsibilities that they had. Again, this is supported by a recent survey, which showed that $62 \%$ of single parents working 16 hours or more,were working between 16 and 20 hours per week rather than longer hours

(Coleman and Lanceley, 2010).

Others were working over sixteen hours, particularly when asked to do over-time, which resulted in one single parent working forty five hours a week. Single parents working more than sixteen hours, expressed concern over the impact of long working hours:

"When I started there it was supposed to be 16 a week. I have been doing anything between 16 so he upped it to 25 at the beginning of the year and some weeks I have done 45 recently because people leaving, people on the sick, they sacked the manager we had and we all had to cover the hours for three months so lots and lots of hours which is not good"

(Olivia, W3).

They were particularly concerned over the impact it had on their children:

"I don't want the big hours I have been doing. It's too much, it's not fair on my kids"

(Olivia, W3).

However, one single parent was happy to be working full time. Her situation was unique to the group with her youngest child being 17 and not needing the same level of care as younger children: 
"I am now working full time but um the changes that have happened around that is because of the ages that my children are my son has gone onto university so he has moved out, my daughter didn't go she left school"

(Claire, W3).

Another single parent working less than 16 hours, had taken the decision to rely on her work income and leave JSA even though in the short term she was marginally worse off by doing this:

"I'm getting less money but like I said the money wasn't so significant and because when I did earn extra money because you can only earn so much and then they stop it so I almost couldn't charge for some of the editing I was doing, so I was doing this work but I couldn't charge for it because it would have affected my benefit which was crazy"

$$
\text { (Francesca, W3). }
$$

The single mothers in the sample worked a range of hours. Being able to combine their work hours with looking after their children was one of their main concerns. The following section will elaborate on this further.

\section{Are their jobs secure and sustainable?}

Parents in this study seemed to be staying in the jobs they first went into. Only one single parent had left her job. Having said that, the number and timing of the hours they worked had changed for a number of single parents. A previous study found more movement between jobs and out of jobs than this study did (Millar and Ridge, 2008). One of the reasons for this difference could be due to single parents now having to go back onto JSA rather than IS and therefore being more inclined to stick with their existing jobs.
The overall lack of jobs due to the effects of the on-going recession, could have a similar effect.

\section{How do they feel about where they are?}

Single parents' experience of being in work can be divided into two clear groups: it either worked out and they really liked it or it didn't work and being in paid work was experienced as stressful.

\section{Positive experiences of being in work}

Interviewees who were positive about their jobs talked at length about the positive impact of being in work. This positive feeling was due to a number of factors. One factor was that single parents in this group simply enjoyed their work:

"I do like the job um that's all I can really say about it really its I do really enjoy it"

(Phoebe, W3)

In addition, there was a strong sense of increased confidence and optimism in this group, as well as belonging to society now that they were working:

'I feel... I feel l've joined the human race um I can hold my head up'

(Melissa, W3).

'Yeah, I feel a lot happier and I have made a lot of new friends, not just work colleagues but with teachers um and I feel even though its only a catering assistant job - you get what you give, don't you?...I'll stay there hopefully until my child, the oldest one, goes to University' (Grace, W3). 
Another factor was that single parents felt they were now a role model for their children.

In addition, positive feelings about being in work could be the result of feeling that the organisation they were working for had invested in them:

"I think they are going to put me in for an NVQ 3 and with you know obviously the prospect of getting 4 as well if I want to go for it. So they are going to do loads of training for me" (Laura, W2).

A final factor was being better off financially. Single parents in work for 16 hours or more are eligible for Working Tax Credit and for In Work Credit for the first year. Those benefits, together with the Housing Benefit and Council Tax Benefit run on, clearly made a difference to this group of single parents. It is rare in policy studies to get such a clear sense of single parents feeling better off. Being better off meant that single parents were able to buy things they would otherwise not have been able to afford:

"It made sure... that we could have a holiday for the first time this year because rather than relying on it, I put that to one side"

(Olivia, W3).

For others, being better off meant that they were able to pay off their debts and therefore able to put themselves on a better financial footing, long term. It was clear that participants even felt better off when they had been in work for more than one year and therefore did not receive various benefits anymore, such as In Work Credit.

\section{Negative experiences of being in work}

For the second group, being in paid employment was not working out so well. Feeling more negative about being in work could be due to a range of factors such as feeling that their current employment provided them with very little opportunities for the future:

"I can't move around to look for something better. I am stuck, I don't know where to go"

(Habiba, W3)

Other negative experiences were due to the work hours and the difficulties of finding suitable childcare for children:

"I have to do one evening a week, that's more or less forced on you as well being [supermarket] and I have had to get cover for that one evening a week and I am struggling every week to find cover because my daughter is 13 , so I am struggling every single week to try and find that cover" (Megan, W3).

Another source of disappointment could be not being able to continue with voluntary work. Juggling their work hours with the conditions of entitlement for other benefits could prove problematic, especially where work hours were fluctuating.

"I: is that 20 hours a week is that about right for you or would you rather do more or less? $R$ : Um its about right for me because unfortunately I can't work overtime and um they owe me 29 hours overtime which they have got to pay me in having time off which is a bit of a bugbear, because I got a pay rise last Friday so I had to go down the rent office and declare it only about $£ 7$ but I had to declare obviously".

(Melissa, W3). 
In addition, working more hours did not necessarily lead to increase in their overall income, something that could be frustrating:

"18 is fine but to be perfectly honest as much as you are not on Jobseeker's Allowance anymore, you are still caught in a benefits trap of housing benefit, and the more you do the less help you get so you are not actually any better off. I am still only £65 a week better off whether you do 24 hours or 16 "

(Lyndsey, W3).

Finally, feeling that their work was having negative effects on the single parents' health did lead to a negative perception of being in employment.

\section{What made work work?}

As outlined in the previous section, experiences of being in work were both positive and negative. Factors contributing to a positive experience were both social, such as having additional family support for childcare, and economic, such as not needing to pay for transport to work as well as having flexible employers. Finding work close to their homes was an additional important factor as the participants therefore incurred no prohibitive travel costs, as they could walk to work.

Another important factor in making work positive was having an employer willing to be flexible. The mothers in this group were working for different organisations, but having a manager who was flexible and showed understanding with regard to their situation as the only carer for their children was also important. Single parents in this group made comments such as: "they're quite accommodating. Like the other week, I had to take my youngest for a check up, l'd be in later, no problem at all"

(Joyce, W3)

or:

"I mean my boss was incredibly understanding"

(Claire, W1).

\section{Feeling valued and listened to by their boss also contributed to the positive feeling about work:}

"I think my boss is quite fair, he will listen, very good at listening" (Leah, W3).

The flexibility however was not only on the part of the manager. The women themselves were flexible in terms of the hours they could work as well as the times and days they could work; they were able to accommodate the needs of their manager:

"I don't work the same hours I don't work the same days so its varied in that respect"

(Melissa, W3).

The flexibility of these single parents was in part because they had support from family and social networks. This support helped them with childcare when they were at work:

"I have been getting my friends to cover at the moment and they have been really cool about it and really helpful. I am very lucky I have got some good friends to come and sit with her while I am at work". (Megan, W3)

Older siblings also played a role in caring for younger children:

"if I work nights [child] is going to be there so I don't have to worry about childcare expenses"

(Melissa, W3). 
In summary then, having a supportive and flexible employer, working near home and having support networks, together with feeling better off,seem to be important factors, in ensuring that being in employment was a positive experience for single parents.

\section{Has it affected the relationship with their children?}

The concerns of the single parents who had moved into work were about finding childcare, the time they spent with their children and their finances.

Working term time only was important as it meant that single parents did not have to look for childcare during the school holidays:

"I work from quarter past 10 to half past one. I get all the school holidays off look, that's what's good as well see, because trying to find a babysitter you got no chance"

(Phoebe, W3).

Single parents reported the effects it has on their children that they were now around less than before:

"my little one struggled and at times still sometimes does with the fact that I am not always around, because he had been used to me being here all the time for him"

(Olivia, W3).

As in other studies, single parents mentioned the trade off between money and time:

"I may have more money but I don't have more time and time is important because you can be skint and be a wonderful mother, you can be a working mum and have all the money in the world, but if you haven't got time for your kids its not much parenting"

(Melissa, W3).
At the same time, single parents also spoke of the pleasure of being able to afford different things for themselves and their children now that they were in work. Overall, single parents managed to combine looking after their children and being in work, but the trade off between having more money and less time with their children was felt by both parents and children. As will be discussed further in chapter 11, having support networks available with which the children were comfortable, could ameliorate some of the effects of the single parent being in work and having less time to spend with their children.

\section{What is their outlook on the future?}

In the study, we asked single parents about their plans for and expectations of the future. A number of themes emerged in this section such as having job security, the care arrangements for their children and how they felt about being in work more generally.

Reasons for this positive feeling were perceived job security, feeling better off financially and also being more respected by society and their family:

'Yeah, I think the future looks sort of lots more promising in the sense as well, I think, now that I am working and I can, you know, my children can look up to me now I like to think'

(Claire, W3).

'Not overly unhappy but more secure, definitely more secure, things are happening ... I feel things are definitely getting better'

(Leah, W3).

Where it was not certain whether they would keep their job, single parents tended to be more worried about the future: in some cases jobs were precarious or temporary: 
"I am doing 16 at the moment between 16 and 22 but one of the companies that I am working for is under administration so that will come to an end within the next couple of weeks and I will lose 4 hours out of that. So if they don't find me some more I shall be back up to the job centre" (Lyndsey, W2).

As mentioned before, there was a sense among a group of single parents that they were stuck in jobs they did not particularly enjoy and that were quite different from what they had been working towards, while on IS:

"But what I really want to do is never going to happen. I really wanted to become a nurse, I wanted to be a midwife but that's not going to happen"

(Olivia, W3).

"I tried my best to get a job but there were no jobs, the only thing was a cleaning job. Yes, I know other people they're doing cleaning but because I struggle, I went to college, I wanted to use my knowledge"

(Habiba, W3).

However, those who were in work also had a number of concerns regarding the future. These concerns were linked to (potential) changes at work, such as working longer hours and the financial implications of that. However, even where there were concerns over the future among those in employment, as one single parent put it:

'Frustrating as it was then, now I see a light at the end of the tunnel, then it was like trying to find the tunnel in the first place to then find the light and to find the end of it...'

(Laura, W3).
Overall, the outlook on the future depended on how the single parents viewed their present situation and whether that was likely to change. Where they were happy with their situation, they tended to look towards the future with a sense of optimism. However, for others, uncertainty around their employment situation or feeling stuck in jobs led to more negatives views on what the future may hold.

\section{Summary}

Single parents in the Employment Group were confident that they would be able to find work,

"I have got a lot of experience in other jobs so I think I just talked my way into it"

(Grace, W3).

They had all worked previously and many worked, albeit less than 16 hours, while claiming IS and JSA. They were therefore still relatively close to the labour market when claiming JSA. Their experiences of being in work varied however. Those who enjoyed work and felt it was sustainable for them and their children found work gave them confidence and self respect:

"yes and also you get some self-respect and confidence as well" (Joyce, W3).

Nevertheless, not all experiences were positive, particularly as parents took low skilled jobs which they were over qualified for in order to get off JSA. These single parents worked in environments where the skills and qualifications they had were not being utilised. 


\section{Moving into Self-Employment}

In this chapter, the experience and motivation of those single parents who moved into selfemployment will be discussed. In particular, the reasons for moving into self-employment, the support they received in setting up their business, how they were managing financially and the role their children played in the endeavour, will be further explored.

\section{Who are the single parents in this group}

In our sample of 50 single parents there were five who were self-employed which equates to the national picture in 2009 as well as in 2011 (ONS, 2010; Coleman \& Lanceley, 2011). They lived in different parts of Bristol and were in their early forties, apart from one mother who was 32 years old. Their children ranged in age from eight to 21 years old.

Three of the sample parents had two children and the other two had one child each. The two parents who had been claiming IS had done so for 18 months and eight years. The other three had been on JSA and this ranged from three to eleven months. They were not a homogenous group. They had different levels of education, very diverse work experiences and had and were gaining qualifications that were far removed from each other. Their qualifications were very varied and ranged from the more practical such as childminding, teaching assistant, chef and translator to the achievement of a Fine Art degree and other art training, a law degree and architecture. In addition degrees had been awarded to members of the group in town planning and

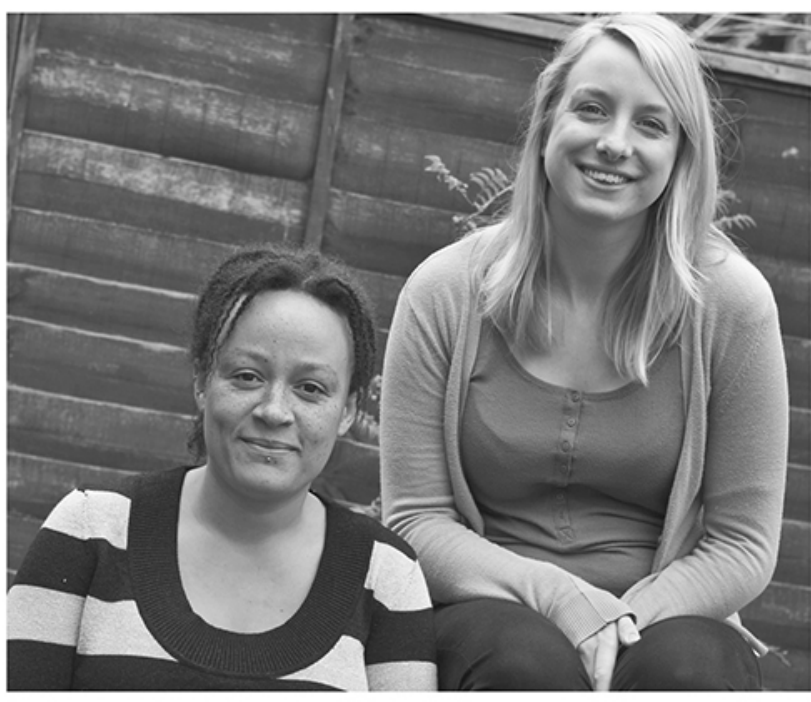

Environmental Biology. Whilst they were very different individuals, all their experiences of the Jobcentre Plus were similar: very poor and very negative. As a group, they had encountered rudeness, an unwillingness to have their qualifications and work experience acknowledged and said that they had been given inconsistent advice:

"..they are just not interested which is the frustration especially when you are doing things yourself, trying to better yourself and they just don't want to support you so it's quite annoying and it's quite degrading. Sometimes you walk out there quite deflated..."

(Marie, W2)

" they took no notice of my degree or anything that I told them that I was doing they basically just want me off Jobseeker's and they are trained,....to give people a really hard time. I remember sitting there waiting to see her and listening to someone else who was a lone parent with a small child and they were absolute bullies.....it was disgusting.."

(Irene, W1)

"If I was to give it a colour, if I was to give that period of time a colour it's grey, yeah, having to sign on..."

(Sophie, W1) 
The Lone Parent Advisors were generally seen to be more knowledgeable and supportive but with the single parents being moved to JSA, it meant that they no longer saw a Lone Parent Advisor. This was viewed as stigmatising and obstructive to moving forwards with their work prospects, because they were seen as unemployed and the fact that they were parents was ignored:

"you are considered the same as everybody else from the homeless person on the street that's on Jobseeker's to..um..well everyone is in the same boat, you don't get help".

(Aisha, W1)

"it doesn't matter that you've got a child, you are treated like anyone else on jobseekers allowance"

(Irene, W1)

There was one single parent whose reason for going self-employed was very different from the others and this was because of her experience of being on JSA for six months. She was a recovering alcoholic and the six month period had been one of the most stressful times of her recovery, so she went self-employed

"because I couldn't see a way out of it."' (Irene, W3).

It had made her very cross and, as a consequence, she had written a letter outlining her circumstances but she had never sent this letter to anyone. In spite of this, she had done it to prove to herself that she had progressed a long way:

"I had to do it to kind of empower myself....it empowered me just writing it because I thought, yes, actually, I have come a long way and I'm not going to put up with this."

(Irene, W3)
Similar to other groups of single parents, they thought that they would be encouraged and supported in returning to the job market by their Lone Parent Advisors and the Jobcentre Plus staff. This was another area of disappointment because they felt that there was not a recognition that, by trying to set up their own businesses they were, in their own sphere, doing something that would put them in work:

"But I had thought that, you know, I would be encouraged, you know, given the opportunity to kind of put myself back together, as opposed to... it was very lax kind of, nobody gave a damn, attitude, you know, you were treated without any respect, without any dignity." (Aisha, W1)

They expended a lot of energy and time setting up their own businesses but there was a view that Job Centre staff did not appreciate this and that their main focus was to get single parents back to work:

"The pressure of having to look for a job that I am not trained, that have no interest in. I had made this choice to further my career........and I felt more depressed because it would mean giving up my time and energy that I was trying to devote to being self-employed..." (Irene, W1)

\section{Determination}

This was a group that appeared to have a background that enabled them to have enough knowledge and motivation to think about and be prepared to, set up their own businesses. They spoke in a way that inferred they would do anything to come off JSA and not have to 'sign on' with the Job Centre: 
“It was purely my idea, I didn't like signing on, I hated the feeling of going and feeling as if you'd done something wrong or the pressure.."

(Sophie, W3)

They wanted to be more in control. They did not want the Job Centre to be able to call them in whenever they wanted to, at a time that was possibly inconvenient for the business that they were in the process of setting up:

"it's [her part-time job] not really a career move for me, it's always been something to underpin my own business, it gives me a little bit of security so that I can do my own business." (Katy, W3)

They had applied for jobs prior to and whilst they were setting up their businesses but were wanting to try and find work that would fit in with what they needed to do to progress their self-employment, for example, training. One parent had applied for about 40 jobs and another had applied for 47 jobs in three months; the latter had signed on with three agencies. She told the Job Centre that she wanted to set up her own business because she couldn't find employment. She asked for some support, but she was told that there was no help available. Another woman expressed her frustration at having to 'sign on' when trying to set up her business. They both alluded to the fact that it felt like banging their head against a brick wall:

'It's frustrating having to sign on whilst l'm trying to set up a business. They're constantly pressuring you to go and get a job...it's frustrating. Especially when you've asked for help and you won't get it, it's really quite a head banging time.. ..." (Marie, W1)
Another of the parents felt that she was always arguing with the Job Centre staff, because there was inconsistency across the staff about what people who were going self-employed needed to do and what criteria they needed to fulfil.

\section{Seeking help}

As has been previously found, many of this group of single parents had found their job through informal networks and through internet searches (Casebourne et al. 2010). They had asked staff at the Job Centre and they usually found that they did not have their needs met, because they were told that there was nothing available. They had therefore looked elsewhere, using friends and other contacts:

"I had to basically work really hard to get anything out of them or any help and they didn't offer me the help I had to find out through somebody else." (Irene, W2)

Examples of training that they would have found helpful included individually tailored job searches, help with job interview skills and help with becoming self-employed. The fact that these were not being provided suggests that the single parents in this sample were not aware of the range of support available to them.

\section{Managing self-employment}

The study participants were working in a variety of part-time jobs, alongside setting up and working in their own businesses. They recognised that, even with possibly three jobs in total, being self-employed was better than having one regular job and not having 
self-employment. This was sometimes at quite a cost, because their lives were frequently hectic due to the balance of working in more than one job, caring for their child and domestic chores:

"it just feels a bit full on and a bit messy that I'm doing a paid job and trying to develop my own business." (Katy, W2)

Each of the parents had a very strong work ethic and wanted to work rather than be at home. One mother had 'always worked' and, when she moved up to Bristol, it was the first time that she had been unemployed. She therefore found it frustrating that she was not offered any active support to help get her back into work, when she was so keen.

Another woman, whilst she was in the process of setting up her own business, felt that the Job Centre staff were just interested in getting everyone into work and off JSA, with little recognition of the fact that she was trying to get her business up and running:

"basically, it's to get us back to work, that's all they're interested in of pushing for you to go back to work, back to work, back to work....and when you ask questions or ask for help I get told we can't do this, we can't do that, we can't help you here, we can't help you there but we can help you when you first go back to work..." (Marie, W1)

In spite of finding it more difficult to manage financially, the interviewees felt that this situation would improve as their business became established and that their business was something for themselves, something that they had an interest in and wanted to be able to focus on.

\section{Additional financial support}

This group of self-employed single parents were still reliant on the additional support in the first year of work through tax credits, benefit run-ons and in-work subsidies. These parents were anxious, because they felt that the systems to calculate the additional financial support were not set up to cope with part-time workers and self-employment. They therefore worried that they might have been overpaid and, as a consequence, at some point in the future they might need to pay back some benefits. Whilst they acknowledged that they needed this support, they were anxious about what would happen after their first year in work when their tax credit income would decrease and they would no longer receive an in-work subsidy.

"I've been doing part-time admin, part-time self-employed, you know I think they often don't have a clue how to assess you and you don't know if they're assessing you correctly.." (Katy, W3)

One mother was just keen to have a fresh start, move forwards with her business plans and try to leave the difficulty of being on JSA and the changes that that entailed, behind her:

"it will be lovely to have a fresh start and I have got high hopes for the business, really, because, you know, even in recession, I don't need to make that much money to cover, although my rent has gone up." (Sophie, W3) 


\section{Impact of being self-employed on the single parents and their children}

Some of the single parents opted to work from home, having chosen self-employment as being more flexible to fit around their children. One mother, self-employed as a child minder, felt that this gave her greater flexibility to combine her work and parenting responsibilities but, at the same time, it made her child anxious about having other children in the home, when he was not there. This flexibility was not being realised because of the Job Centre staff calling them in for appointments at times that were difficult. One mother, without a car, was called to the Job Centre for an appointment at four o'clock in the afternoon, just after school. The journey always took a long time. When such occurrences coincided with a lack of concern for their circumstances, the single parents were very angry:

"it really makes me angry to be truthfully honest, it annoys me that I want to better myself and get myself off the benefits system once and for all and to make a little bit of a difference in my community and I can't because no one wants to help me."

(Marie, W1)

Other members of the study sample worked outside the home, due to the nature of their part-time job and also the work that they were doing, within their own business. This latter ranged from being involved with artistic events, a catering business, freelance consultancy and alternative therapy. Whilst being self-employed was not necessarily the easiest option, it was certainly one that these single parents strongly believed in and they were determined enough to carry it forward.
However, this may be costly in terms of their worries over the financial situation, which was often fluctuating, depending on the state of their own business. One parent had become established in her self-employment and she felt better off, both financially as well as emotionally, by being able to do something productive:

"I have been better off because if you're working then your tax credits go up so you get your working tax credits along with the child tax credits.... On the minimum, I may get as least as much as I was making on JSA plus I'm doing something productive."

(Aisha, W3)

\section{Payment changes}

Some of these single parents had experienced financial difficulties when switching from one benefit to another. This was usually seen as a system problem, either the fault of the staff at the Job Centre, because of losing the relevant paperwork, or because their child was on the cusp in terms of age, when the transfer to JSA became compulsory. These problems were usually unexpected and it meant that they might have had to go several weeks without receiving any benefits. JSA payments stopped for one of these parents after apparently being told by Job Centre staff that she was categorised as selfemployed even though she had only worked for an hour as self-employed, when she was trying to build up her business. Whilst she was waiting for this to be resolved, she was without any payments, which therefore deterred her from doing small jobs in the future. One mother was also worried by working and having enough money, because of the 'crossover to 16 hours work' and therefore not knowing whether she would be better off signing off or signing on. 
These gaps in payment brought out the single parents' determination to be successfully self-employed, so that they did not have to rely on staff at the Job Centre and they did not have to continue to 'sign on':

"I might struggle a bit financially but its better than having to be with Jobcentre Plus, thank you."

(Aisha, W1)

\section{Adaptable children}

Their relationship with their children remained good but the single parents were aware that they expected their children to be more flexible and that their life, especially in the holidays, might not be as routine as previously. However, they did feel that their children benefitted from seeing them working which often made them more accepting of their situation than they might be otherwise:

"I think it's quite good that they see me going out doing something on my own. You know, it's completely my own creation, so yes, they're really good about it." (Katy, W3)

\section{"I didn't want her to see me not doing} anything.." (Sophie, W3)

These parents often felt rather guilty about the fact that their children had to fit around their needs and their timing but, ultimately, felt that this adaptability was probably beneficial for their children. One parent, who was becoming a child-minder, was aware that the prospect of having new people in the house would be daunting for her child, but felt that he would calm down once it started and probably enjoy playing with the other children. She also felt guilty because he would be with his grandparents or his father during the holidays, so that he would not be at home much during the main part of the working day: "so I mean, the poor little boy he is like pass the parcel is the only way I can describe him. But it's trying to juggle both families and him to make sure he is happy and contented in his little bubble is the hard part." (Marie, W3)

Parents felt that their priority as a parent was impinged on and the balance between work, childcare and domestic chores was very challenging. These single parents were also aware that if they felt well in themselves and were happy, that this rubbed off on their children. If they were happy, then their children were; if they were anxious, their children expressed symptoms of anxiety. There was also the feeling that they were providing a good role model for their children. They felt that their children could see that they were not accepting what was given to them but they were fighting for what they wanted:

"I feel inspired and motivated and I have goals and I want to achieve things... they see that and I hope...you know, and I think that is a good example to set to your kids, is that you're not just doing a 9 to 5 job that's drudgery, that you hate..., that you're sticking out for what you really want to do."

(Irene, W3)

\section{Outlook on the future}

Their views on the future were generally positive. They continued to feel motivated and that they were moving forward, albeit with ups and downs. Self-employment was what they wanted, no matter what challenges they might face and how frightening it might be:

"I would like it [part-time job] to come to an end in March and then l'd do my own business full-time I suppose and it would give me the motivation to actually have the courage to start doing it full-time." (Katy, W3) 


\section{Summary}

This group of single parents was very diverse, they had varied interests, their backgrounds were very different and the ages of their children were wide-ranging. They appeared to have a determination to improve themselves, to do something that they were interested in and to act as a role model for their children. Their experience of attending Jobcentre Plus was negative and to get off JSA, they were prepared to experience more financial insecurity than might otherwise have been the case, so that they could set up their own business. To this end they often sought out their own support, advice and training. These parents had a positive outlook on the future, there was sense that they were developing and that they continued to be motivated. 


\section{Moving onto Employment Support Allowance}

In this chapter, the journeys of single parents in the study, who had experience of Employment Support Allowance (ESA) are explored. Particular attention will be paid to the factors influencing those journeys, personal experiences, implications for family relationships and expectations for the future.

\section{Arriving on ESA}

There were five single parents in this group; their biographies were mixed in terms of previous employment experience and qualifications. Backgrounds included a health professional, a housing worker, a post doctoral student, an office worker and one group member who had previously worked in the service sector, in low skilled and low paid employment. Work histories and reasons for not working included a qualified nurse from overseas, whose qualifications did not meet the standards set within the UK, and therefore had not worked since her arrival in 2007. Another had previously worked for a charity, which had closed its branch and transferred to London: she had claimed IS for six months prior to transferring to ESA. Those on ESA tended to have one or two children over the age of eleven and had been claiming benefits for over four years. Only one of the single parents on ESA had been claiming less than a year.

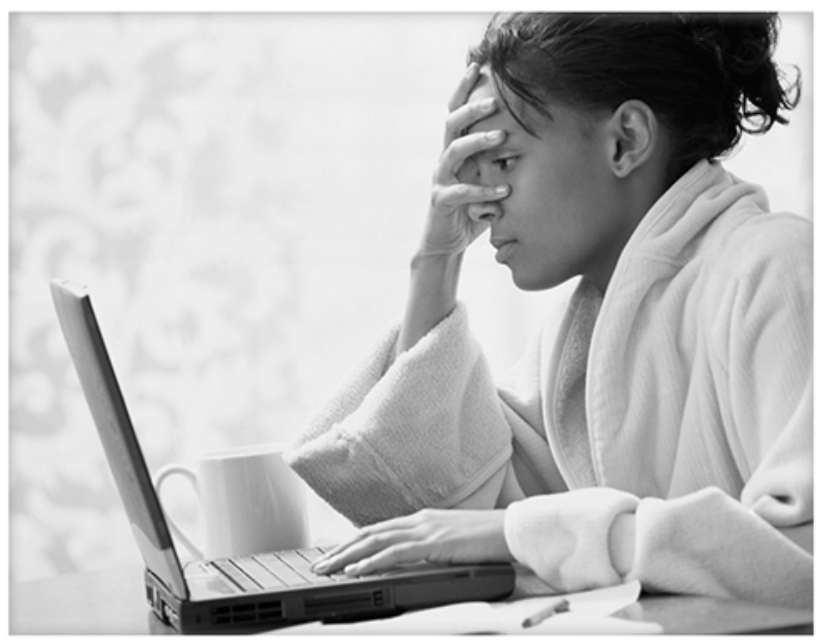

\section{The experience of Employment Support Allowance}

While some single parents had a straightforward transfer from IS to ESA, others had been required to appeal to have their right to ESA established. Single parents described the growing anxiety associated with this wait, which had caused further deterioration in their health. The level of confusion for some single parents who 'bounced' between ESA and JSA was clear illustrated in the extract below:

"I had prepared paper, I showed them, I say yes, they say yes, you right but you must attend here every two weeks. I say sometimes I'm off my feet, do you know I'm not feeling very well because I have bad, bad depression and sometimes I can't even wash up. How do I attend. I am sick but no, the rules is the same for everybody"

(Nadifa W3).

The impact on those having to move between benefits was centred on concerns about missed payments or having their income stopped:

I: "Okay and what did you say to them when they said your money was stopped?"

$R$ : "I said look l've got to get food and all that, gas, electric and for my daughter to go to school."

(Natalie, W1) 
This issue was also identified in previous studies (Casebourne et al., 2010).

Successful transfer to ESA brought a 'a sense of relief' connected to the removal of the requirements associated with JSA. The relief was often based on anxiety connected to failed attempts at previous employment, often associated with mental health difficulties which had further undermined their confidence in their ability to find work:

"I worked in a café and um so I was there and then it started off ok and that but then my depression started showing through a bit and they sort of said oh I don't think that this job is for you........" (Lauren, W3).

Not all single parents took this view. One participant, interviewed the day prior to her attendance for a work capability assessment, anticipated that she would be transferred back on to JSA and was philosophical and realistic about the outcome. Having worked as a professional for over ten years, she felt her period on ESA had been a temporary 'blip' caused by complications after limb surgery, which had now resolved:

"...I had a real bad stress issue, I definitely was needed to go onto ESA um however I feel like I am on sort of the tail end of that now so but yeah definitely at the time if I had to go to Jobseeker's and go and sign on and be actively seeking work and taking on like jobs that weren't necessarily what I wanted to do or whatever. I found that would have been very difficult to just sort of..." (Katherine, W3).
Managing illness and caring for children

Those claiming ESA suffered long-term chronic conditions such as depression, chronic fatigue, gastrointestinal disease, back pain and anxiety. Worries about health dominated single parent's views about past access to work and possibilities for the future.

Nevertheless, accounts often centred on the management of symptoms associated with their chronic disease particularly their unpredictability, rather than work. Tiredness was a real problem, as single parents attempted to conserve their energy in order to care for their children. This group identified the difficulties of everyday planning because of the impossibility of anticipating how you were 'going to feel'. The following extract demonstrates the level of consideration and organisation managing chronic conditions and the associated fatigue demanded:

"You can't plan, it's very difficult to plan things. Yes, I feel like I'm quite on a better at the moment because I am able to do something every day but I try not to book too many things in. Normally when l've got one appointment one day I don't do anything ... I don't plan anything else and if l've got more energy l'll do something at home."

(Francesca, W3).

This experience combined with caring for children, worrying about money and looking for work was felt to be overwhelming. Single parents, supported long term by benefits, made reference to the stress and anxiety caused by the anticipation of looking for work alongside the challenges faced in caring for children. 
The burden of childcare is expressed by Lauren:

"(Sighs) um well it's just getting through each day actually at the moment with my as I say my oldest son at school and um my youngest son you know he plays up any chance he can to try and get out of going to school because that's what his brother used to be like but um so it's just getting through each day to be quite honest that's how it feels." (Lauren, W3).

The demands of attending Jobcentre Plus fortnightly, in addition to requests to attend presentations and back to work sessions, felt like a drain on their limited energy. Participants reported that this, combined with the stress of anticipating discussions about returning to work, led to an exacerbation of anxiety and stress-related symptoms.

However, claiming ESA was dependent on single parents receiving a medical diagnosis that established they were 'not fit to work' and was experienced as stressful and complex.

Some of this group perceived that it was fairer for the doctors who knew them, to decide if they were fit for work, rather than anonymous assessors who failed to understand their emotional and mental health needs. One single parent did not have a clear diagnosis, and it was difficult to establish how her ill health was impacting on her ability to find work. Other researchers have maintained that some single parents have a preference to stay at home and care for their children (Haux, 2009; Millar and Ridge, 2001; Holtermann et al., 1999). In this instance, this appeared to be the case, but was the exception.

\section{Finance and the future}

Even though some single parents reported instances when relying on ESA meant a reduction in family income, it was still a relief not to have to live with the emotional demands of meeting JSA requirements:

"I'm still glad I don't have to sign on anymore, I'm just totally relieved that I don't have to go through that whole process. Like I say for me my situation is that I haven't been that well so for me it's been the stress of even though I'm getting less money but like I said the money wasn't so significant and because when I did earn extra money because you can only earn so much and then they stop it so I almost couldn't charge for some of the work I was doing, so I was doing this work but I couldn't charge for it because it would have affected my benefit which was crazy."

(Francesca, W3).

However, that was not to suggest that money concerns were not a feature of their daily lives:

"Well it's just ... I'm constantly worrying about money, constantly. I've got my diary, I've got everything written in diary, what day it's got to come out of what and what comes in and what goes out, yes you're just constantly ... I wake up in the morning oh god what have I got to do? Do you know what I mean, it's just constant worry."

(Katherine, W3).

Single parents talked of living 'hand to mouth', which meant explaining to their children why there was not sufficient income for the things they liked to do. While younger children appeared to accept this, 
older children could become resentful and

frustrated at their parents inability to work. There was a general acknowledgement that this was far from the 'ideal life' parents had wanted for their children. However, there was also a level of resignation about the challenges of living in poverty and for some a focus on the things they did have: family, friends, comfortable housing and good schools:

"Yes, obviously as a parent you want your child to have ... you imagine you're going to have this nice life for your child don't you I guess but and I guess it hasn't quite been quite like that. But then I have to sort of remind myself on other levels that actually we are quite lucky, we've got a really lovely family nearby, we do live in a nice flat and goes to a really nice school and she's been really happy there."

(Francesca, W3).

It was the same friends and family who provided loans when things got really financially tough, and payments were missed. Nevertheless, some single parents were optimistic about the future, highlighting a range of aspirations: training to become qualified as a teacher; becoming a Tai Chi instructor or returning to care work and nursing. Single parents anticipated this meant they would need support. For example Nadifa needed help to develop her skills in English, if this was to be at all possible. In fact all those interviewed reported wanting support to develop their CVs or explore how previous skills or experiences were transferable to other work. One single parent reported feeling despair about the future. Life was perceived as a struggle on every level, with concerns over debt, children's behavioural difficulties combined with feeling depressed leaving little opportunity to think about the future. Nevertheless, she anticipated continuing her voluntary work where she loved working with animals.

\section{Summary}

Those on ESA had arrived there through long term conditions, often associated with mental health concerns such as anxiety, depression and fatigue. All had previously worked, but were now in a position that managing their illness, combined with the demands of caring for children, were as much as was possible for them. The demands of JSA were considered far in excess of what was manageable and caused considerable anxiety and stress, which exacerbated their ill health. Increasing concern was raised about the role of those undertaking work capability assessments. In removing them from ESA and returning them to JSA, the assessors failed to understand the extent of their ill health. There was some indication that older children felt frustrated and resentful of their parent's inability to work. Nevertheless, single parents did look to the future, hoping for better health and finally meeting their work aspirations. 


\section{Staying on Jobseeker's Allowance}

\section{Who are the single parents in this group?}

In the review of the literature on single parents not in work (Chapter 3), a number of characteristics are generally associated with single parents not being in work. These are having a child under five, having three or more children, being single rather than divorced or separated, having a long-term illness or health problem, not having any qualifications, not having any recent work experience and not looking to move into work in the near future (Haux, 2009; Millar and Ridge, 2001; Holtermann et al., 1999).

Analysis by Berthoud (2003) suggests that having more than one of these characteristics significantly lowers the likelihood of single parents moving into employment. As the transfer from Income Support (IS) to Jobseeker's Allowance (JSA) affected only single parents whose youngest child was seven or older at the time this research was carried out, the first characteristic, having a child under five, does not apply. However, the other six characteristics do apply to this sample of single parents who were receiving JSA at the end of the project. The group will be described, referring to the characteristics identified above.

Starting with the number of children, of the 15 single parents in this group, six had three or more children, while the remaining nine had one or two children.

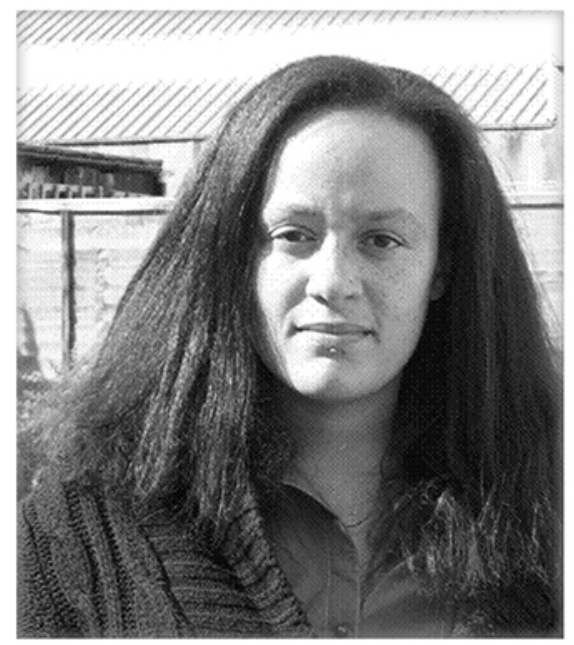

We did not ask single parents in this study about their route into single parenthood; therefore, we are not able to reveal the proportion of single parents in the sample who are single versus being divorced or separated. Regarding the health status of the participants in this group, the words most often used to describe their well-being were "stressed" and "depressed". This mirrors the findings of Peacey (2009). The level of stress and feeling depressed seemed to vary between single parents and across time, but could be bad enough to enable some respondents to move to Employment Support Allowance (ESA), though some of those were subsequently considered not to have passed the medical test and ended up back on JSA. However, other health issues do not seem to feature prominently in the lives of the group.

The parents in this group had a range of qualifications, ranging from GCSEs to university degrees. However, what seems notable about this group is that a number of single parents had gained additional qualifications since having children such as diplomas in retail or were currently working on childcare qualifications. Some of the qualifications were in the more alternative professions, such as complementary medicine. 
With regard to recent work experience, almost all the interviewees in this group had worked in the past. However, half of the parents in the sample had been on IS since the birth of their youngest child, while the other half had been receiving IS for a shorter period. Nine out of the 15 parents had been on IS for five or more years compared to six single parents who had been on IS for less than five years. Surveys of single parents not in work, have consistently suggested that nine out of ten single parents were looking for work though a substantial proportion would like to move into work some time in the future (Holtermann et al., 1999; Millar and Ridge, 2001; Haux, 2009).

However, all the parents in this group wanted to work and were actively looking for work. It is likely that the characteristics of single parents in this group went some way to explaining why they were not in employment at the end of the project. The following sections will explore their situation in more detail and include additional factors in the analysis such as their work search activity and desired job criteria.

\section{What are they doing now?}

All the participants in this group were receiving JSA at wave 3. However, when looking at this group more closely, their situation becomes more diverse. A number of the group had come off JSA during the fieldwork, either into work or onto ESA, but had subsequently started receiving JSA again. Those who have returned from being in employment to JSA had either experienced problems at their place of work or found that they were not making as much money as they had been hoping, being self-employed. The process of re-claiming JSA tended to go smoothly:
"It was actually quite positive um they were... they were very nice to me, very pleasant to me so I can't complain about that really and it all went quite smoothly.... Yeah, yeah they helped me there was a couple of letters that I didn't understand so they helped me sort that out so.." (Jessica, W3).

The fact that all everyone in this group were on JSA at wave 3, does not mean, however, that they were not engaged in paid or voluntary work and in some cases, training. This will be elaborated further below.

\section{Working less than 16 hours per week}

A number of single parents in this group were working less than 16 hours. Some were hoping that the hours of their current job could either be extended to 16 hours or that the experience would lead to another job. For example, working as a note-taker at university:

'Yeah and it would be great if I worked 3 full days a week or something it would be great if I had it in one chunk instead of flitting here, there and everywhere because I just feel disorganised and chaotic and trying to keep on the chores I just feel yeah its tiring.'

(Hailey, W3)

Where they were working a small number of hours per week it depended on whether they enjoyed the work as to whether they were keen to increase their hours in that job and be able to come off JSA, or whether they were looking for other work. In some instances, single parents were not keen to extend the hours of their current job as the work was physically very tiring. Instead they would rather get another, less physical, job for 16 plus hours. 


\section{Doing voluntary work}

A number of single parents engaged in voluntary work, at times quite extensively. The reasons for doing voluntary work varied from wanting to help people or wanting to give back, to gaining skills that would help them getting a job.

"Now I am working with homeless people for two years. Yeah volunteering its good for me I feel good when I go there unless to go job centre yeah...myself I got this one myself yes around two years ago now because when ... my son when he came home ... so I said to them I don't have any money to give some help I went there and they helped me at the time I said to them if you have something to do I will do I went full time and they know for me there they are afraid I am working with them now Sunday, Tuesday and Thursday I am working."

(Mariam, W2)

"I work with the [primary school] I work with year $1 s$ and year 2s I stay with them in the playground. I support the teachers I go with the ? in assembly and when they are eating.... I learn a lot I learn how the school operates I learn new rules and responsibilities I even help Somali children who don't speak English. Making a little difference in children is very rewarding....Very close I might even get a job in there because of how hard I work I have even been given a badge there and feel I am already one of them. I must say I learned so much."

(Yasmin, W2)

The single parents generally enjoyed the voluntary work they were doing, with the exception of one case where the organisation was not set up to integrate volunteers into their work.
The voluntary work could last several years and in some cases there was a sense of progression in the type and amount of voluntary work done by single parents, e.g. from working for a charity to working in schools.

However, not all single parents in this group were keen on the idea of voluntary work and there was a sense that working for free meant feeling less valued. This view was voiced by some single parents who had done a lot of voluntary work or were still doing voluntary work at the moment, but who felt that they 'deserved' to be paid for their work:

"So even though I am doing lots of volunteering, I am actually working really, I'm not getting valued as a paid worker. So it's psychologically you have to kind of have that inner conversation with your self esteem. I am ok [laughs] I am a worthy person, you know I don't bring home a wage packet every week.

(Rachel, W2)

'Yeah I have done loads I have done loads of voluntary work and I don't want to do it anymore [names three organizations] I think I deserve some paid work now." (Heidi, W2)

Some single parents were opposed working for free on principle and did not want to engage in unpaid work, as they felt it would lead to more employers being able to make use of free labour. 


\section{Work search and ideal jobs}

As mentioned above, all the parents in this group were actively looking for work. Single parents in this group used a range of methods from looking in the newspaper, going round local shops and looking on the internet. There was perhaps a stronger sense in this group of work fitting around school hours.

The preference for working school hours partly stemmed from having had experience of working shifts and trying to juggle childcare, from a view of their priorities as parents as well as the lack of alternatives, e.g. the availability of after school clubs or informal networks.

"I used to work by [supermarket] and now they changed the shift because they say you have to start at six in the morning and I am a single mum and I have to bring my children to school eight to nine. In other words they said ok you will have to start... I used to work part time and they say you will have to start 2 o'clock and you will have to finish at 6 o'clock I have got that shift. That shift also is not possible because 3 they are finishing school so I have to leave one at home and I pick up the smallest one who was 9 years."

(Fatima, W2)

For some single parents, the preference for only working school hours led them to re-train in order to be able to work in school. Other preferences for jobs were that they were local in order to avoid travel costs and time. One single parent summed up her ideal job as:

"I would like a nice paying job that doesn't pay me peanuts, that isn't too far away that I could get to on one bus not two one, because they are already expensive enough for $£ 4.19$ or even better walking distance?"

(Abigail, W3)
In terms of the kind of work they wanted to do, the parents on JSA at wave 3 , fell into two groups. The first group was prepared to do any kind of job. The other group, however, had preferences for working in schools, doing administrative work and not doing cleaning jobs. These preferences tended to be based on previous work experience, their own ability as well as the possibility of working school hours: for example, cleaning jobs seemed to be available mainly in the early morning and evening. Self-employment was also a popular option for some of these parents, either because it would help them to manage their health condition and work or because it would mean that they would be their own boss.

\section{Work Programme}

A number of parents in this group had been on JSA for a year by the time of the third interview and were transferred to the Work Programme. However, the timing of the research meant that the interviews were usually just before they were transferred and therefore, we were not able to explore the change in status further.

\section{Impact of being on JSA on the single parents and their children}

Being on JSA, in some cases for over a year, seemed to impact on single parents and their families in a number of ways and the impact changed over time. Initially, the transfer to JSA left single parents feeling anxious generally and in particular about the change in the budgeting and sanctions (see also Chapter six). Once single parents had been on JSA for a while, they got used to the change in budgeting and also seemed to settle into a jobsearching pattern sufficiently to satisfy the Job Centre staff. However, partly as a result of having done this job search activity, 
the parents in this group experienced a lot of rejection and that affected both their mood as well as their confidence in getting a job, in the future:

"There's I find that as my time has gone on I have become less and less motivated, it does take it out of you, you send so many CV's out and apply for so many jobs and you just never even get a reply back or you get interviews and then you know nothing and it can be really quite soul destroying at times and you have got to you know you have to be really quite strong to not take it too personally. "

(Nikki, W3)

There was also a sense that single parents were perceived differently as a result of the changes to the policy (for more on this, see chapter 8). This affected the group of single parents on JSA particularly as they felt the sense of expectation that they should be working but were not able to find work:

"Yeah ok the impact has been like I said before the impact, the main impact is an emotional impact where before I was a responsible single parent and now I am dole scum and it went from one to the other very quickly you know what I mean, one minute I was doing the right thing now I am doing the wrong thing and it is quite difficult."

(Samuel, W3)

"Um I don't talk about it much because I am a bit ashamed possibly actually yeah I think they realise I am in a tricky position and I am a single parent um and they are aware I am pretty skint um, I don't really talk about it, I am quite private about it actually yeah."

(Hailey, W3)
Single parents also spoke about how being on JSA for over a year affected the relationship with their children. In particular, the levels of stress experienced by single parents generally and about their limited finances in particular, seemed to affect the relationship with their children.

"My kids are suffering because they come home with letters and they say I want to do this club, I want to do that club, I can't afford any of it. If it isn't free they can't do it, they go to an art club at the Wellspring on a Saturday morning and that's where I work and I only know about it because I work there and it's really for kids that live in Barton Hill but that's like £2 each so they get to do art, pottery, stuff like that but that's... you know but you come home and it's like £25 a term for them to do something once a week after school with a professional coach" (Zoe, W1)

"Yes, we're arguing a lot at home, because I said to her l'm stressed out and then she wants to go to groups or go to ... and then I haven't got the money for it because it's a drop in money and then she doesn't understand because she's only 10 years old you know and then she says my friend ... you know they're doing this or they can somewhere, yes but they've got a mum and dad that both work. I'm a single parent that doesn't work." (Ashley, W2)

The same single parent commented at a later wave:

"Yes. I feel like I'm failing my daughter, the older she's getting I feel that I'm failing her because I can't provide the things that she needs. What sort of parent does that make me?" (Ashley, W3). 


\section{Outlook on the future}

That single parents felt relaxed about the future was the exception rather than the rule:

I: "How do you feel about your future at the moment?"

$R$ : "It looks very gloomy? at the moment even though I am doing my courses and everything constructive it feels pretty gloomy because of people accepting me to work for them and that's it really just to be accepted to work for a place and just to work really."

.I: "Yeah so are you worried about getting a job and stuff is that kind of...?"

$R$ : "Getting into a job yeah money is hard at the moment and I need a job... people are finding it hard to get into jobs I feel that there is no hope for me at all."

(Felicity, W2).

At wave 3, the same single parent was feeling more optimistic, in part as a result of having been transferred to the mandatory work programme:

I: ..."and if you so you are going into this mandatory work now and then are you, you know how hopeful are you about your future and about that you will get work in the end?" R: "Optimistic."

(Felicity, W3).

However, generally, comments such as this one:

"Well until I can see the job market improve I don't think l've got much of a future"

(Heidi, W3)

were more typical for single parents in this group, as were comments indicating that worries about the future had persisted.
"I am very concerned and worried that if I do not manage to find a job that I don't know what the future holds in store as to what they will do. How can I put this into words? As to what the future steps are if I do not find work, I don't know what will happen, whether I'd end up going to daily sign on or ... I've heard all sorts of different rumours." (Hannah, W2)

"Yes, I am very worried for how things will work out for my own situation but if I do get a job and do well at a job then I think things will be okay, I hope things will be okay. But I do worry about being able to afford everything ... and be able to sort of keep my family going and the home going, whether I do get a job or if I don't. If I get a part time job will the benefits be enough that top you up? Will that be enough to cope with the extra expenses that I'm going to find occurring? So either way I'm pretty worried."

(Hannah, W3)

\section{Why are they not in work?}

The answer to this question about why the single parents in this group are not in work is likely to be multi-faceted. Single parents were keen to work and their work search strategies did not seem much different from those who had moved into work. In terms of the jobs single parents in this group were applying for, they tended to fall into two groups. The first group of single parents was applying for any kind of job, while the second group had preferences regarding the type of job and/ or the work hours. However, as pointed out in the policy chapter (Chapter 2), the impact of the recent recession has seen a general rise in the level of unemployment. In particular, there have been job losses in the public sector, which tends to be a more family friendly employer, and there is more competition for part-time jobs. 
In addition to the lack of jobs, the characteristics of single parents in this group are also likely to play a role. Single parents in this group have usually had long spells on IS and therefore not much recent experience of paid work. A number of single parents in this group have three or more children and while most of those are teenagers, the need to be around as a parent tended to be a theme in some of the interviews (see also Chapter 11 on Caring for Older Children). In two cases, the children had health issues, which necessitated more hands-on care from the single parents.

The level of qualifications varied between single parents from having GCSEs to having university degrees. In addition, a number of the parents had gained additional qualifications in IT, retail and health and safety in recent years. Therefore, the level of qualifications will impede some of the single parents in this group to find work but by no means all of them. The single parents also spoke about their networks and a number of them had family, who could and had helped in the past, both financially as well as with childcare. For some, this was not the case because their family either did not live close by or were employed themselves and therefore not able to pick up a child from school. Older children tended not to be seen as source of childcare.

However, as discussed earlier in this chapter, a number of the participants were working a small number of hours already, doing a range of voluntary jobs as well as studying towards further qualifications. In other words, it could be argued that single parents in this group were engaging in work-related activity that should theoretically give them a better chance of moving in to work of 16 hours or more.
Yet, this was not always possible as either the employers did not have more hours, or because the work was quite physical and therefore potentially not sustainable formore hours.

In addition to the characteristics, however, the parents in this group were clear that their children came first. They talked of the importance of being around for their children, e.g. to make sure that they got off to school and arrived safely. This translated into a preference among some in the group to only work during school hours. 


\section{Summary}

Single parents in this group had quite diverse characteristics in terms of the lengths of time they had been on IS, the number and age of their children as well as their qualifications. What they had in common was that they all wanted to be in paid employment. Single parents in this group were not in work of 16 hours or more, but were engaged in quite substantial levels of paid and voluntary work, to demonstrate and gain additional skills. A couple of single parents had re-applied for JSA, having been self-employmed for some time. However, for those who had stayed on JSA for over a year, by the end of the study, the impact of many unsuccessful job applications and the financial constraints had left its mark. The parents talked about how it had affected their sense of self-worth, had added to the general pressure of being a single parent and all of this together was starting to have a negative impact on their relationship with their children.
The interviewees in this group generally seemed to be concerned about the future, including a worry that the labour market might not improve for some time. Initially, it was not immediately obvious why this study sample were not in employment as they did not seem to differ markedly in terms of their characteristics or their work search activities from those who had moved into employment. Similar to their counterparts in employment, some single parents in this group were keen to work within school hours, in order to look after their children. However, they appeared to have less access to part-time jobs within easy travel distance and less access to social and family networks that might support their childcare role. Perhaps the most obvious reason why this group was not in employment is that the labour market has not recovered from the recent recession. 
"It gave opportunities to get out and build confidence; experience of work with UWE and to get university accreditation was important at the time because it gave me a boost.

1 dont think I will be able to use it

since I am not anticipating doing a university course but helpful on my CV (PR8)".

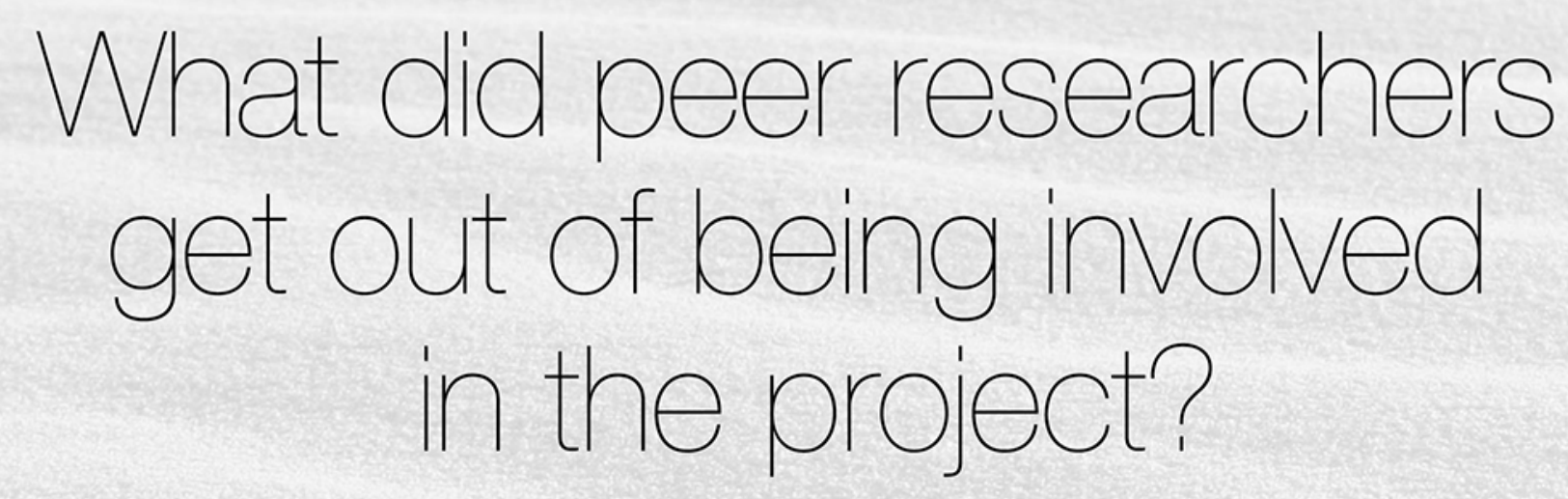

A number of themes emerged when peer researchers talked about what had changed for them as a result of being involved in the project. In particular, was an increase in confidence as a result of the training and support and of having a new role and status both in their own eyes and those of their children. Participants enjoyed the status associated with being a 'peer researcher' as well as the opportunity of meeting a range of different people and learning to cope in a range of interviewing situations. 


\section{Caring for Older Children}

In this chapter, single parents' experience of childcare issues from when they were transferred from Income Support to Jobseeker's Allowance will be discussed. Particular attention will be paid to its impact on work, the age at which children can be left on their own at home, childcare in relation to when a child is ill, walking to school and childcare as a problem for parents and not the Job centre.

\section{Impact of childcare on work}

Information about childcare arrangements and sources of advice predominantly came from the Lone Parent Advisor and other Job centre staff. However, advice and discussions about childcare arrangements and what support was available were often absent and/or inconsistent. Parents reported several barriers to employment. The most frequently cited barrier was around childcare, especially in relation to flexibility of working arrangements and proximity to school and home. Those parents who could rely on informal arrangements were more concerned about the impact of looking after their child on the family member or friend and how suitable it was for the child, especially if the family member was a grandparent who had their own health issues. Parents who needed to rely on formal childcare expressed more anxieties. These related to someone they did not know looking after their child and if an appropriate carer would be looking after their child:

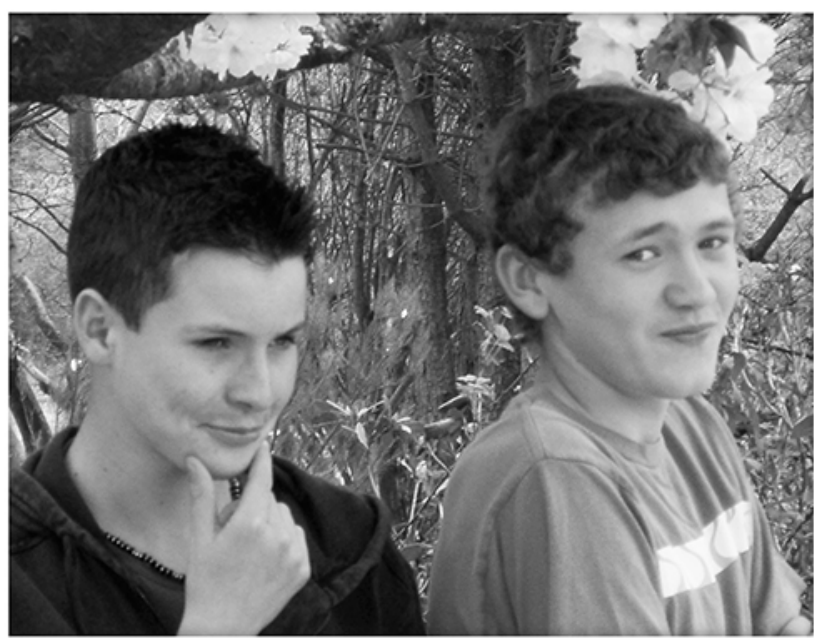

"because I said I wouldn't have childminders, I said no, ...... I wouldn't have ... they would hate after school clubs and they would hate having a childminder". (Joyce, W2).

Parents who were able to work during school hours did not use childcare but they also expressed concerns about losing their job, as found in previous work around childcare and job loss (Casebourne et al., 2011). As previously reported (Lane et al., 2011), there is a lack of available childcare for those single parents. This is especially so for those wanting cover for school time (both in and outside school hours) and school holidays and for those with children, who were too old for childminders but not old enough to be left on their own, from the parent's perspective:

"my children are older as well. There's about two childminders in the area that do take children over the age of 8 but whether they have got vacancies .... so the problem is the childcare rather than the job really."

(Jessica, W2) 
Age of children when left on their own

Parents were undecided about the age at which they would leave their child on their own, in the home. This often depended on what other support mechanisms they were able to draw on, whether there were siblings in the home and the maturity of the child in question. For example, one mother who had to leave her 12 year old daughter at home during the day until $4 \mathrm{pm}$, was not particularly concerned, because the daughter spent most of the day asleep and a nearby friend, who knew the daughter well, would pop in during the day. Her view changed when her daughter had to be left in the evening, even though the daughter would only be alone for a couple of hours:

"means I am home after her but its only like for two hours that she is here anyway which I am not happy about but there you go it's just one of those things, what else am I supposed to do."

(Megan, W3).

Parents often questioned their own practices about leaving their child on their own at home. This usually related to whether their judgement might be questioned, if something went wrong when their child was alone:

"my ten year old walks home from school and my eleven year old comes home on the bus from school and let themselves in and they were alright and they're on their own for an hour, am I going to get into trouble for doing that?"

(Zoe, W3).
Views about the age at which children could be left alone were varied with many thinking that around thirteen was acceptable.

However, parents usually clarified this by saying that their child was 'responsible' or that they could 'trust' them. This element of maturity was more important than the actual age of the child. A parent's view as to whether their child was competent to be left on their own influenced their views on JSA and the difficulty of finding a job that fitted in with school hours or that their working hours or place of work:

"he is good as gold, he is responsible and like I said he is 13 in December so he is now left on his own" (Lyndsey, W3)

"Not 7, 14 because if they made the age for children the age of 14, they could stay on their own, so where children at the age of $7 / 8$ it's more difficult for parents to work so doing that was completely stupid."

(Felicity, W3).

The lack of a specific age at which, legally, children can be left on their own at home was known by many parents but often thought to be unhelpful. Conflicting information was given to some parents from different staff (Jobcentre versus Social Services) and this led to further confusion. This was especially so when, for example, it was used as a reason for insisting that the mother took the job that was on offer, even if there was no one to care for her child when she was at work:

"yes I was told there is no legal age limit you can leave your child and that was what was pushed my way basically so yeah pretty disgusting"...

(Chloe, W2) 


\section{The ill child}

A common theme in these interviews, as well as previously reported (Peacey, 2011, Ridge \& Miller, 2011), is that the single parent will need to deal with any family need or crisis alone; there is usually no other adult for that parent to draw on. However, parents were very clear that they would still put the needs of their children before that of work. This may result in having a significant impact on the working lives of single parents with younger children, since the parent will not be able to leave them at home alone, when ill:

"if you have to have time off and stuff you end up being sacked and then you got to go because I did work for a bit and then you got to go through that waiting weeks and weeks without any money so I think they should just wait until the children are about sort of at least at high school age." (Joyce, W2).

Parents spoke of their concern about the issue of what might happen if their child was ill and the need to have an employer who would be understanding and/or offered flexible working arrangements. In addition, parents were often unsure how sympathetic the Jobcentre would be when their child was ill and therefore not be able to sign on. It was evident that parents were unaware of the flexibilities built into the system of claiming JSA (Gloster et al., 2010). Consequently, some had taken their child with them to the Job centre. "there's more pressure to try and drag my kids out of bed when they're ill and take them to the Jobcentre and they expect you to do that and if I don't take them when they're ill to go and sign on then my benefits get cut whereas when I was on Income Support, I didn't have to sign on." (Heidi, W2).

Parents whose children had chronic conditions (asthma, Asperger's, learning difficulties, post-traumatic stress disorder) experienced greater problems with childcare. In some cases, this would mean that the child had more problems at school and, as a result, might need to be collected during the school day. Whilst these children were often unable to be left at home alone, as found in previous reports (Peacey, 2009; Lane et al., 2011), it was also difficult to find appropriate childcare:

"with [child] being ill a childminder or after school club would have been no good at all.

(Joyce, W2).

Single parents appear to have been given little information about JSA legislation, or certainly not in a manner they had understood or remembered. They may have been informed but staff do not typically inform all parents about the flexibilities so that staff themselves, can maintain some control over decisions taken. An area identified in previous research (Casebourne et al., 2010). 


\section{Walking to school}

Single parents expressed concern about their child getting to school and back. They felt that they should be in a position to be able to walk them to school, especially if they were at primary school or had health or educational difficulties. For some, this was in relation to what they felt was part of a parent's role. For others, it related to safety and ensuring that their child went to school:

"Yeah its not that actually well to me its so important that I take him to school I pick him up .... but it doesn't take into account my you know my kind of beliefs about being a parent." (Hailey, W3)

"My son refuses to go to school you see um so I chose the evening shift which is like 2 until 6 so I can be there in the morning to get him out of bed to go to school...". (Laura, W3).

For other single parents, taking to and fetching their child from school was very important for them. They felt no need to justify their feelings but felt very strongly that their child was more important and that was why they needed a job that would enable them to do the school run, especially taking their child to school in the morning. There was a view that their priorities as parents of young children were being compromised and their capacity to parent was being challenged.

"to me it's so important that I take him to school I pick him up ..... but it doesn't take into account my you know my kind of beliefs about being a parent." (Hailey, W3)
"I don't mind if I have got to work 9-3 as long as I can take my son to school and pick my son up I'm happy but".

(Samuel, W2).

Those parents with slightly older children discussed the need for their child to go to school without them and, if they had more than one child, there was an emphasis on the importance of walking together:

"So I discussed it with them before I took the job because I said to them look you have got to walk to school together and back and um you are going to have to have a key and let yourselves in.."

(Grace, W3)

A quote from one single parent encapsulated in one sentence the strength of many single parents' about walking their child to school feelings:

"I want to be there, I want to take him to school, I want to pick him up from school." (Hailey, W1)

\section{Whose responsibility is childcare?}

It was clear that some parents felt that they were being expected to take responsibility for organising childcare, when they were not in a position to do so. If they had not found a job, it was difficult to contact and arrange childcare, as they were being advised to do, because they did not know the hours that they would need:

"I don't know where to start... I don't understand...I don't know what to do, what do you do just ring up the child carer find out and say would you be able to help if I found this sort of work?"

(Felicity, W3). 
The difficulty of setting up childcare was a frequent theme. There was a lack of options and the Jobcentre were not really interested in helping the parent. Parents reported being given very little support in finding appropriate childcare and viewed Jobcentre staff as just wanting to 'suit their statistics' (Megan, W2).

"that's not their concern, my child care issues aren't their concern, their concern is getting me off Jobseeker's and getting me into employment." (Nikki, W2).

The correct support package, including childcare, is seen to be key to increasing the single parent employment rate which, in turn will help tackle both worklessness and child poverty (Freud, 2007, Harker, 2006). Whilst this may be the case, the parents in this study felt targeted in a way that other parents might not have been and stated that their individual circumstances were not taken into account. This was strongly expressed even though contrary to what the regulations for parents stipulate (Gloster et al., 2010).

\section{Summary}

Consistency and accuracy of advice and information given to single parents about JSA legislation appears to be lacking. To alleviate some of the single parents' concerns about leaving their older child, more appropriate childcare is needed for young people. Walking their child to school was a key aspect for single parents, especially for parents of younger children. If consideration of individual circumstances and needs of parents and children was more evident, single parents might feel less targeted. 


\section{Training Opportunities}

This chapter explores the views and experiences of the single parents in the study, in relation to the training provision, while claiming Jobseeker's Allowance (JSA). One of the main differences between receiving JSA and IS is that recipients of JSA have to be available for work within a fortnight, which limits their ability to participate in more time intensive and longer-term training courses. The issue of training has largely been neglected by other recent research on welfare reform (Gloster et al., 2010; Casebourne et al., 2010). Its absence is surprising considering that the desire to do training featured prominently in single parents accounts in this study. In this chapter, the expectations and motivations of single parents to engage in training, their experience of training opportunities on JSA and their experience of participating in training will be discussed.

\section{Expectations and motivations for training}

What all of the participants had in common was that they expected to be able to access training while on JSA. There was a sense that the transfer to JSA meant the start of moving towards work via training, rather than having to be available for work immediately. Overall, the parents in this study were keen to engage in and continue with training.

The motivations of single parents for wanting training fell into four main groups: a chance to retrain, avoiding menial jobs, mentally preparing for the labour market and seeing it as a stepping stone. Those who saw it as an opportunity for "retraining" wanted to attend a diverse array of courses from teaching assistant, administration and food hygiene to university access courses.

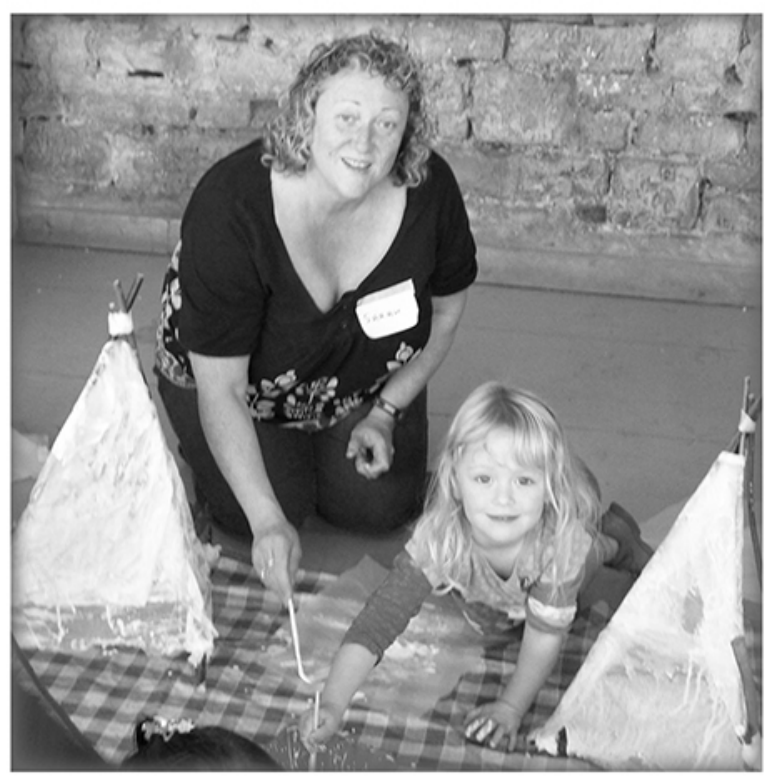

Another group saw it as an opportunity to obtain skills and learning that would facilitate the type of job they wanted to apply for and could prevent them only being able to access low paid employment:

"I would do training, I don't want to just end up with a menial job." (Zoe, W1).

"If you want something more than packing shelves in a supermarket or cleaning toilets, you know you are going to have to do something aren't you, some kind of training." (Beth, W2).

The third group perceived training as a way of increasing their confidence to apply for work:

"If they are giving you some sort of training its making your feel motivated to feel confident to go for a better job." (Grace, W1).

"You become more confident, you learn new skills, you feel more confident in applying for jobs." (Yasmin, W2). 
Finally, those who had been out of work for a number of years, saw training as a stepping stone to work, as a way of re-engaging with the labour market:

"I've been out of it that long that in some ways I could do with total retraining."

(Olivia, W1).

For these single parents, training such as course on $\mathrm{CV}$ writing and computer skills were the main types of training they were interested in. One single parent who had been out of work for a number of years could not imagine being able to find a job without first attending a training course. She felt she would struggle to apply for jobs without sufficient support and CV writing skills:

"I'm not being funny but I'm fifty and three years, l've been working at home ... not working at home but being at home doing my own thing for the last sort of ... well since my youngest was born really and then suddenly forced out into this environment with no sort of ... how can I put it ... well no backup nothing, just thrown out there, it's like being chucked off the end of a fishing line you know, you're the bait. It made me feel absolutely oh my god first of all it really did but slowly getting there, slowly getting there. I went on a workshop actually which is a professional and executive workshop called Prospect and they were brilliant, they really boosted my confidence."

(Megan, W1)

\section{Single parents' views on the availability of training and support on JSA}

The expectations of training provision, once on JSA, were at odds with the reality of the JSA regime, which focuses on moving single parents into work as soon as possible. Some single parents' plans for employment included undertaking full-time training that would last several years. Yet, according to JSA regulations, JSA recipients are not allowed to engage in full-time training as they have to be available for work at short notice. Furthermore, advisors did not seem keen to discuss and suggest training more generally, even shorter courses.

“Once you're on Job Seekers they just kind of leave you to it and they just ... I don't know, they don't offer support or help, they just sign."

(Penny, W1).

The disjuncture between the training expectations of single parents and reality of the JSA regime was felt the most keenly by those who wanted to train for a particular career. These single parents were interested in becoming teachers, midwives, and childminders:

"I've got to go for my level three of my childminding which is a bit more in depth of knowledge of what l've got to do as a childminder."

(Marie, W1).

"I want to do the midwifery, well I want to do the Access to Midwifery at college which I wanted to do over one year." (Olivia, W1). 
This group however, were acutely aware that if they started or continued training while on JSA they would still be required to actively seek work and have to leave the training, were they to find employment.

"I can't go back to any kind of training because if you do that you got to get a job and be willing to give it up straight away."

(Samuel, W1).

Moreover, they were also aware that, had they begun the same training while on Income Support, then they may have been able to have finished the course.

\section{Finding out about training}

Training was not discussed as a matter of course in the meetings with Jobcentre advisors. Lone parents who enquired about the possibilities for undertaking training received mixed reactions. Some single parents were told of relevant training courses and how to attend:

"they then sent me to an advisor which she sent me into town....... I had to go down there, I had to do two days a week and that was helping me do my CV." $\quad$ (Chloe, W1).

Others were disappointed to be given phone numbers to contact the providers themselves or directed to Learn Direct and the Bristol Evening Post newspaper:

"He didn't offer me any information about that it was sort of like oh go off and look up that yourself sort of thing." (Francesca, W1).

\section{Training attended}

The table below details the type of training undertaken by the study sample during their JSA claim. It suggests that only a small number of them had accessed training while receiving JSA. In addition, there was a small number of single parents who were offered training but did not think it suitable and so declined.

\begin{tabular}{|l|c|}
\hline Training attended while on JSA & Number of participants \\
\hline No training & 27 \\
\hline Back to work course & 5 \\
\hline CV writing & 5 \\
\hline Business Start up & 4 \\
\hline Admin and ICT & 2 \\
\hline ESOL & 2 \\
\hline Food Hygiene & 1 \\
\hline Maths & 1 \\
\hline Security & 1 \\
\hline Unclear & 3 \\
\hline Total & $51^{\star}$ \\
\hline
\end{tabular}

*One participant undertook two training courses.

\section{Experiences of training}

There were a number of single parents who felt that the Jobcentre was not happy to volunteer information regarding training. Indeed, single parents had to persuade the Jobcentre to allow them to attend a course, which, in some cases:

"took a couple months of nagging...she put it to me that there were courses available like um Confidence Building, Interview Skills, help with my CV and I said yeah brilliant I'll do all that and I had to push and push and push for that and the only one I got was help with my CV." (Jessica, W1). 
When the Jobcentre did suggest training, the most popular suggestions were either CV writing or Back to Work courses. Although these courses fitted the needs for some single parents others wanted access to different courses:

"They put me onto someone last time I signed on, to get a CV done." (Phoebe, W2)

Nevertheless, some single parents did have useful experiences of training provided both by the Jobcentre and local agencies such as Tomorrows People, Clean Slate, Seetec and Brave. As a result of a positive training experience, single parents felt more able to apply for jobs:

"I think it's good for my confidence and it's good to have that because I have applied for a few admin jobs." (Rachel, W2) - (discussing an ICT course).

"Yes it did help me quite a bit to sit down and realise there are many different ways of looking for a job, not just in the Jobcentres or newspapers and asking your family and friends but you can directly approach companies and ask if there is actually any work going" (Hannah, W2) - (discussing training on how to find work and creating a $\mathrm{CV}$ )

They also felt more confident:

"I did find that useful because that made me much more confident about approaching galleries and that so that was quite useful yeah definitely" (Megan, W3). (discussing training provided by Seetec for becoming self employed).
Single parents wanting to become selfemployed felt particularly let down by the support on offer to them from the Jobcentre:

"the Jobcentre not really set up selfemployed people." (Katy, W1).

Participants felt they were being actively discouraged from becoming self employed:

"she made it as difficult as possible for me to start my own business or do anything towards a creative artistic job, she just wanted me to go for any kind of interview to get any job to get off Jobseeker's."

(Irene, W1).

However, when they were able to access training, particularly from agencies such as Brave, single parents had a positive training experience and found the services on offer to be very useful:

"Brave were really, yeah really quite good. I had a couple of one-to-one sessions with uh, I can't remember what his line of work was, I think he might have been a Banker, but any way yeah and it just makes you focus your mind on your business plan." (Katy, W1).

"First of all a one day workshop of starting your own business then I had one to one sessions with an advisor as to how to do things like accounts, to um project what I would be doing in the first year of trading things like that that I didn't have a clue about." (Irene, W2). 


\section{Problems with attending training courses}

There were a number of parents, however, who attended a training course and found the provision to be unsuitable for their needs such as the times, travel costs and the quality of training.

A particular issue was with the start and finish times of the courses. A 9am start and 5.30pm finish each weekday meant it was impossible for single parents to attend for the whole day:

"I am going to one at the Park Centre on a Friday morning but I can't go for the whole time because it starts at 9.30 and I have got to get [child] to school." (Laura, W1).

Training was described as not:

"fitting in with one parent families, not at all."

(Grace W1).

Others were sent on training courses in the school summer holidays which had no childcare attached to them:

"they arranged it again for in the school holidays and I said well I've got no childcare."

(Ashley, W1).

\section{Cost of training}

The cost of public transport and the inconsistency in the reimbursement of travel expenses also caused some single parents to struggle when attending training as the quotes below demonstrate:
R: "it was still very vague and so I thought I'm not spending five pounds a day coming out to Kingswood and it takes me hours to get there."

I "Didn't they offer to pay for your bus fares for the training?"

$R$ "No, they did on the Launch Pad but they didn't for Kingswood." (Penny, W1).

"I went on a hospitality course but you've got to fund yourself to get there. So if it's for a week or two, you've got to find the bus fare to get there, you don't get that back and out of your benefits, that amounts to quite a bit."

(Emily, W2)

\section{Suitability of training}

The suitability and usefulness of the content of some of the courses was also a feature of negative training experiences. At times, single parents felt that the training did not meet their expectations:

"they sent me on a course on Monday at the Park Centre in Kingswood. To be honest I could have ran it myself. It wasn't really for me I didn't think they were listening to what I needed."

(Grace, W1)

Single parents reflected that the course would have been useful if they were able to utilise their learning:

"they have helped me to write my first CV. I didn't know what one of those was (laughs) um but yeah first basic copy of a CV with as much information as I could recall on it 
um they printed that out for me and also emailed it to my email address um so I have got a copy of it on my computer even though at the moment I don't actually know how to attach things from you know... I found it very difficult..."

(Hannah, W1).

The training provided could be expected to reflect their distance from the labour market and shared barriers to employment while taking into account existing experience and qualifications. However, this does not appear to have happened. The training offered appears to have no relation to their qualifications. For example, single parents with $A$ levels were offered back to work training while some with no qualifications were not offered training. Conversely other single parents with no qualifications were offered CV writing courses and back to work training, while some with degrees were offered no training.

\section{Summary}

Single parents, on the whole, were keen to undertake training; the provision of training on JSA however, fell short of their expectations. Single parents were disappointed that the Jobcentre staff were not encouraging them, as a matter of course, to gain new or additional skills to facilitate their move into employment. In some cases, the Jobcentre staff made it clear that single parents were to find work rather than undertake training, regardless of how useful to finding work the training would be.

The experience of training was quite mixed, with some courses being seen as very useful, while others did not meet the expectations of single parents in terms of the amount of new information they contained, as well as the quality of the teaching. Where single parents had positive training experiences, it left them feeling better prepared for work in terms of confidence and job-searching skills. This applied particularly to those wanting to set up their own business. 


\section{"I think it's been nice to think you're doing something and it's like a proper job sort of thing and set a good example for your children, you know you're not necessarily just going to sit around on benefits (PR6)."}
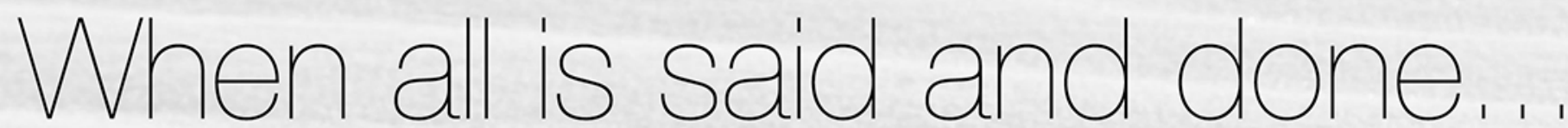

At the end of the project, the peer researchers were asked to reflect on the process as a whole, their journeys but also how they perceived their own situation compared to the single parents they had interviewed. The discussion of the overall process resonated with many of the themes mentioned in earlier paragraphs, namely the importance of accessible childcare, good communication, the value of training, the increase in confidence as a result of participating in the project and the wider benefits on both a personal and professional level. Peer researchers reflections on their own current situation in relation to employability, yielded more unexpected results. While several of the peer researchers had existing academic qualifications, during the project,

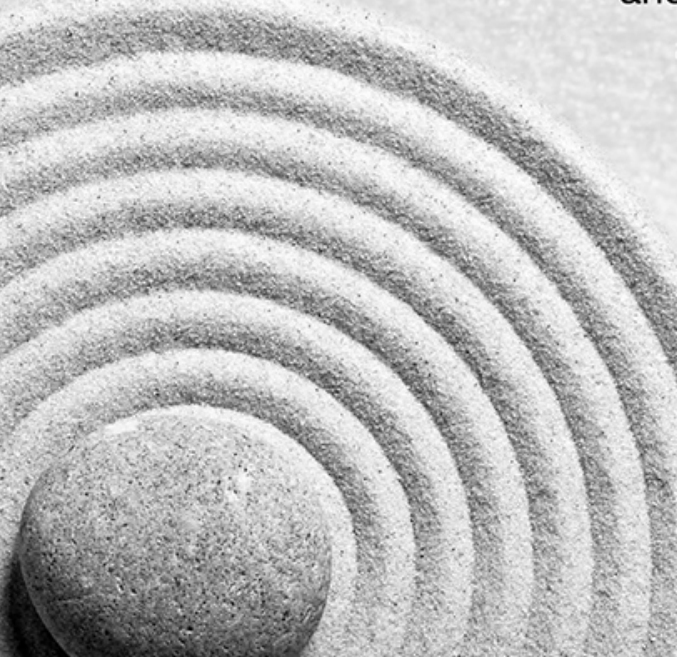

a number were engaged in full-time training or were scoping opportunities for their future. Peer researchers had been optimistic about the match between their aspirations in terms of the kind of work they wanted to move into and the progress they were making towards their goals. However, at the end of the project the picture became more mixed. A number of the peer researcher's children were coming up to the age where the peer researchers would themselves have to be available for work. Throughout the field work, peer researchers had listened to the stories of single parents, specifically in relation the levels of support interviewees had received from the Jobcentre and the difficulty of finding suitable work. These stories appeared to prompt a number of peer researchers to change their strategy and to start applying for 'just about any job', as a preferable strategy to being transferred to JSA 


\section{Single parents experiences of Jobcentre Plus and Welfare Reform}

In this chapter single parents' views and experiences of Jobcentre Plus as JSA claimants will be explored, followed by their views of the welfare reform, more generally. In particular, 'what makes a 'good' and 'bad' advisor', how job-search was supported and monitored and the use of sanctions will be discussed. Other studies on single parents' experiences of the Jobcentre as JSA claimants have reported on recent changes. These include no longer being able to see the same Lone Parent Advisor, issues around the knowledge of the single parent flexibilities and in work benefits by Jobcentre staff and the increased pressure on Jobcentre staff as a result of their larger caseloads due to the recession (Gloster et al., 2010; Casebourne et al., 2011).

An important aspect of single parents' views on the welfare reform was the way in which they held sometimes competing and contradictory views of the welfare reform. They agreed, with the broader underlying principle that single parents should be required to work. At the same time, they felt, on a personal level, that the demands of JSA did not take account of their personal circumstances. In this chapter, these views are explored, alongside single parents' concerns about the impact of the current economic climate on looking for work and the availability of childcare.

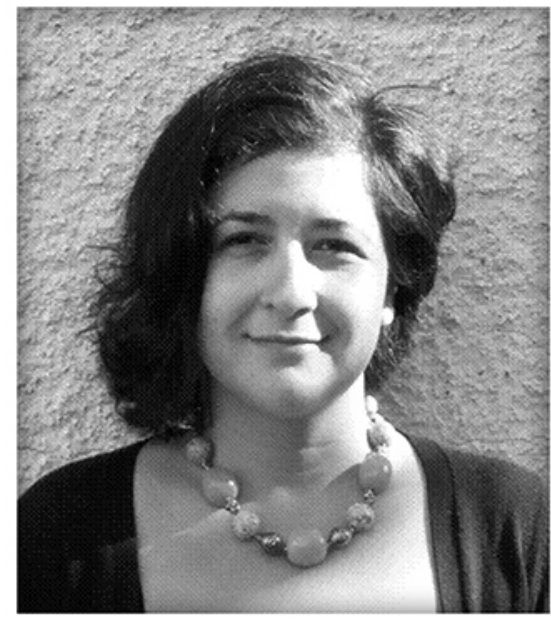

JCP: Seeing a different advisor each time

Perhaps the biggest change for single parents when being transferred to JSA, apart from having to be available for work and having to sign on regularly, was that they saw a different advisor at each visit. While on IS, parents tended to have meetings with the same Lone Parent Advisor and could build up a rapport. This meant they were not required to go through their circumstances and personal history each time.

\section{Under JSA, however, the interviewees} frequently saw a different advisor and this was felt to be problematic for a number of reasons: it meant they often had to repeat a lot of the personal information they had already given other advisors. Since it was difficult to build a rapport with that advisor, they could therefore not always get tailored advice and they could never be sure what reception and recommendations they would get with the next advisor. 
R: "um, it was just really nice to have one person to speak to and you know get to know each other a bit."

I: "Yeah."

R: "So you didn't keep having to, you know, every time you went to the Jobcentre, you didn't have to see somebody different.... "and go through your personal circumstances again."

(Yasmin, W1).

Some single parents talked about the new arrangement in terms of existing arrangements being changed that suited them, as well as different attitudes from the advisors they were encountering now:

"Um I don't like being told by a little girl half my age why can't I do this job and why can't I... I just find it very patronising because some of these girls are only in their 20's and they just... they haven't got a clue it would be better if I... if I... that man that I saw when I initially went back on to JSA, I mean he summed it up, he said well the first job / got was a lollipop man it was the only thing that fitted in. If I could see him every week when I sign on and speak to him, I would feel so much better um what else was I going to say (pause) it was even things like the time that I need to sign on is 10 o'clock in the morning and I said to this man oh that's brilliant because that fits in with school hours. This other lone parent advisor had me signing on at 3 o'clock so all the time I was thinking am I going to make it back and the man said to me well I gave you 10 o'clock because I realised you got to get back for the school run. Its little things like that..."

(Jessica, W2).
Parents talked about not being sure about the reception and assessments that were going to be made by the next advisor. This matters in the context of JSA as there are sanctions attached to non-compliance:

'when every bit of paper that you sign moves you onto a different stage and are seeing a completely different person, you've got to start again with the explaining to them from the beginning duh, duh, .... and it's like and you feel like you are not getting anywhere and you are always having to explain yourself, make apologies, feeling inferior, yeah, feeling like... I mean, again, that's my view, they are probably not looking at me like that but that's how it makes me feel'

(Sophie, W1).

\section{What makes a 'good' or 'bad' advisor?}

In general, single parents had clear views of the characteristics of 'good' and 'bad' advisors. A typical description of a 'good' advisor was:

'she was just so kind, really wanting to help people genuinely, you know, there was a sense of kind of you know you are a human being ... and that was fantastic' (Heidi, W1).

$R$ : "Yes I am getting that one yeah that's what I mean she was as good as gold that [advisor] absolutely brilliant she was."

I: "Brilliant so you were able to see the same person several times or were you just seeing her..."

$R:$ "...yeah she fitted me in..."

I: "...brilliant..."

$R$ : "...to sort me out yeah she was as good as gold."

I: "Great what made her so good?" 
R: "She'd listen because I could talk to her about the problem I got she was a lovely woman and she would listen to you and she would understand so... I mean if I see her again, if I got to go back there, I would be happy, lovely lady. I mean a couple of times I couldn't sign on with her because she was out ill but no lovely it all went smoothly I am still waiting for um... oh what are they called, local taxation..."

(Phoebe, W3).

Once they were on JSA, single parents met a number of advisors who left them feeling upset, given that they met so many of them. Characteristics of 'bad' advisors according to single parents were lack of interest and sympathy, not being well informed, suggesting jobs outside school hours, making them feel uncomfortable, not taking their individual circumstances into account, and simply being disrespectful. Some single parents talked about the frustration of being referred from one advisor to the next, if their case was somewhat unusual:

"Well nobody seemed to have all the information. Everybody wanted to try and put you in touch with a different person or a different department um I remember getting really frustrated on the phone once because they had overpaid me ... I was really annoyed about the way the letters implied that I was trying to deceive them in some way by not telling them about my money and I told them right from the time I applied for it, but because I hadn't sent those invoices in and then of course I had this overpayment that I had to pay back um... but when I tried to speak to somebody about it, they wanted to put me through to another department and I said can't you check with the other department and ring me back and they refused to do that, but um so I got very frustrated about that."

(Francesca, W3).
At times some parents felt that their career aspirations were not taken seriously by the advisors they encountered:

I: "Is there anything else at all you would like to add about your experience of being on job seekers allowance?"

R: "Well (coughs) because of (child) situation and trying to sort of get a freelance job as a designer or some of mine were ok its a bit pie in the sky but JK Rowling did it the Harry Potter author and she was on job seekers a single parent living in a council flat and if you think negative you are not going to do anything. But um I went down the job... I took my portfolio down absolutely wonderful work you know on my CV it was applying for a job as a freelance photographer newspaper thing and um and then I went down there one day and my Lone Parent Advisor said it's a hobby. So she belittled me by calling it a hobby and she said why don't you go down the doctor and say you are stressed out and see if you can get put back on income support and stay on that until [child]goes into hospital. So in other words she was asking me to lie to the doctor so she was totally negative on everything and then I had to go for a in work interview up in Hartcliffe and I mean I can walk from one end of Bristol to the other its no hassle to me..." (Melissa, W3)

Other parents also felt that their individual circumstances were not taken into account when asked to come into the Jobcentre and that they received little sympathy at times of personal crisis: 
"Yes, and I had prepared paper, I showed them, I say yes, they say yes, you right but you must attend here every two weeks. I say sometimes I'm off feet, do you know I'm not feeling very well because I have badly, badly depression and sometimes I can't even wash up and how do I attend? Nothing ... you know __sometimes you know some people have to be __ do you know? How do I say ... they look at me not the same everybody, I am sick but no, the rules is the same for everybody."

(Nadifa, W3)

Single parents, in this sample, did not see much or anything of their Lone Parent Advisor once they had transferred to JSA. Where single parents had not been getting on with their Lone Parent Advisor, this was a welcome change. Others felt that it was part of now being treated like all other job seekers:

$R$ : "No because then I found out through a friend of mine who went from income support to being self employed, that they have a Lone Parent Advisor but when you are on job seekers you don't get a Lone Parent Advisor because you are considered the same as everybody else from the homeless person on the street that's on job seekers to um well everyone is in the same boat you don't get help." (Irene, W2).

\section{Knowing the right questions to ask}

There was a sense among some participants that they needed to know which questions to ask in order to get the information they needed. On a number of occasions, relevant information, e.g. about building up a business or about the hours single parents were allowed to participate in training per week, were only acquired through pushing their advisor to find out the answers.
This involved participants knowing what information to ask for as well having the confidence to insist on an answer. This also meant that single parents turned to friends and other organisations for further advice on setting up their business or writing a CV:

"no, they don't give you any extra advice, you have got to ask them and you have got to sit there and you have got to make them go out and yeah, you have got to really trigger it off or they will just send you back off the way you came in... " (Grace, W1).

\section{Advice for searching for jobs}

Previous research suggested that the job search appointments tended to be brief (Casebourne et al., 2011), frequently lasting only five minutes. However, both waiting times and travelling to and from the Jobcentre could be considerably longer, adding to a sense of frustration of some single parents. Like previous studies, what happened at the job search appointments varied from a very short exchange about whether the single parent had looked for work to a more substantial discussion about how they were going about looking for work and looking on the internet together:

"I don't know really. I don't think they have got time to help me it's when you go and sign on its quite rushed and all they do is go on their website, the Direct Gov website and tap in to see if anything matches the sort of work I want to do and I can do that myself."

(Jessica, W3). 
The perception by single parents of how the new regime worked, was that they were required to demonstrate a certain level of job search activity, i.e. applying for three jobs per week. A number of single parents mentioned that advisors appeared to treat this as a box ticking exercise in itself and not really be too interested how much an individual had done and how useful that had been:

"I kind of almost felt that as long as you have written everything that you are meant to do that they don't actually care what you have done - So there was no active support..."

(Aisha, W1).

However, while the requirements for job search seemed pretty straightforward to some parents and not even particularly onerous, some single parents learned how to respond in a way that met the information required by the various forms in a way that avoided further probing by the advisor:

"I was providing enough information for her not to have to asked me anything apart from what was related to the information on the form" (Olivia, W1).

Other single parents were unclear and worried about being sanctioned for not having fulfilled their obligations:

"I mean I could look in the newspaper and find no particular suitable jobs. Am I supposed to write that down because it's not exactly something I can prove and is it enough?" (Hannah, W1).

\section{Taking children to the Jobcentre}

There was also comment about having to take their children to the Job Centre. On the whole, they would have preferred not to do this, as they did not think it was very positive environment for children. It was not considered suitable for the children to hear about the health circumstances of their parents nor be exposed to the pressure some single parents felt during those interviews:

"Well, they did say to me oh you can bring your children in but I don't really want to take them to be honest with you they are not the nicest places to go into..." (Beth, W1).

"We will go together of course and I don't want my son to hear you know my financial problems when I am talking to them. It's not good for then he thinks you know we are poor family and my mum is struggling with depression and the money and I don't want my son to hear those kind of things because it is affecting his self-confidence as well as a child he feels you know poor between his friends...um.. I don't think they care."

(Ayla, W1).

\section{The use of sanctions}

Single parents were more likely to experience the threat of sanctions than the sanctions themselves. Single parents, particularly in the first interview, talked about the threat of JSA being stopped featuring regularly in their encounters with advisors. The threat of sanctions was less prominent in the subsequent waves, perhaps because both advisors and those single parents still on JSA had settled into the process. 


\section{The feel of the new regime}

One of the key findings of Peacey (2010) is that single parents felt 'under pressure' as a result of moving onto JSA. Parents in this study also mentioned that they felt under pressure to find a job, but a stronger expression was used frequently by single parents in this study, namely, that they felt they were treated like 'criminals':

"I mean how they talk like I am a criminal, you know, stealing money from the government"

(Ayla, W1).

A number of more general issues were raised in relation to being on JSA. There was a sense that they were not treated as individuals, that their individual circumstances were not taken into account and that advisors were not sympathetic to their individual circumstances.

\section{Views of welfare reforms}

Initially, parents reported feeling optimistic that the welfare reforms could bring additional support, guidance and opportunities for them. They suggested it was fair and reasonable that single parents were required to undertake paid work and make both a financial and social contribution, to children, families and their communities. There was also an acknowledgement that perhaps some claimants were exploiting the system:

"to be truthfully honest I understand why they do it because there's a lot of people that will try and take the mickey out the system but it's hard as a mum trying to be in two places at once sometimes." (Marie, W1)
Single parents cited a range of potential benefits connected to paid work: good health and well-being, contributing to their community, setting a good example for their children and getting out of poverty. Those who had relied on benefits longer term recognised the negative consequences of being away from the labour market in terms of skills and confidence and their ability to secure work. In the following quotes, participants articulated a strong analysis of both the role of the welfare state in supporting people at times of crisis and the benefits of work:

"In theory.....I don't think there is such a thing as a free ride, I don't agree with that personally, because we all pay into the tax system but the system is there for us to take advantage of when like for me when there was nothing else there, it's there..... There are people who take advantage of the benefits system but it's open to abuse and there are people who don't who really use the system for what it's meant to be and those are the people that the system fails every single time." (Aisha, W3).

"Work it is good for your health, for you health emotional and physically, it's good for your children you will be a good role model so I agree that they pushed people to get a job but some ... on the other side is the cutting ....is a bit hard for people on low income"

(Fatima, W3)

However, the speed of introduction, combined with perceived lack of support from JCP, led some participants to rapidly changing their views, not least because it created a lot of fear: 
“Changing over, I don't think the support was very good at all. I think they could make it a lot less frightening than they do." (Jody, W3)

Fears of not being able to successfully find work were further compounded by the threat of benefit cuts or withdrawal, after apparently failing to comply with the new conditions set out within the reforms. Some participants raised the moral aspects of these changes describing them as disgusting, a return to the 'workhouse days'.

\section{Understanding the context of welfare reforms}

Participants were also acutely aware of the broader economic context in which they were looking for work. While there was a broad consensus that the policy objective was reasonable, enacting it at a time of recession and high unemployment was reported as unsettling and challenging:

"It was very unsettling, yes. As I say it's stressful yes, because on one hand I really want to go back to work and it will be really good you know that's setting a better example for my child and on the other hand you kind of know what the job market is like and what ... you know it's not that easy to find a job that will fit around your childcare needs and that you might actually enjoy. Yes the reality of it is it's quite hard....hard yes." (Sophie, W3).
Others were more forthright in their views describing it as frustrating and demoralising:

"No less, it's completely demoralising, it's like a whole process of making you feel like although the economy is crap and there aren't any jobs actually it's your fault personally and how dare you come up here and take this money that you aren't really entitled to because you're scrounging it because you're not doing anything for it, you're ... it's quite horrible actually." (Zoe, W3)

As the extract below highlights, there were also perceived consequences for single parents of being pushed into part time employment, where often the work was low paid and with few job prospects. This raised questions about longer term sustainability or the extent to which this kind of work would provide them with a route out of poverty:

"I'm very confused, I think it's a luxury to have the choice of whether to work or not and it's reasonable to expect to work part-time but then if you work part-time generally the pay is so much poorer so you're automatically saying to all single parents yes, it's fine to work part-time but the reality is you'll be paid rubbish money and then you're in that trap aren't you? And as a part-time worker, you can't really progress your career because you don't have the spare time which is frustrating, so yes you sort of get left behind with the crappy jobs but I don't know what the solution is. I think it is reasonable to expect people to work but at this moment in time those jobs aren't there anyway." (Katy, W3) 
Some believed that focusing on single parents at a time of recession was in itself punitive. It was not about supporting them back into the workplace, but further stigmatising their dependent relationship on the state. This was articulated by the participants through their experiences of contact with JCP. JCP staff were perceived to be failing to link single parents to jobs that were appropriate to their skills and caring responsibilities; single parents were critical of the perfunctory way staff performed their job, often offering very little advice or support. JCP staff were often experienced as disrespectful and judgemental in their attitudes and this was perceived to be part of a broader policy view, that those on benefits were scroungers, happy to rely on the state and too lazy to look for work:

"There's something horrible about having to reveal all of your life to somebody that you've never met before, give them personal details of your relationship and when you broke up. Details of your family, all your financial details, somebody else has got all this information about you ... I know it's great and we do have these benefits systems in place and obviously I've been supported by that but it's weird how they offer you these benefits but then make you feel a little bit like a criminal for taking them

(Francesca, W3).

This could be further compounded by single fathers, where there is an expectation by the Job Centre and employers about men and women's work:

"well the job search is going as it always goes there aren't any jobs for men of my age between the hours of 9 and 3, they just don't exist." (Samuel, W3)

\section{JSA and Caring for Older Children}

While a small number of the sample suggested that their advisor had been supportive and genuinely interested in their progress, one of the most unifying aspects of their accounts was the view that the government had failed to understand the specific needs of single parents, particularly in relation to childcare and the parenting demands of older children. Those interviewed felt policy makers had not understood how caring responsibilities were demanding, complex and often unpredictable, particularly for those caring for children with poor health, behavioural difficulties or disabilities. Participants articulated feeling under increasing pressure to manage competing demands, including attending hospital appointments, managing ill-health, attending school meetings to discuss children's behaviour, responding to challenging behaviour alongside meeting the requirements of JSA. Concerns were also raised about leaving children at home alone, without adequate supervision. While the general consensus was that children should not be left before 11, advice from JCP had been inconsistent and possibly outside the law. There was genuine concern that parents could get into serious trouble for neglecting their children if they left them unsupervised:

"But I think it should be left until your kids are old enough to let themselves in the house after school with a key and be alright for an hour until you get home and I don't even know what age that would be to be honest. Being absolutely honest I don't know, if I was to go and get a job now and I was to let my ten year old walk home from school and my eleven year old come home on the bus from school and let themselves in and they were alright and they're on their own for an hour, am I going to get into trouble for doing that?"

(Zoe, W3). 
Lack of quality childcare provision, specifically designed for older children, was seen as bound up in the failure of the reforms to address the barriers preventing single parents feeling confident to take up work opportunities. It was suggested that weighing up the need to get a job with meeting their child's needs raised real internal conflict:

"working is very important for us as well I mean everybody wants to work... but the first thing as a single mum we think of our children not work.... the children is more important than the work." (Ayla, W1)

\section{Summary}

On the whole, single parents had quite a different experience of visiting the Jobcentre as JSA claimants than they did as IS claimants. They were now seeing a different advisor each time and thus not able to build up rapport with any one advisor and this often meant that they had to repeat often quite personal details, each time. Single parents had clear views on what made a 'good' or 'bad' advisor. 'Good' advisors had an ability to listen and were sympathetic. 'Bad' advisors would not take single parents' individual circumstances into account, e.g. when it came to being able to meet signing on times, or would be disrespectful of their career plans.

Single parents felt unsettled by meeting different advisors each time, as their assessment now mattered because the obligations had increased. The job-search interviews could be perfunctory and advisors were not regarded as having been particularly helpful, when it came to searching for jobs. In addition, some single parents felt that it could be a matter of knowing the right question to ask in order to get an answer, rather than information being provided voluntarily. Finally, some single parents felt uncomfortable about taking their children to the Jobcentre, as they did not want them to hear all about their personal circumstances, such as their health condition. 


\section{Discussion}

This chapter draws together all the main findings and discusses the implications for single parents who wanted to work but found that suitable jobs were difficult to find, particularly in respect of caring for older children. Whilst single parents felt well informed about the transition to Jobseeker's Allowance, lack of training combined with uncooperative experiences at the Jobcentre was identified as unhelpful in moving their work aspirations forward. In particular, seeing different advisors at each visit meant parents were unable to establish an ongoing relationship with Jobcentre staff and there was no continuity in their job search. In this study, none of those interviewed who found work reported doing so through their Jobcentre contact; but through existing networks such as friends and previous employers. This study was able to track single parents' journeys over a period of time and these are referred to in respect of their and their children's health and wellbeing. Lastly, the benefits of using a participatory approach are discussed and future recommendations identified.

\section{Wanting to work}

There are a number of key themes coming out of this research. Importantly, there was a strong sense that single parents wanted to work, a finding reiterated in other studies (Colenman and Lanceley, 2011;Casebourne et al., 2010; Millar and Ridge, 2001).

Motivations for wanting to work included: the desire to be better off financially, being a role model for their children,

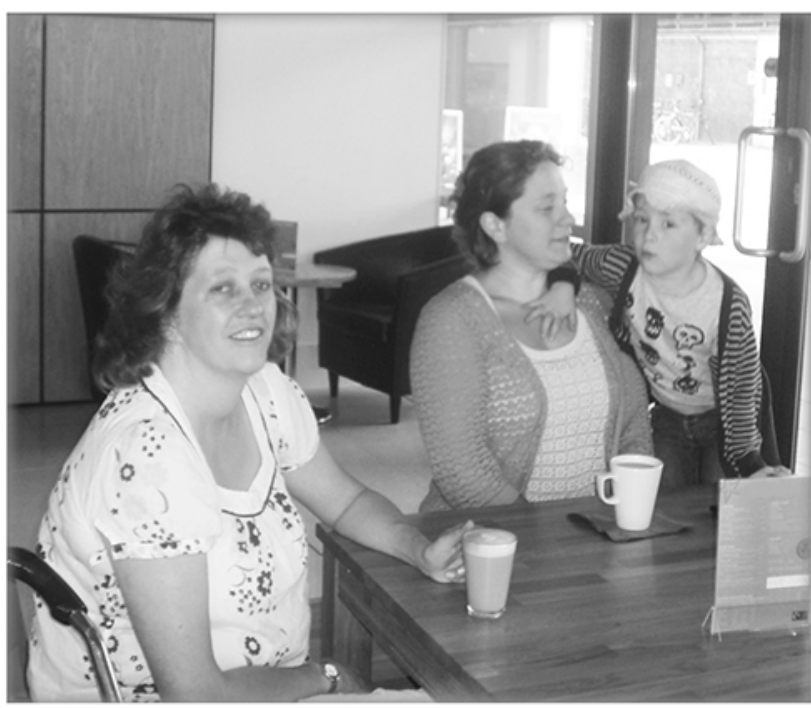

developing social contacts at work, building a career as well as coming off JSA. Linked to this is the second theme: that suitable jobs were difficult to find as a result of the recent recession. Competition for fewer part-time jobs has increased (TUC, 2012) and therefore it was a struggle for single parents to find any job that 'fitted in' with their childcare responsibilities.

When single parents were flexible with regard to the hours they were able to work, had an extended family or older children, finding work was more likely. However, when single parents had to restrict themselves to school hours, finding a job was very hard. The difficulty of finding an appropriate job, meant participants were critical of the timing of the reform that had introduced labour market obligations at a time when unemployment had hit a record high. The importance of suitable jobs for single parents was highlighted as early as 1991(Bradshaw and Millar, 1991) but has been further emphasised by subsequent research on employment sustainability (Evans et al., 2003). Jobcentre Plus (JCP) was perceived to be unhelpful in respect of liasing with employers, e.g. to ask whether a full-time job could be shared, or to arrange work placements. 
In these instances, JCP could have been more pro-active in contacting employers to encourage job share arrangements, and to ensure that jobs were tailored to school hours. It should also have been be possible to liase with employers to enable single parents to build up their hours where they were working fewer than 16 hours.

The third major theme that emerged from the research relates to single parents' views of their needs when caring for their (older) children. Here the report makes a unique contribution to the field in describing in detail what caring for older children signifies for single parents in terms of time and responsibility. For example, being there when children set off to school and when they came home was seen as very important, particularly as they started secondary school. Ensuring that children attended school and that they did 'not fall in with the wrong crowd' was seen as a crucial aspect of successful parenting during adolescence. This was a particular concern for mothers of teenage boys.

As has been highlighted by previous studies (Miller \& Ridge 2011; Ridge and Millar 2009), the activity level of single parents while not in work was impressive as many engaged in voluntary work and training. Some also tried to undertake work of less than 16 hours a week with a view to building up a portfolio of skills and experience. Again, single parents in the study felt that advisors were not forthcoming with information about childcare nor was there an acknowledgement that appropriate provision of childcare for older children was often not available.
Jobseeker's Allowance: transition, training and advisors

Single parents experience of the transition to JSA and the Jobcentre is another key theme. Overall, single parents seemed to be well informed about the transition to JSA, as has been found in previous studies (Gloster et al., 2010; Casebourne et al., 2010). However, the change in payment rhythm from weekly Income Support to fortnightly Jobseeker's Allowance did come as a surprise to some single parents and could cause considerable financial disruption. This has since been addressed by aligning the payment rhythms of the two benefits. While single parents seemed well informed about the changeover from IS to JSA, they seemed to be less clear about how claiming JSA would differ in practical terms from claiming IS.

A strong theme in this study was single parents' expectations that they would be able to undertake training that would help them to move into jobs that they wanted to do and that had a career trajectory. However, Jobseeker's Allowance is essentially designed with newly unemployed men in mind and therefore recipients have to be available for work immediately, thus excluding those who are engaged in training.

Whilst single parents in this study were keen to work, they had the sense that they would be able to move into jobs for which they were appropriately qualified or would be training towards jobs they would enjoy. From their perspective those jobs would have a career trajectory and/or would be a job they could fit around their children. 
If these needs and interests are not

addressed, the rights of women and opportunities for them will be further eroded. There is a clear need for additional measures that encourage single parents to engage in training while on IS and allows them to continue and complete training when they transfer to JSA. This would lead to more secure and better jobs in terms of pay, sustainability, progression, job satisfaction and work hours. Single parents were no longer able to speak to a lone parent advisor and this was seen as a great loss. Moreover, meeting a different advisor each time made parents feel unsettled because they had to repeat personal experiences otherwise each advisor could initiate sanctions against them. Therefore, lone parent advisors should be reinstated or, at the very least, the general advisors should be provided with better training. In addition, there should be an attempt to link single parents with individual advisors in order for some rapport to be established, thus making the meetings more productive for both parties.

Like previous studies, we did not find any evidence of single parents being fast tracked into more intensive work support programmes whilst on JSA (Casebourne et al., 2010; Gloster et al., 2010). Single parents were worried about the transfer to JSA and what to expect, e.g. whether they would be sanctioned if they had not applied for a sufficient number of jobs and how they could prove their job-searching activity. Over time, the cause for concern shifted from not being able to meet the job-seeking requirements to not being able to find a job.

\section{Following single parents' journeys over time}

The advantage of researching single parents over time was that we were able to follow their journeys as well as get a sense of the durability of the new arrangements (see also Millar and Ridge, 2008). In addition, the relatively large sample size of this study meant that we had sufficient single parents in the two smaller groups to look at single parents who were receiving Employment Support Allowance and, in particular, single parents who had moved into self-employment. Previous studies have not focused on selfemployment, yet, this has emerged as a route into work for single parents that allows them to combine doing work of their choice with looking after their children.

All single parents in the sample were in the target group of single parents to be transferred to JSA, i.e. all had children over seven years old. Single parents had gone on journeys with four destinations: employment, self-employment, on Employment Support Allowance or remaining on JSA. The key factors that determined the direction that single parents took seemed to be their previous skills and work experiences, their social networks, their health, finding flexible employers as well as a desire to come off JSA. Where employment was successful, single parents felt substantially better off financially, more confident, enjoyed their work and thought they were providing a good role model to their children. Where employment did not work so well, single parents did not feel better off, due to high travel costs and interactions with other benefits and felt trapped in jobs with little career trajectory or jobs that were affecting their health. 
In terms of the jobs the single parents in this study had moved into, and taking into account the major reduction in public sector employment, their jobs mirrored the present gendered nature of the labour market: the majority of women's part time work occupies roles within the traditional three C's of cleaning, catering and caring. In contrast, the main motivation of single parents who moved into self-employment was to be able to do the kind of job they wanted and were able to combine it with looking after their children. The single parents in this group seemed particularly resourceful in accessing the necessary training and information together to start up and run their own business. Business proposals were not always well received by advisors. However, once set up, single parents in this group also felt financially better off.

For those single parents who moved to ESA, their main issue was to manage their illness while looking after their children. Impending work capability assessments were usually sources of additional pressures and, as shown elsewhere, the journeys to ESA were not always straightforward with single parents moving between JSA and ESA (Casebourne 2010). Finally, the group of single parents who had not been able to find a job and was still receiving JSA at the end of the study, seemed quite diverse in terms of their characteristics. All of the single parents in this group were keen to work but also keen to be able to combine work with looking after their children. They spoke of the impact of being on JSA for a longer time in terms of the financial constraints, the number of failed job applications as well as the different, and more negative, perception of single parents now that they were on JSA.
The outlook and aspirations of single parents for their children were mixed. In some instances, being able to get children to school and making sure they stayed out of trouble seemed to occupy single parents. In other cases, the children were doing well in school and the parents hoped that their children would go to university and enter professions such as medicine and law, i.e. to do better than they themselves had been able to do.

In terms of the outlook on the future, this depended to a large extent on which destination they had achieved. On the whole, single parents in employment and self-employment felt more optimistic about the future than those on JSA and ESA. However, uncertainty about employment being sustainable, about the lack of jobs and impending changes to the tax and benefit system emerged as key worries.

\section{Health and well-being}

The significance of the impact of employment and income on mental health is well established (Gregg, Harkness \& Smith 2009; Gardner \& Oswald 2007; Winkleman \& Winkleman 2009). Economic analysis of the reforms of the 1990's, that included 'in work tax credits' and 'welfare to work programmes', demonstrated that key outcomes of the reforms were to mitigate against the negative aspects of relationship breakdown in terms of finances, employment and mental pressure (Gregg, Harkness \& Smith 2009). The reforms introduced by Labour since 1998, were seen not only to have improved levels of employment and the numbers of hours worked by single parents, but were also protective of mental health. 
Single parents were more likely to stay in employment during divorce, but also suffer less deterioration in mental health (Jenkins 2008). In addition, outcomes associated with self-esteem and mental health of their teenage children, were improving (Gregg, Harkness \& Smith 2009).

This study used qualitative methods to explore single parents' reflections on their health and well-being and those of their families. Questions focused on disability or ill health, personal difficulties, mental health and well-being, the perceived impact of JSA on health (physical/mental) and access to health care services. This took place during the second and third interviews when the demands of JSA had become firmly established and single parents had moved on from the initial shock associated with the welfare changes. Those in work, including those who were self-employed, often identified a sense of well-being and enjoyment connected to feeling part of the world of work, with improved self esteem and confidence.

This was also associated with improvements in family life that additional income brought. Feeling part of a team gave single parents a sense of connectedness, to colleagues and the organisations they were part of. This made them feel purposeful and optimistic about the future. Those single parents who had moved into self-employment had sometimes seen this as a way of managing their long term conditions, having more control over the timing and the nature of the work taken on. However, this is not to suggest that there were no negative impacts. For those who had taken up work perceived as menial, there was frustration and a sense of resignation, as the opportunities for training to improve their position were withdrawn.
This was often in contrast to those in the 'not in work' groups, who were supported by ESA and JSA. Single parents who were supported by benefits suffered greater ill health than the general population. In a recent DWP study 28 per cent reported a longstanding illness, 12 per cent of who identified a mental health problem (Coleman \& Lanceley 2011). Similar to those in Pearcey's (2009) study, those on JSA most often reported experiencing 'depression and stress' and for some this became severe enough to move onto ESA. For others, symptoms tended to be in a state of flux and demanded intermittent visits to their general practitioner for treatment, or resignation that given their life circumstances 'it was to be expected'. It was not always clear how the mother's emotional ill health impacted on her children. A recent study that examined experiences of children whose mothers had failed to get entry into the labour market, highlighted that children were sometimes undertaking the care of their parents (Ridge, 2009). While physical care of parents by children was not identified in this study there was a sense that children accommodated and supported their mothers when they were feeling depressed, anxious and fatigued. In addition, single parents were aware that their own emotional and psychological health affected their children's state of mind.

An additional aspect of health and well being was associated with the significant number of parents who reported having children with longstanding health problems: respiratory illness, developmental and behavioural difficulties and mental illness. Parents made regular visits to education, health and welfare organisations in addition to caring for them during regular absences from school. 
Similar to other work in the field, this study confirms that single parents with older children who are not themselves in work often had children with serious health difficulties (Peacey 2009) and had to deal with these challenges alone (Peacey, 2011; Ridge \& Miller, 2011).

\section{The benefits of a participatory approach}

While there is a large volume of work written and researched about the lives of single parents (Gregg, Harkness and Smith, S. (2009) there is a dearth of studies in which single parents themselves are central to all aspects of the research and policy process (SPAN, 2009; Bennett \& Roberts 2004). The approach taken in this study recognised important advantages of placing peer researchers from single parent communities at the heart of the research. From the perspective of the researchers themselves, there were gains associated with their involvement through studying, skills development, confidence building and empowerment. Unlike this study, previous research with single parents had not linked this learning and development to academic credit, through the process of 'evidencing work based learning'. This is a recognised qualification that would support the future work aspirations of the peer researchers in their own transfer onto JSA. The collaboration between a university and the charitable sector supported participation practically through childcare provision, training, career and advancement opportunities. This enabled a wide range of skills, expertise and infrastructure to be drawn upon to develop research that was innovative, credible and stood up to rigorous scrutiny by policy researchers within the field.
Nevertheless, peer researchers also identified areas of further improvement. These were connected to more involvement in the writing of the research bid, better communication and consistency of approach throughout the life of the project. It was suggested these improvements would have mitigated against tokenism and improved participation and skill development of peer researchers across the three-year period. From the perspective of interviewees, it was notable the low numbers of single parents who dropped out of the research, given the high level of commitment required over two years. Motivations for this were explored, single parents wanted to share their views, in addition to feeling listened to by researchers who had a genuine empathy, interest and understanding of the situations faced. This supports claims made that using participatory approaches improves retention in studies (Buchanan, et al, 2006). Overall, this study has been the first to report on the views of 50 single parents over a three-year period and actively involve a group of peer researchers in many aspects of the research process.

The final chapter will now outline recommendations emerging from the data. 


\section{Jobcentre Plus, Social Mobility and Training}

- Reinstate the role of Lone Parent Advisors. Their role should include the provision of individualised support, sensitive to the needs of single parents in managing both their parenting and employment responsibilities.

- Improved training structures for Jobcentre staff. If Jobcentre Plus advisors are to be retained, the training for them, for Jobcentre Plus managers and Work Programme providers should address the specific needs of single parents to ensure that they are embedded in service delivery. This training should encompass knowledge of childcare provision, Jobcentre Plus flexibilities open to single parents and the significance of travel and social networks to single parents.

- Support for training programmes that would further single parents' future advancement in the labour market. Training should be available when single parents are on income support with children under 5 and before they are out of work for more than one year and enter the Work Programme.
- Transparent information should be available from all local Jobcentre Plus offices stipulating the tailored support available for single parents including training opportunities and childcare.

- Self-employment proved to be a viable option for single parents in this study because it provided flexibility in caring for their children. Single parents, who want to become self-employed, should be signposted to specialist support and training flagged up by Jobcentre Plus and Work Programme providers.

- A change in policy is needed so that parents can access self-employment training when they first go onto JSA. Regulations need to be altered so that self-employment is seen as a viable option from day one, not after six months. 


\section{Employment and Gender}

- Public Sector organisations including Jobcentre Plus and private organisations contracted by government to provide statutory services such as Work Programme providers, have a public sector equality duty to promote equality of opportunity for single parents given that the great majority are women. It is clear from our findings that Jobcentre Plus and contracted services need to be publically accountable and comply with the duty in order to prevent the erosion of single mothers' gender equality opportunities, including training, recognition of existing skills, provision of childcare and better opportunities for quality part-time employment.

- In the light of these findings, we will ask the Work and Pensions Select Committee to review the treatment of single parents in the benefit system with regard to advancing equality of opportunity in welfare to work policies and practices.
- Jobcentre Plus, and contractors providing employment support, should play a proactive role in encouraging employers to design quality jobs with part-time hours. For example, this could include requesting every employer who wants to advertise a job with the agency, to define the flexibilities available and whether the role might be adapted to part-time hours.

- Pilot a job-share register. The DWP could use the register to incentivise employers financially to recruit two people to share a full-time role.

- Develop parent/worker models for delivering welfare to work initiatives. This study demonstrated that parents were more likely to take up and remain in work if supported in their parenting roles. More focus on developing support and flexibilities for the parent/worker is needed by government, employers and Jobcentre Plus. 


\section{Well-Being of Children}

- Government should embed children's well being into the ethos of Jobcentre Plus service delivery. Jobcentre Plus Advisers must be trained in their legislative responsibilities towards the well-being of children. The Children's Commissioner should be asked to investigate whether current policy and practice in Jobcentre Plus threatens the wellbeing of children; and how policy and practice could be changed within Jobcentre Plus and contracted employment services to improve the well-being of children who live in single parent households.
- The Government should review childcare for older children as a policy priority. It should encourage a debate on care for older children including the development of a childcare services for secondary aged children, wrap around school care and provision for children in the school holidays.

- Parents are legally responsible for their children's safety and care until they reach 16 . The DWP, Jobcentre Advisors and Work Programme Advisors must never recommend or threaten to sanction single parents who do not think that they can safely leave their children on their own or do not have suitable childcare.

\section{Financial Security}

- The policies for single parents of 'In-Work Conditionality' and sustainable and better paid work should be linked. For example, if single parents are offered the opportunity to train and improve their skills this in turn, promotes their prospects of higher paid employment.

- Removal of financial disincentives to work from the tax and benefits system. This would ensure that people who work more hours are rewarded financially. The model of Universal Credit should enable single parents to gain financially when they move into working more than 16 hours per week. 


\section{References}

Alakeson, V.,2012. The Price of Motherhood: women and part-time work. London: The Resolution Foundation.

Berthoud, R., 2003. Multiple disadvantage in employment: A quantitative analysis. York: Joseph Rowntree Foundation.

Bennett, F. and Roberts, M., 2004. Participatory approaches to research on poverty. York: Joseph Rowntree Foundation.

Bradshaw, J. and Millar, J., 1991. Single Parent Families in the UK. London: Her Majesty's Stationary Office.

Bennett F. and Roberts, M., 2004. From Input to Influence: Participatory approaches to research and inquiry into poverty. York: Joseph Rowntree Foundation.

Brewer, M., Browne, J. and Sibieta, L. (2010), Child Poverty in the UK since 1998-1999: Lessons from the past decade. London: Institute for Fiscal Studies.

British Sociological Association, 2002. Statement of Ethical Pracitce for the British Sociological Association, March 2002 (Appendix updated May 2004). London: British Sociological Association.

British Education Research Association, 2004. Revised Ethical Guidelines

for Educational Research. London.: BERA

Bristol City Council, 2011. Childcare Sufficiency Assessment and Action Plan 2011-2014 [Online]. Available from:

http://www.bristol.gov.uk/sites/default/files/documents/children_and_young_people/early_educati on_and_childcare/Childcare\%20Sufficiency\%20Assessment\%20and\%20Action\%20Plan\%20201 1\%20to\%202014_0.pdf [Accessed March 2012]

Bristol City Council, 2011. Local Economic Assessment [Online]. Available from: http://www.bristol.gov.uk/page/economic-information-and-analysis [Accessed March 2012]

Bristol City Council, 2011 Bristol Child Poverty Strategy 2011-2020. [Online] Available at http://www.bristol.gov.uk/page/about-bristol-child-and-young-people-service\#jump-link-4 [Accessed March 2012]

Casebourne, J., et al., 2010. Single Parent Obligation: destinations of single parents after Income Support. London: Department for Work and Pensions.

Carcillo, S. and Grubb, D., 2006. From inactivity to work: the role of active labour market policies, Paris: Organisation for Economic Co-operation and Development. 
Child Poverty Action Group, 2012. Save Child Benefit, CPAG policy briefing, by Rhys Farthing, London:CPAG

Coleman, N. and Lanceley, L., 2011. Lone Parent Obligations: supporting the journey into work, London: Department for Work and Pensions.

Department for Work and Pensions and Department for Education, 2011. A new approach to child poverty: Tackling the causes of disadvantage and transforming families' lives. London: Her Majesty's Stationary Office.

Cm7913, 2010. Twenty First Century Welfare, London: Her Majesty's Stationary Office.

Department for Work and Pensions, 2007. Ready for work: Full employment in our generation. Norwich: Her Majesty's Stationary Office.

Coppock, V., 2011. Children as Peer Researchers: Reflections on a Journey of Mutual Discovery. Children \& Society, vol. 25; pp. 435: 446.

Crabtree, M. and Miller, W.,1992. Doing Qualitative Research. Newbury Park: SAGE.

Dewar, L., 2012. Is the Work Programme Working for Single Parents? An Analysis of the Experience of Single Parents Moving onto the Work Programme. Single Parent Action Network: Bristol

Duncan, S. and Edwards, R., ed., 1997. Single mothers in an international context: Mothers or Workers?, London: University Collage London Press.

Department of Work and Pensions, 2012. Support to help lone parents into work. Press release, 23 March 2012.

Department of Work and Pensions,2010. Welfare in the 21st century, London.

Elliot, A., Watson, A. and Haines, U.,2002. Harnessing expertise: involving peer interviews in qualitative research with hard-to-reach populations. Health Expectations, vol. 5; pp. 172:176.

Evans, M., Harkness, S. and Ortiz, R. A., 2004. Lone parents cycling between work and benefits. Leeds: CDS.

Field, F., 2010. The Foundation Years: preventing poor children becoming poor adults. The Report of the Independent Review on Poverty and Life Chances. London: Cabinet Office.

Gardner, J. and Oswald, A., 2007. Money and mental wellbeing; a longitudinal study of mediumsized lottery wins, Journal of Health Economics, vol. 22; pp. 49 -60.

Gibbs, G.,2007. Analyzing Qualitative Data. London: SAGE. 
Gingerbread, 2012. Statistics [Online] Available at:

http://www.gingerbread.org.uk/content.aspx?CategorylD=365 [Accessed March 2012]

Gloster, R., Casebourne, J., Culshaw, S., Marva, L., O'Donnell, A. and Purvis, A., 2010. Single Parent Obligations: early findings of implementation as well as experiences of the Income Support and Jobseeker's Allowances regimes. London: Department for Work and Pensions.

Gregg, P., 2008. Realising Potential: A Vision for Personalised Conditionality and Support. London: Her Majesty's Stationary Office.

Gregg, P., Harkness, S. and Smith, S., 2006. Welfare reform and lone parents in the UK, CMPO Working Paper. Bristol: University of Bristol.

Gregg, P., Harkness, S., and Smith, S., 2009. Welfare Reform and Lone parents in the UK. The Economic Journal, vol. 119; pp. 38- 65.

Harker, L., 2006. Delivering on child poverty: what would it take?, London: Department for Work and Pensions.

Haux, T., 2009. Lone parents and welfare-to-work reform: A policy appraisal. Thesis (Doctor of Philosophy (PhD)). University of Bath.

Haux, T., 2011. Activating Single Parents: An Evidence-Based Appraisal of the Welfare-To-Work Reform in Britain. Social Policy and Society, vol. 11(1), pp. 1 - 14

Heron, J., 1996. Co-operative inquiry research into the human condition. London: SAGE.

HC42-1, 2008. Alleviating deprivation, improving social mobility and eradicating child poverty. London: Department for Work and Pensions Committee.

Holtermann, S., Brannen, J., Moss, P. and Owen, C., 1999. Single Parents and the Labour Market: Results from the 1997 Labour Force Survey and Review of Research. Sheffield: Employment Service.

Horton, T and Reed, H., 2010. Don't forget the spending cuts! The real impact of Budget 2010. Briefing paper for the TUC and Unison, June 2010.

JRF \& Women Like Us, 2012. Building a sustainable quality part-time recruitment market March 2012 London.

Kennedy, S., 2010. Lone parents and Jobseeker's Allowance: House of Commons Library paper $\mathrm{SN} / \mathrm{SP} / 5532$.

Kilkey, M., 2000. Lone mothers between paid work and care: the policy regime in twenty countries. Aldershot: Ashgate. 
Lane, P., Casebourne, J., Lanceley, L. and Davis, M.,2011. Lone Parent Obligation: childcare and the Jobseeker's regime. London: Department for Work and Pensions.

Ledwith, M. and Springett. J., 2000. Participatory Practice. Community based action for transformative change. Bristol: Policy Press.

Lewis, J., ed., 1997.. Lone Mothers in European welfare regimes: Shifting policy logics. London: Jessica Kingsley.

Lewis, J., 2006. Children, changing families and welfare states. Cheltenham: Edward Elgar.

Lewis, J. and Giullari, S., 2005. The adult worker model family, gender equality and care: The search for new policy principles and the possibilities and problems of a capabilities approach, Economy and society, vol. 34(1); pp. 76-104.

Lister, R., 2006. Children (but not women) first: New Labour, child welfare and gender in Critical Social Policy, vol. 269(2); pp. 315-335.

Millar, J. and Ridge, T., 2001. Families, Poverty, work and care: A review of the literature on single parents and low income families with children. Leeds: CDS.

Millar, J. and Ridge, T., 2008. Relationships of Care: Working Single Mothers, their Children and Employment Sustainability Journal of Social Policy, vol. 38; pp. 103-121.

Millar, J. and Ridge, T., 2009. Relationships of care: working lone mothers, their children and employment sustainability, Journal of Social Policy, 38 (1), pp. 103-121.

Millar, J, and Rowlingson, K., 2001- eds.. Lone parents, employment and social policy, Bristol. Bristol: Policy Press.

Millar, J., 2001. Work-related activity requirements and labour market programmes for lone parents, Lone parent, employment and social policy: Cross-national comparisons. Bristol: Policy Press, pp. $189-210$.

National Children's Bureau, 2003. Guidance for Research. London: National Children's Bureau. Noble, M. et al., 2008. The English Indices of Deprivation 2007. London

Organisation for Economic Co-operational Development, 2007. Babies and bosses: reconciling work and family life: A synthesis of findings for OECD countries, Paris: Organisation for Economic Co-operational Development.

Office of Budget Responsibility, 2011. Economic and Fiscal Outlook. London.

Office for National Statistics, 2012. Labour Market Statistics: March 2012. London. 
Office for National Statistics, 2009. The reference for this is not needed as it is cited as being taken from Coleman and Lanceley.

Osbourne, G (Rt Hon), 2012. Budget Statement [Online]. HM Treasury. Available from: http://www.hm-treasury.gov.uk/budget2012_statement.htm [March 2012].

Peacey, V., 2009. Signing on and stepping up? Single parents' experience of welfare reform. London: Gingerbread.

Philpott, J., 2012. Work Audit - March 2012. London: Chartered Institute of Personnel and Development.

Reason, P. and Bradbury, H., 2006. Handbook of action research. London: SAGE

Ridge, T. and Millar, J., 2010. Following Families: Working Single-Mother Families and their Children, Social Policy \& Administration, vol. 45(1); pp. 85-97.

Ridge, T. and Millar, J., 2011. Following families: Working lone-mother families and their children. Social Policy \& Administration, 45 (1), pp. 85-97.

The National Archives. The Social Security (Lone Parents and Miscellaneous Amendments) Regulations (2008). Her Majesty's Stationary Office. Available from:

www.legislation.gov.uk/uksi/2008/3051/contents/made. [Accessed March 12th 2012]

Ridge, T., 2009. It Didn't Always Work': Low-Income Children's Experiences of Change in Mothers Working Patterns in the UK. Social Policy and Society, vol. 8(4); pp. 503 - 613.

Sands, D, 2012. The impact of Austerity on Women. London: Fawcett Society.

Save the Children and the Daycare Trust, 2011. Making Work Pay - the Childcare Trap Survey. London.

Single Parent Action Network, 2007. Proofed for Parents by Parents: Toolkit, Bristol: SPAN and Big Lottery

Strauss, A. and Corbin, J.,1990. Basics of Qualitative Research: Grounded Theory Procedures and Techniques. London: SAGE.

Tomaszwewski, W., Chanfreau, J. and Barnes, M., 2010. Single parents and employment: an exploration of findings from the Families and Children Study 2006-08, London: Department for Work and Pensions

Trades Union Congress, 2010. The Gender Impact of the Cuts citied in the Fawcett Society Policy Briefing Cutting Women Out: March 2012 p6. Available at:

http://fawcettsociety.org.uk/index.asp?PagelD=1239

Trades Union Congress, 2012. Labour Market Report, Number 24, March 2012, London. 
Thurley, D., ed., 2003. Working to target? Can policies deliver paid work for seven in ten lone parents?. London: OneParentFamilies.

University of Warwick \& Coventry Women's Voices, 2011. Unravelling Equality: a human rights and equality impact assessment on the spending cuts on women in Coventry. Warwick: May 2011.

Welfare Reform Bill, 2011. Public Bill Committee Fifteen Sitting 3 May 2011 (morning) Page 651 House of Commons Hansard. Available at: www.parliament.uk

Welfare Reform Bill, 2011. Public Bill Committee Fifteen Sitting 3 May 2011 (morning) page 662 House of Commons Hansard Available at: www.parliament.uk

Winkleman, J. and Winkleman (1998) Why are the unemployed so unhappy? Evidence from panel data, Economica, vol. 65(257); pp. 1 - 15.

The Work Foundation, 2011. Prospects and Challenges for Economic Recovery. 